\title{
Synthesis of D-desthiobiotin-Al-2 as a novel chemical probe for autoinducer-2 quorum sensing receptors
}

\author{
Vanessa Miranda ${ }^{a}$, Inês M. Torcato ${ }^{a, b}$, Karina B. Xavier ${ }^{b}$ and M. Rita Ventura ${ }^{a, *}$ \\ ${ }^{a}$ Instituto de Tecnologia Química e Biológica António Xavier, Universidade Nova de Lisboa, Avenida da \\ República, 2780-157 Oeiras, Portugal. \\ ${ }^{\mathrm{b}}$ Instituto Gulbenkian da Ciência, 2781-901 Oeiras, Portugal. \\ *rventura@itqb.unl.pt
}

\begin{abstract}
In processes regulated by quorum sensing (QS) bacteria respond to the concentration of autoinducers in the environment to engage in group behaviours. Autoinducer-2 (Al2 ) is unique as it can foster interspecies communication. Currently, two Al-2 receptors are known, LuxP and LsrB, but bacteria lacking these receptors can also respond to Al-2. In this work we present an efficient and reproducible synthesis of a novel chemical probe, D-desthiobiotin-AI-2. This probe binds both LuxP- and LsrB-class receptors from different species of bacteria. Thus, this probe is able to bind receptors that recognise the two known biologically active forms of Al-2. A protocol to pull down receptors bound to D-desthiobiotin-Al-2 with anti-biotin antibodies has also been established. This work highlights the potential of conjugating chemical signals to biotinylated derivatives to identify and tag signal receptors involved in quorum sensing or other chemical signalling processes.
\end{abstract}

Keywords: Al-2, Al-2 receptors, Chemical Probe, Quorum sensing

\section{INTRODUCTION}

Quorum sensing (QS) is a process mediated by the production and detection of small extracellular signalling molecules, named autoinducers, which accumulate in the environment in proportion to cell density. This process allows bacteria to monitor population density and regulate gene expression accordingly. ${ }^{1-3}$ Antibiotic production, biofilm formation and bioluminescence are examples of group behaviours that become effective when cells are working in unison and thus are regulated by $\mathrm{QS}^{1-3}$ In Gramnegative bacteria, intra-species communication is achieved mainly by production and detection of acyl-homoserine lactones ( $A H L)$ whereas in Gram-positive bacteria, oligopeptides are the most common autoinducers. However, a universal QS signalling molecule, autoinducer-2 (AI-2), has been identified both in Gram-negative and -positive bacteria and is involved in inter-species communication. ${ }^{2,4}$

Al-2 is comprised of a family of molecules that exist in chemical equilibrium (Fig. 1). (S)4,5-Dihydroxypentane-2,3-dione (DPD) is the linear precursor that is the product of the reaction catalysed by the LuxS enzyme. This linear molecule can then acquire different 
cyclic forms when in solution. ${ }^{5}$ To date two DPD derivate molecules have been identified as signalling molecules: S-THMF-borate ((2S,4S)-2-methyl-2,3,3,4tetrahydroxytetrahydrofuran-borate $) \quad$ and $\quad R$-THMF $\quad((2 R, 4 S)-2-$ methyl-2,3,3,4tetrahydroxytetrahydrofuran. ${ }^{4,5}$

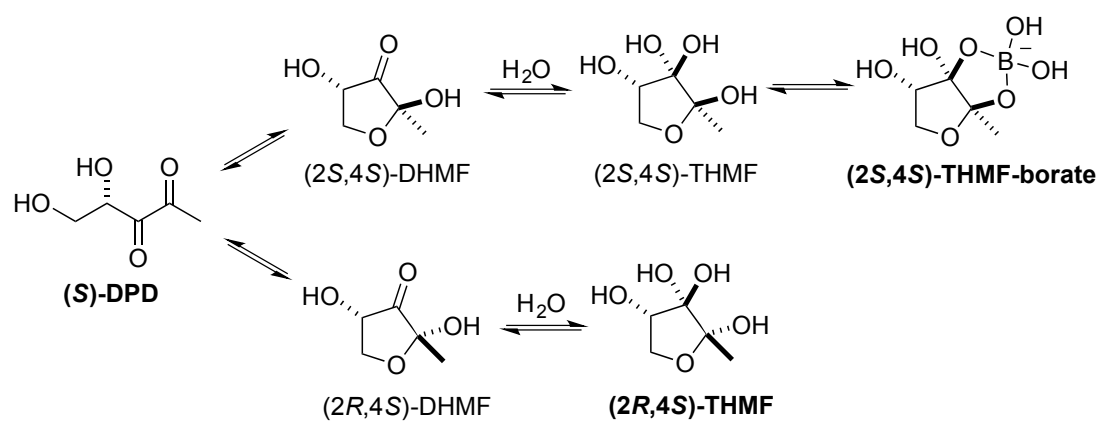

Figure 1. Linear and cyclic forms of $\mathrm{Al}-2$.

Although the Al-2 synthase, LuxS, has been identified in more than 500 bacterial species $^{6}$ only two receptors have been identified, LuxP and LsrB. ${ }^{2}$ LuxP binds the $S$ THMF-borate form of $\mathrm{Al}-2$ and, upon binding, interacts with a membrane-spanning sensor histidine kinase regulating a phosphorylation signal transduction cascade and the production of bioluminescence in Vibrio harveyi. LsrB, however, binds R-THMF and, upon binding, interacts with the membrane components of an adenosine triphosphate binding cassette $(A B C)$ transporter to facilitate $\mathrm{Al}-2$ internalisation and processing. ${ }^{4,7-11}$ The distinct amino acid composition of the binding site of these receptors is reported to explain the recognition of the different $\mathrm{Al}-2$ adducts. ${ }^{7,12}$

Additional classes of $\mathrm{Al}-2$ receptors are hypothesised to exist as phenotypes regulated by $\mathrm{Al}-2$ have been identified in species where LuxP and LsrB are absent ${ }^{2}$. For example, in Enterococcus faecalis, an opportunistic pathogen that is among the leading causes of nosocomial infections due to its strong ability to form biofilms, high concentrations of Al-2 induce phage release and, consequently, virulence. ${ }^{13}$ Another example was identified in Staphylococcus aureus, a human pathogen able to cause an assortment of diseases ranging from minor skin infections to life-threatening syndromes, in which biofilm formation is regulated by Al-2. ${ }^{14}$ Nevertheless, no known receptor has been identified in these bacterial species and identification of new classes of $\mathrm{Al}-2$ receptors has proven a challenge. The low sequence homology between LsrB and LuxP $(11 \%)^{2,5,7,15}$ raises the possibility that other types of receptors, which also share low homology with LuxP and LsrB, might exist but cannot be identified through classical bioinformatic approaches using sequence comparisons. Moreover, although these receptors share the same structural fold, the class I fold of periplasmic binding proteins, so do many sugar binding proteins. Therefore, simple identification of fold is thus not sufficient to differentiate between potential $\mathrm{Al}-2$ receptors and other ligand binding proteins. This makes the 
development of new strategies to identify novel Al-2 receptors crucial for the study of quorum sensing processes in bacteria lacking LuxP or LsrB homologues.

A chemical probe to identify Al-2 receptors, based on the structure of rhodamine, was previously developed. This probe was able to bind LsrB receptors which recognise $R$ THMF, but not the LuxP receptor which binds the S-THMF-borate form of Al-2. ${ }^{10}$ To the best of our knowledge, there are no chemical probes able to recognise both Al-2 receptors. Other classes of QS signal analogues, for AHLs, were explored to target LuxR-type receptors; ${ }^{15,16}$ however, these molecules are only inhibitors and/or activators of known QS receptors. As a biological tool, the system biotin/desthiobiotin with streptavidin or avidin is widely used for different applications, taking advantage of the ability of creating non-covalent bonds such as ionic, hydrogen-bonding and hydrophobic interactions. ${ }^{17}$ These molecules are used for example to: study protein-protein or proteinligand interactions, ${ }^{17}$ immobilise DNA on the surface of microarrays, ${ }^{18}$ study of new RNAprotein interactions ${ }^{19}$ and to purify and/or immobilise proteins. ${ }^{20}$ Therefore, many commercially available tools exist to study compounds covalently linked to these molecules. D-desthiobiotin is a derivative of D-biotin and is also used as a biological tool for similar applications. ${ }^{21,22}$

Here, we present the synthesis of a new chemical probe, based on the structures of DPD and D-desthiobiotin (DB-Al-2, Fig. 2). D-desthiobiotin was used instead D-biotin because the sulfur atom was not compatible with the oxidation step of the synthesis. When D-biotin was used, the corresponding sulfone was obtained instead of the desired di-ketone.

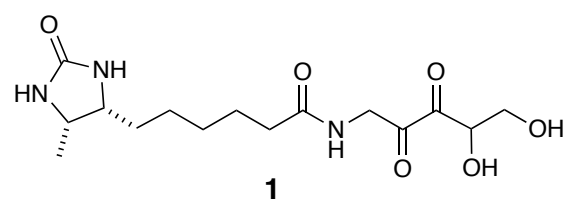

Figure 2. Structure of the synthesised chemical probe D-desthiobiotin-Al-2 1.

\section{RESULTS AND DISCUSSION}

\subsection{Chemical Synthesis}

Due to the biological relevance of the different DPD isomers it is important to develop probes that have the flexibility needed for DPD to acquire different conformations as the conformation that will be recognised by new receptors is not known.
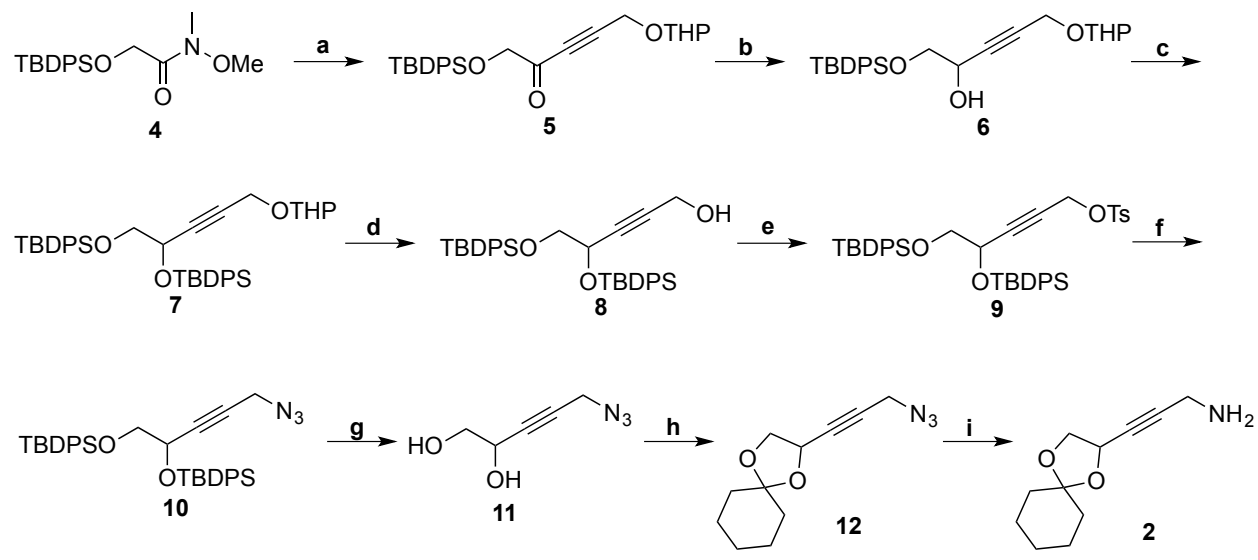
a) 2-(prop-2-yn-1-yloxy)oxane (3), $\mathrm{LDA}, \mathrm{THF},-78$ to $0{ }^{\circ} \mathrm{C}, 90 \%$. b) $\mathrm{NaBH}_{4}, \mathrm{MeOH}, 0{ }^{\circ} \mathrm{C}$ to r.t., quantitative yield. c) TBDPSCl, DIPEA, DMAP, $\mathrm{CH}_{2} \mathrm{Cl}_{2}$, r.t., $95 \%$. d) $p$-TsOH. $\mathrm{H}_{2} \mathrm{O}, \mathrm{MeOH}$, r.t., $95 \%$. e) $p-\mathrm{TsCl}, \mathrm{KOH}, \mathrm{Et}_{2} \mathrm{O}, 0{ }^{\circ} \mathrm{C}$ to r.t., $95 \%$. f) $\mathrm{NaN}_{3}$, DMF, r.t., $95 \%$. g) TBAF, THF, r.t., 76\%. h) 1,1-dimethoxycyclohexanone, $\mathrm{H}_{2} \mathrm{SO}_{4}$, DMF, r.t., $84 \%$. i) $\mathrm{PPh}_{3}, \mathrm{H}_{2} \mathrm{O}$, THF, r.t., $94 \%$.

Scheme 1. Synthesis of linker 2 to coupling with D-desthiobiotin.

To prepare D-Desthiobiotin-AI-2 (1) we first synthesised linker (2, Scheme 1). Linker 2 was specifically designed to bond to D-desthiobiotin at the C-1 position of the DPD derivative. In this way, no interference with the cyclisation would occur, this is crucial for the interaction of the DPD with the biological receptors. Although we are able to efficiently synthesise the enantiomeric pure form of $D P D,{ }^{23}$ in this work we synthesised the racemic form to avoid the exclusion of any new receptor which can recognise different DPD adducts. The alkylation of the Weinreb amide $4^{23}$ with propyne 3 afforded the ketone 5 in $90 \%$ yield (Scheme 1). The nonseteroselective reduction of ketone $\mathbf{5}$ with $\mathrm{NaBH}_{4}$ gave alcohol $\mathbf{6}$ that after protection with the silyl group afforded the alkyne 7 in excellent yield. The C-1 position had to be converted into an amine for the coupling with the carboxylic acid of the D-desthiobiotin. Alkyne 7 was converted to alcohol $\mathbf{8}$ in $\mathbf{9 5 \%}$ yield and protection with tosyl chloride afforded compound $\mathbf{9}$. After azide $\mathbf{1 0}$ formation and sylil deprotection, diol 11 was achieved. Finally, linker 2 was obtained after protection with 1,1-dimethoxycyclohexanone and conversion of the azide via Staudinger reaction to the corresponding amine (Scheme 1). The cyclohexylidene group is easily hydrolysed to obtain the free form of the DPD. ${ }^{23}$ The linker 2 could be prepared in large scale, maintaining the efficiency of the synthesis. The synthesis of this compound is a good example of the use of the strategy previously developed ${ }^{23}$ as an efficient method to prepare DPD analogues for different applications. Also, different linkers based on the DPD structure could be easily prepared to be coupled with D-desthiobiotin.
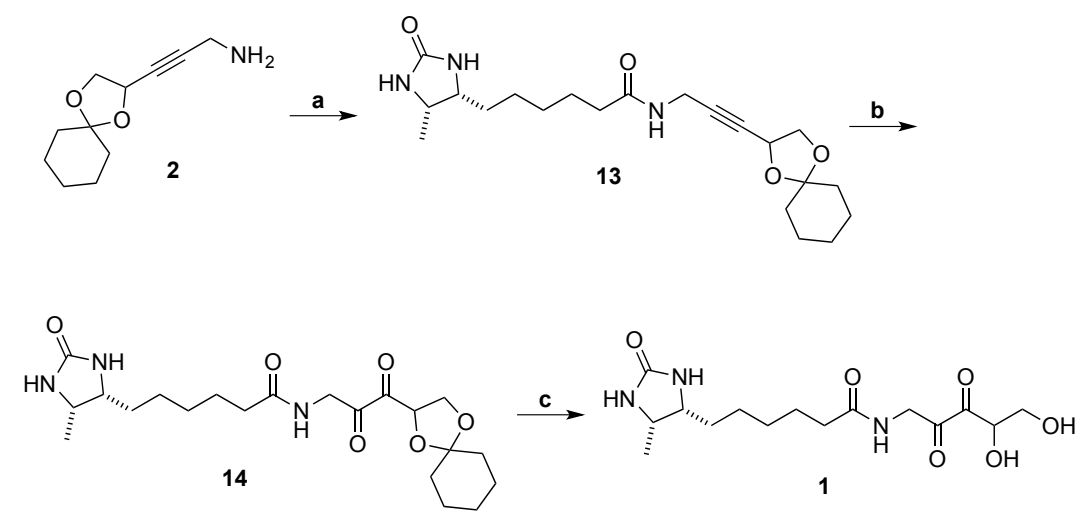

a) D-desthiobiotin, $\mathrm{EDC}, \mathrm{HOBt}, \mathrm{MeCN}$, r.t., $50 \%$. b) $\mathrm{OsO}_{4}\left(2 \%\right.$ aq. sol.), $\mathrm{KClO}_{3}, \mathrm{H}_{2} \mathrm{O}: \mathrm{Et}_{2} \mathrm{O}$, r.t., quantitative yield. c) $\mathrm{D}_{2} \mathrm{SO}_{4}, \mathrm{D}_{2} \mathrm{O}: \mathrm{DMSO}-d_{6}$, r.t.

Scheme 2. Synthesis of the chemical probe D-desthiobiotin-AI-2 1. 
The coupling reaction between linker 2 and D-desthiobiotin was achieved in 50\% yield (Scheme 2). Di-ketone 14 was obtained successfully in quantitative yield using $\mathrm{KClO}_{3}$ and $\mathrm{OsO}_{4}{ }^{24}$ The oxidation of compound 13 was attempted using $\mathrm{RuO}_{2} \cdot \mathrm{H}_{2} \mathrm{O}$ and $\mathrm{NaIO}_{4}$ described in the DPD synthesis, ${ }^{23}$ however compound 14 was not isolated. The final chemical probe $\mathbf{1}$ was obtained after an hydrolysis protocol which consisted of preparing a solution of the compound 14 in DMSO- $d_{6}: \mathrm{D}_{2} \mathrm{O}(1: 4)$ and adding $10 \% \mathrm{D}_{2} \mathrm{SO}_{4}{ }^{25,26}$ After 16 hours of stirring, the mixture was washed with deuterated chloroform to remove the cyclohexanone in solution and no further purification was need.

\subsection{D-desthiobiotin-AI-2 binds both LuxP and LsrB receptors}

To determine the functionality of this chemical probe we tested binding of D-desthiobiotin-Al-2 (DB-Al-2 1) to known Al-2 receptors, including the well-characterised LuxP from $V$. harveyi and the canonical LsrB receptor from Escherichia coli (EcLsrB). For LuxP we used LuxP bound to two fluorescent proteins, CLPY, which is routinely used for AI-2 detection assays. ${ }^{27}$ Recently, an LsrB receptor with a different binding site was identified in Clostridium saccharobutylicum, ${ }^{28}$ and we also tested this non-canonical LsrB receptor (CsLsrB).

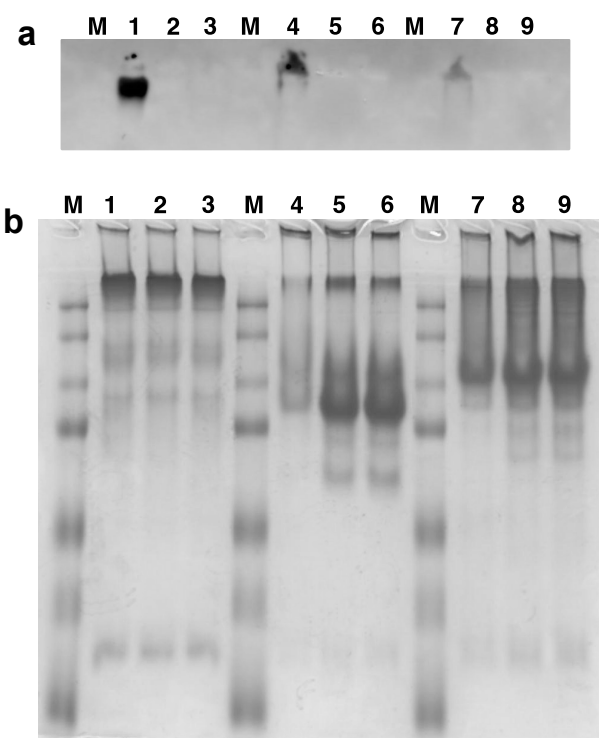

Figure 3. D-desthiobiotin-Al-2 1 is able to bind both LuxP and LsrB receptors. (a) Western-blot membrane incubated with an anti-biotin antibody able to recognise D-desthiobiotin. Protein standards (M), CLPY-LuxP incubated with DB-AI2 (1), D-desthiobiotin (2) and buffer (3); CsLsrB incubated with DB-Al-2 (4), with D-desthiobiotin (5) and buffer (6); EcLsrB incubated with DB-Al-2 (7), D-desthiobiotin (8) and buffer (9). (b) Native PAGE gel of the same samples.

After an affinity purification, these receptors were incubated with DB-AI-2 1. To test for specificity, as controls, receptor proteins were also incubated with non-conjugated Ddesthiobiotin and with buffer alone. Next, these samples were run in a native gel to prevent denaturation of the receptors. The native gel was used for immunoblotting using an anti-biotin antibody able to recognize D-desthiobiotin ${ }^{29}$ (Fig. 3a). A native gel run in parallel with the same samples was stained with Coomassie to visualize the bands (Fig. 3b). In the wells of LsrB proteins incubated with DB-Al-2 (Fig. 3b, wells 4 and 7 ) some bands are fainter, indicating that 
when bound to DB-Al-2 these proteins might have a slightly different conformation influencing migration in the native gel, as an SDS-PAGE gel, ran in denaturing conditions with the same samples (Fig. S1), showed that all the samples had the same protein concentrations. Signal was only detected in the Western blot when the partially purified proteins were incubated with DB-AI-2 1 (wells 1, 4 and 7), showing that the antibody recognised the DB-Al-2 bound to both LuxP and LsrB receptors (Fig. 3a). No bands were detected in the negative control wells loaded with the receptors incubated with non-conjugated D-desthiobiotin (wells 2, 5 and 8), or buffer (wells 3, 6 and 9). Thus, it is possible to conclude that there is no unspecific binding of Ddesthiobiotin (unbound D-desthiobiotin should run off the gel) and of the antibody to the receptor proteins.

\subsection{D-desthiobiotin-Al-2 can pull-down LuxP}

Having established the functionality of the chemical probe, a strategy for pulling down the Al-2 receptors was needed. Since we showed that an anti-biotin antibody is able to recognise the DB-Al-2-receptor complex, we opted for immunoprecipitation. To optimise this procedure, we employed magnetic beads conjugated to protein $\mathrm{G}$ that has the ability to immobilise antibodies (Fig 4a).

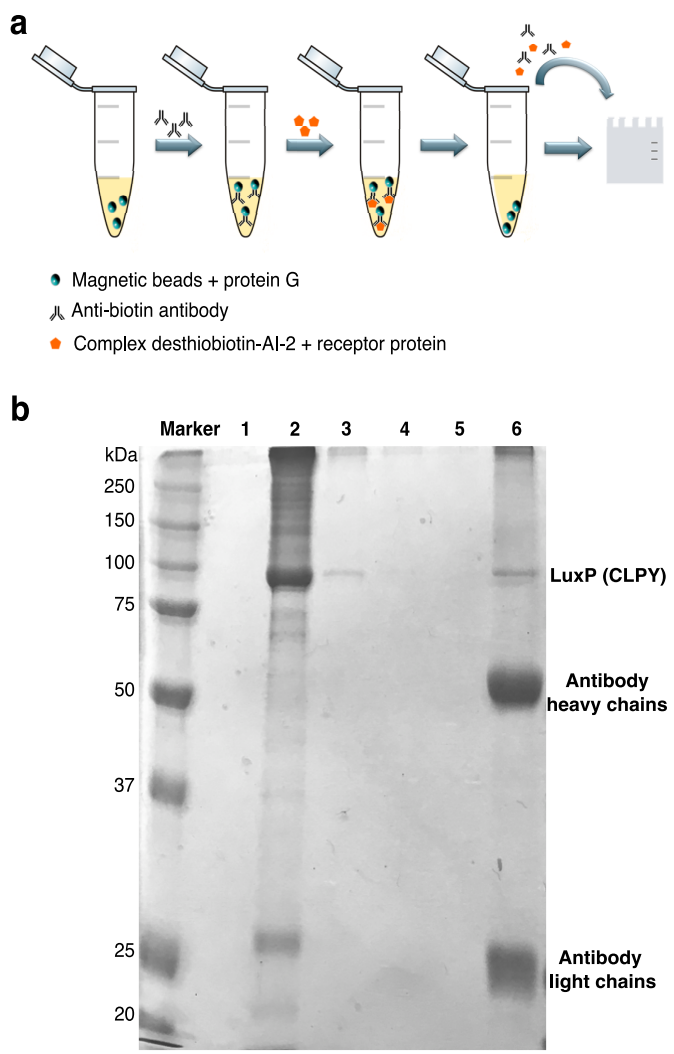

Figure 4. Pull-down of Al-2 receptors using DB-Al-2 1. (a) Scheme of experimental procedure. Magnetic beads conjugated with protein $G$ were incubated with an anti-biotin antibody able to recognise D-desthiobiotin. Unbound antibody was then removed by magnetic separation. A protein sample with partially purified LuxP (CLPY) previously incubated with the DB-Al-2 probe was added to the antibody-conjugated magnetic beads. The mixture sample/antibody-conjugated beads was incubated for $1 \mathrm{~h}$ at room temperature with agitation. Antibodies-conjugated magnetic beads should retain the LuxP complexed with DB-Al-2, three washing steps were employed to remove unbound proteins. Next, LuxP was eluted by denaturation and eluted samples were subjected to SDS PAGE electrophoresis. (b) SDS PAGE gel of the washes and elution steps of the procedure described above. Protein 
standards (M), unbound antibody (1), protein sample that is not retained by the complex beads/antibody (2), washes to eliminate unbound sample (3-5) and elution of the receptor protein (6). Since denaturing conditions were used the antibiotin antibody was also eluted.

Using this approach, we were able to pull-down LuxP through one-step purification. Moreover, magnetic separation improved the process as washes and elutions are faster and consume fewer reagents. The denaturing conditions used caused the antibody to elute with LuxP (Fig. 4b). However, all the known Al-2 receptors have around 30-40 kDa and thus, other receptors are expected to have a similar molecular weight. This means that bands of interest should appear in between the heavy and light chains of the antibody. Nevertheless, if this presents a problem going forward, covalent linking of the antibody to the beads can readily be accomplished. Additionally, specific elution using synthetic Al- $2,{ }^{23}$ which should have higher affinity to $\mathrm{Al}-2$ receptors, can also be optimised.

\section{CONCLUSION}

In summary, a new chemical probe able to bind both LuxP and LsrB receptors was successfully designed and synthesised. In this work, we show that DB-AI-2 is the first chemical probe able to bind the two different types of known receptors, demonstrating that the molecule of $\mathrm{Al}-2$ in this probe has the plasticity necessary to acquire the different conformations needed to bind different types of receptors. It has, therefore, great potential as a tool for the discovery of new receptors, which might bind different forms of Al-2. New classes of Al-2 receptors are hypothesised to exist as bacteria such as $E$. faecalis and $S$. aureus, where no proteins with significant similarity to the known receptors were identified, possess phenotypes regulated by Al-2. Thus, DB-Al-2 will be an important tool for the identification of new Al-2 receptors in relevant commensals and pathogenic bacteria where no Al-2 receptors have been identified. The acquired knowledge will be extremely important for the development of strategies to modulate Al-2 mediated quorum sensing and the collective behaviours that contribute for the establishment of bacterial infections.

Moreover, the synthetic process developed for DB-Al-2 is flexible and efficient in terms of yields and atom economy. Thus, it can be further applied to other compounds like Al-2 analogues or other quorum sensing molecules originating new chemical probes. Broadly, the use of the probe developed here exemplifies the advantage of using biotinylated derivatives as conjugates to study chemical binding proteins involved in signalling transduction pathways or other biological processes.

\section{MATERIALS AND METHODS}

\subsection{Chemical Synthesis}

\subsubsection{Materials}

${ }^{1} \mathrm{H}-\mathrm{NMR}$ spectra were obtained with a Bruker Avance II+ $(400 \mathrm{MHz})$ spectrometer, at 400 $\mathrm{MHz}$ in $\mathrm{CDCl}_{3}$ or $\mathrm{D}_{2} \mathrm{O}$ with chemical shift values $(\delta)$ in ppm downfield from 
tetramethylsilane in the case of $\mathrm{CDCl}_{3}$ and ${ }^{13} \mathrm{C}-\mathrm{NMR}$ spectra were obtained at $100 \mathrm{MHz}$ in $\mathrm{CDCl}_{3}$ or $\mathrm{D}_{2} \mathrm{O}$. Assignments are supported by $2 \mathrm{D}$ correlation NMR spectroscopy studies. Preparative chromatographic separations were carried out by flash chromatography using Kieselgel 60, $(0.032-0.063 \mathrm{~mm})$. Analytical TLC was performed on aluminum-backed Merck $60 \mathrm{~F}_{254}$ silica gel plates. Reagents and solvents were purified and dried according to ref. ${ }^{30}$ All the reactions were carried out under an inert atmosphere (argon), except when the solvents were not dried.

\subsubsection{Preparation of 2-(ethynyloxy)oxane 3}

Propyne 3 was prepared and characterised according to the literature. ${ }^{31}$

\subsubsection{Preparation of $\mathbf{N}$-Methoxy- $\mathbf{N}$-methyl-2-(tert-butyldiphenylsilyloxy)acetamide 4}

Weinreb amide 4 was prepared and characterised according to the literature. ${ }^{23}$

\subsubsection{Preparation of 1-[(tert-butyldiphenylsilyl)oxy]-5-(oxan-2-yloxy)pent-3-yn-2-one 5}

To a solution of diisopropylamine $(1.6 \mathrm{~mL}, 11.2 \mathrm{mmol})$ in THF $(8 \mathrm{~mL}), 1.6 \mathrm{M}$ solution of $\mathrm{n}$ BuLi in hexane $(6.3 \mathrm{~mL}, 10.7 \mathrm{mmol})$ was added dropwise at $-78{ }^{\circ} \mathrm{C}$ and the mixture stirred at $0^{\circ} \mathrm{C}$ for 15 minutes. At $-78^{\circ} \mathrm{C}$, a solution of propyne $3(1.57 \mathrm{~g}, 11.2 \mathrm{mmol})$ in THF $(8 \mathrm{~mL})$ was added and the mixture stirred for 30 minutes. Still at $-78^{\circ} \mathrm{C}$, a solution of Weinreb amide $4(2.00 \mathrm{~g}, 5.6 \mathrm{mmol})$ in THF $(10 \mathrm{~mL})$ was added. The mixture was stirred at $-78^{\circ} \mathrm{C}$ for 20 minutes and then at $0^{\circ} \mathrm{C}$ until all starting material had been consumed (TLC), approximately 2 hours. The mixture was quenched with a saturated aqueous $\mathrm{NH}_{4} \mathrm{Cl}$ solution $(20 \mathrm{~mL})$ and extracted with $\mathrm{CH}_{2} \mathrm{Cl}_{2}(3 \times 20 \mathrm{~mL})$. The combined organic layers were dried with anhydrous $\mathrm{Na}_{2} \mathrm{SO}_{4}$, filtered and concentrated under vacuum. The residue was purified by flash column chromatography (90:10 Hexane/EtOAc) to afford the ketone $5(2.20 \mathrm{~g}, 90 \%)$ as a colourless viscous oil.

${ }^{1} \mathrm{H}-\mathrm{NMR}\left(\mathrm{CDCl}_{3}\right), 400 \mathrm{MHz}: \delta$ 7.68-7.66 (m, 4H, Ar), 7.44-7.37 (m, 6H, Ar), $4.77(\mathrm{t}, 1 \mathrm{H}$, $\mathrm{J}=3.2 \mathrm{~Hz}, \quad \mathrm{C} \underline{\mathrm{H}}$ from THP), $4.39\left(\mathrm{~d}, 2 \mathrm{H}, \mathrm{J}=1.7 \mathrm{~Hz}, \mathrm{C} \equiv \mathrm{CCH}_{2}\right), 4.32 \quad(\mathrm{~s}, 2 \mathrm{H}$, TBDPSOC $\left.\underline{H}_{2} \mathrm{C}=\mathrm{O}\right), 3.81-3.76\left(\mathrm{~m}, 1 \mathrm{H}, 1 \times \mathrm{xCH}_{2}\right.$ from THP), 3.54-3.49 $\left(\mathrm{m}, 1 \mathrm{H}, 1 \times \mathrm{xCH}_{2}\right.$ from THP), $1.80-1.50\left(6 \mathrm{H}, \mathrm{m}, 3 \times \mathrm{CH}_{2}\right.$ from THP), $1.10\left(\mathrm{~s}, 9 \mathrm{H}, \mathrm{C}\left(\mathrm{CH}_{3}\right)_{3}\right)$ ppm. ${ }^{13} \mathrm{C}-\mathrm{NMR}$ $\left(\mathrm{CDCl}_{3}\right), 100 \mathrm{MHz}$ : $\delta 185.4(\mathrm{C}=\mathrm{O}), 135.6(\mathrm{Ar}), 132.6\left(\mathrm{C}_{\mathrm{q}} \mathrm{Ar}\right), 130.0(\mathrm{Ar}), 127.9(\mathrm{Ar}), 97.2$ $\left(\underline{\mathrm{CH}}\right.$ from THP), $91.0(\underline{\mathrm{C}} \equiv \mathrm{C}), 83.0(\mathrm{C} \equiv \underline{\mathrm{C}}), 70.5\left(\mathrm{TBDPSO} \mathrm{CH}_{2} \mathrm{C}=\mathrm{O}\right), 62.0\left(\mathrm{CH}_{2}\right.$ from THP), $53.8\left(\mathrm{C} \equiv \mathrm{CCH}_{2}\right), 30.0\left(\mathrm{CH}_{2}\right.$ from THP $), 26.7\left(\mathrm{C}\left(\mathrm{CH}_{3}\right)_{3}\right), 25.2\left(\mathrm{CH}_{2}\right.$ from THP $), 19.3$ $\left(\underline{\mathrm{C}}\left(\mathrm{CH}_{3}\right)_{3}\right), 18.8\left(\mathrm{CH}_{2}\right.$ from THP). FTIR (Neat): $1720(\mathrm{C}=\mathrm{O}), 2155(\mathrm{C} \equiv \mathrm{C}) \mathrm{cm}^{-1}$. HRMS: calcd. for $\mathrm{C}_{26} \mathrm{H}_{32} \mathrm{O}_{4} \mathrm{SiNa}^{+}[\mathrm{M}+\mathrm{Na}]^{+} 459.2070$; found 459.1962 .

\subsubsection{Preparation of 1-[(tert-butyldiphenylsilyl)oxy]-5-(oxan-2-yloxy)pent-3-yn-2-ol 6}

To a solution of ketone $5(0.790 \mathrm{~g}, 1.8 \mathrm{mmol})$ in dry $\mathrm{CH}_{2} \mathrm{Cl}_{2}(5 \mathrm{~mL})$, at $0^{\circ} \mathrm{C}$, tertbutyldimethylsilylchloride $(0.60 \mathrm{~mL}, 2.7 \mathrm{mmol})$, diisopropylethylamine $(0.63 \mathrm{~mL}, 3.6$ mmol) and a catalytic amount of DMAP were added. The reaction mixture was stirred 
allowing the temperature to rise until r.t., after 16 hours all the starting material was consumed and water was added. The mixture was extracted with $\mathrm{CH}_{2} \mathrm{Cl}_{2}$, dried with $\mathrm{Na}_{2} \mathrm{SO}_{4}$, filtered and concentrated under vacuum. Without further purification, alcohol 6 was obtained ( $0.819 \mathrm{~g}$, quantitative yield) as a colourless viscous oil.

${ }^{1} \mathrm{H}-\mathrm{NMR}\left(\mathrm{CDCl}_{3}\right), 400 \mathrm{MHz}$ : $\delta$ 7.69-7.65 (m, 4H, Ar), 7.44-7.38 (m, 6H, Ar), 4.77 (t, $1 \mathrm{H}$, $\mathrm{J}=3.37 \mathrm{~Hz}, \mathrm{C} \underline{\mathrm{H}}$ from THP), 4.52-4.50 (m, $1 \mathrm{H}, \mathrm{C} \underline{\mathrm{HC}} \equiv \mathrm{C}), 4.31$ (ddd, $1 \mathrm{H}, \mathrm{J}=15.7 \mathrm{~Hz}, \mathrm{~J}=3.5$ $\mathrm{Hz}, \mathrm{J}=1.8 \mathrm{~Hz}, \mathrm{C} \equiv \mathrm{CCH}_{2}$ ), 4.23 (ddd, $1 \mathrm{H}, \mathrm{J}=15.7 \mathrm{~Hz}, \mathrm{~J}=3.5 \mathrm{~Hz}, \mathrm{~J}=1.8 \mathrm{~Hz}, \mathrm{C} \equiv \mathrm{CCH}_{2}$ ), 3.82$3.70\left(\mathrm{~m}, 3 \mathrm{H}\right.$, TBDPSOCH $\mathrm{H}_{2} \mathrm{CH}$ and $1 \mathrm{xCH}_{2}$ from THP), 3.51-3.47 $\left(\mathrm{m}, 1 \mathrm{H}, 1 \mathrm{xCH}_{2}\right.$ from THP), $\left.1.63-1.49\left(\mathrm{~m}, 6 \mathrm{H}, 3 \times \mathrm{CH}_{2} \text { from THP), } 1.07 \text { (s, 9H, C( } \mathrm{CH}_{3}\right)_{3}\right)$ ppm. ${ }^{13} \mathrm{C}-\mathrm{NMR}$ $\left(\mathrm{CDCl}_{3}\right), 100 \mathrm{MHz}: \delta 135.6(\mathrm{Ar}), 135.5(\mathrm{Ar}), 132.9\left(\mathrm{C}_{\mathrm{q}} \mathrm{Ar}\right), 132.8\left(\mathrm{C}_{\mathrm{q}} \mathrm{Ar}\right), 129.92(\mathrm{Ar})$, 129.91 (Ar), 127.84 (Ar), 127.82 (Ar), 96.8 ( $\mathrm{CH}$ from THP), $67.4\left(\mathrm{TBDPSOCH}_{2} \mathrm{CH}\right), 63.2$ $(\underline{\mathrm{CHC}} \equiv \mathrm{C}), 61.9\left(\mathrm{CH}_{2}\right.$ from THP), $54.2\left(\mathrm{C} \equiv \mathrm{CCH}_{2}\right), 30.2\left(\mathrm{CH}_{2}\right.$ from THP), $\left.26.8\left(\mathrm{C}_{(\mathrm{CH}}\right)_{3}\right)$, $25.3\left(\mathrm{C}\left(\mathrm{CH}_{3}\right)_{3}\right), 19.3\left(\underline{\mathrm{C}}\left(\mathrm{CH}_{3}\right)_{3}\right)$ ppm. FTIR (Neat): $2158(\mathrm{C} \equiv \mathrm{C}), 1022(\mathrm{C}-\mathrm{O}-\mathrm{C}) \mathrm{cm}^{-1}$. HRMS: calcd. for $\mathrm{C}_{26} \mathrm{H}_{34} \mathrm{O}_{4} \mathrm{SiNa}^{+}[\mathrm{M}+\mathrm{Na}]^{+}$461.2226; found 461.2119.

\subsubsection{Preparation of 2,2,9,9-tetramethyl-5-[3-(oxan-2-yloxy)prop-1-yn-1-yl]-3,3,8,8-}

\section{tetraphenyl-4,7-dioxa-3,8-disiladecane 7}

To a solution of alcohol $6(0.815 \mathrm{~g}, 1.9 \mathrm{mmol})$ in dry $\mathrm{MeOH}(5 \mathrm{~mL})$, at $0^{\circ} \mathrm{C}, \mathrm{NaBH}_{4}(0.141$ $\mathrm{g}, 3.7 \mathrm{mmol}$ ) was added. The reaction mixture was stirred allowing the temperature to rise to r.t., after 3 hours all the starting material was consumed and water was added. The mixture was extracted with EtOAc, dried with $\mathrm{Na}_{2} \mathrm{SO}_{4}$, filtered and concentrated under vacuum. The crude residue was purified by flash column chromatography (90:10 Hexane/EtOAc) to afford the alkyne $7(1.160 \mathrm{~g}, 95 \%)$ as a colourless viscous oil.

${ }^{1} \mathrm{H}$-NMR $\left(\mathrm{CDCl}_{3}\right), 400 \mathrm{MHz}: \delta 7.75$ (d, 2H, J=6.90 Hz, Ar), 7.71 (d, 2H, J=7.3 Hz, Ar), $7.65(\mathrm{t}, 4 \mathrm{H}, \mathrm{J}=6.2 \mathrm{~Hz}, \mathrm{Ar}), 7.40-7.32(\mathrm{~m}, 12 \mathrm{H}, \mathrm{Ar}), 4.64-4.56(\mathrm{~m}, 2 \mathrm{H}, \mathrm{C} \underline{\mathrm{H}}$ from THP and $\mathrm{C} \underline{\mathrm{HC}} \equiv \mathrm{C}), 4.11-4.02\left(\mathrm{~m}, 2 \mathrm{H}, \mathrm{C} \equiv \mathrm{CCH}_{2}\right), 3.81-3-68\left(\mathrm{~m}, 3 \mathrm{H}, \mathrm{TBDPSOC} \underline{\mathrm{H}}_{2} \mathrm{CH}\right.$ and $1 \mathrm{xCH}_{2}$ from THP), 3.44-3.40 (m, $1 \mathrm{H}, 1 \times \mathrm{CH}_{2}$ from THP), $1.78-1.45\left(\mathrm{~m}, 6 \mathrm{H}, 3 \times \mathrm{CH}_{2}\right.$ from THP), $1.08\left(\mathrm{~s}, 9 \mathrm{H}, \mathrm{C}\left(\mathrm{CH}_{3}\right)_{3}\right), 1.02\left(\mathrm{~s}, 9 \mathrm{H}, \mathrm{C}\left(\mathrm{CH}_{3}\right)_{3}\right)$ ppm. ${ }^{13} \mathrm{C}-\mathrm{NMR}\left(\mathrm{CDCl}_{3}\right), 100 \mathrm{MHz}: \delta 136.1$ (Ar), 135.9 (Ar), $135.7(\mathrm{Ar}), 135.6(\mathrm{Ar}), 133.6\left(\mathrm{C}_{\mathrm{q}} \mathrm{Ar}\right), 133.5\left(\mathrm{C}_{\mathrm{q}} \mathrm{Ar}\right), 133.4\left(\mathrm{C}_{\mathrm{q}} \mathrm{Ar}\right), 133.3$ ( $\mathrm{C}_{\mathrm{q}} \mathrm{Ar}$ ), 129.62 (Ar), 129.58 (Ar), 127.6 (Ar), 127.5 (Ar), $127.4(\mathrm{Ar}), 96.5$ ( $\mathrm{CHC} \equiv \mathrm{C}$ ), 85.1

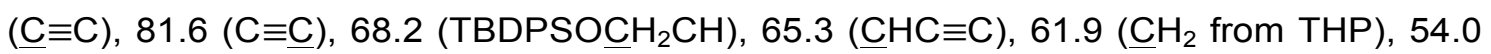
$\left(\mathrm{C} \equiv \mathrm{CCH}_{2}\right), 30.2\left(\underline{\mathrm{CH}} \mathrm{H}_{2}\right.$ from THP), $26.9\left(\mathrm{C}\left(\mathrm{CH}_{3}\right)_{3}\right), 26.7\left(\mathrm{C}\left(\mathrm{CH}_{3}\right)_{3}\right), 25.4\left(\mathrm{CH}_{2}\right.$ from THP), $19.3\left(\underline{\mathrm{C}}\left(\mathrm{CH}_{3}\right)_{3}\right), 19.2\left(\underline{\mathrm{C}}\left(\mathrm{CH}_{3}\right)_{3}\right), 19.1\left(\underline{\mathrm{CH}_{2}}\right.$ from THP) ppm. FTIR (Neat): $2170(\mathrm{C} \equiv \mathrm{C})$, 1111 and 1079 (C-O-C) cm ${ }^{-1}$. HRMS: calcd. for $\mathrm{C}_{42} \mathrm{H}_{52} \mathrm{O}_{4} \mathrm{Si}_{2} \mathrm{Na}^{+}[\mathrm{M}+\mathrm{Na}]^{+}$699.3404; found 699.3296 .

\subsubsection{Preparation of 4,5-bis[(tert-butyldiphenylsilyl)oxy]pent-2-yn-1-ol 8}

To a stirred solution of alkyne $7(0.57 \mathrm{~g}, 0.84 \mathrm{mmol})$ in dry $\mathrm{MeOH}(5 \mathrm{~mL})$ at r.t., $p$ toluenesulfonic acid monohydrate $(11 \mathrm{mg}, 0.06 \mathrm{mmol})$ was added. After 2 hours all the starting material had been consumed and the reaction mixture was quenched with a 
saturated aqueous $\mathrm{NaHCO}_{3}$ solution $(10 \mathrm{~mL})$ and extracted with EtOAc $(3 \times 10 \mathrm{~mL})$. The combined organic layers were dried with anhydrous $\mathrm{Na}_{2} \mathrm{SO}_{4}$, filtered and concentrated under vacuum. The residue was purified by flash column chromatography 195:05 Hexane/EtOAc) to afford the alcohol 8 (473 $\mathrm{mg}, 95 \%)$ as a colourless viscous oil.

${ }^{1} \mathrm{H}-\mathrm{NMR}\left(\mathrm{CDCl}_{3}\right), 400 \mathrm{MHz}$ : $\delta$ 7.78-7.65 (m, 8H, Ar), 7.44-7.33 (m, 12H, Ar), 4.62-4.59 $(\mathrm{m}, 1 \mathrm{H}, \mathrm{C} \underline{\mathrm{H} C} \equiv \mathrm{C}), 3.93\left(\mathrm{~d}, 2 \mathrm{H}, \mathrm{J}=1.4 \mathrm{~Hz}, \mathrm{C} \equiv \mathrm{CCH}_{2} \mathrm{OH}\right), 3.81$ (dd, $1 \mathrm{H}, \mathrm{J}=6.9 \mathrm{~Hz}, \mathrm{~J}=10.2$ $\mathrm{Hz}, 1 \times \operatorname{TBDPSOC}_{2} \mathrm{CH}$ ), 3.71 (dd, $1 \mathrm{H}, \mathrm{J}=4.7 \mathrm{~Hz}, \mathrm{~J}=10.1 \mathrm{~Hz}, 1 \times \operatorname{TBDPSOC}_{2} \mathrm{CH}$ ), 1.08 (s, 9H, C( $\left.\left(\mathrm{CH}_{3}\right)_{3}\right), 1.05$ (s, 9H, C( $\left.\left.\mathrm{CH}_{3}\right)_{3}\right)$ ppm. ${ }^{13} \mathrm{C}-\mathrm{NMR}\left(\mathrm{CDCl}_{3}\right), 100 \mathrm{MHz}: \delta 136.3(\mathrm{Ar})$, 136.0 (Ar), 135.7 (Ar), $134.1\left(C_{q} A r\right), 133.3\left(C_{q} A r\right), 129.71(\mathrm{Ar}), 129.66(\mathrm{Ar}), 129.64(\mathrm{Ar})$, 129.61 (Ar), 127.7 (Ar), 127.6 (Ar), 127.3 (Ar), 85.1 ( $\underline{\mathrm{C} \equiv \mathrm{C}),} 84.1(\mathrm{C} \equiv \underline{\mathrm{C}}), 68.2$ (TBDPSOC $\left.\left.\left.\mathrm{H}_{2} \mathrm{CH}\right), 65.2(\underline{\mathrm{C}} \mathrm{HC} \equiv \mathrm{C}), 50.9\left(\mathrm{C} \equiv \mathrm{C} \underline{\mathrm{C}} \mathrm{H}_{2} \mathrm{OH}\right), 26.9\left(\mathrm{C}(\underline{\mathrm{CH}})_{3}\right)_{3}\right), 26.7\left(\mathrm{C}_{(\mathrm{CH}}\right)_{3}\right)$, $19.2\left(\underline{\mathrm{C}}\left(\mathrm{CH}_{3}\right)_{3}\right)$ ppm. FTIR (Neat): $2156(\mathrm{C} \equiv \mathrm{C}), 3673(\mathrm{OH}) \mathrm{cm}^{-1}$. HRMS: calcd. for $\mathrm{C}_{37} \mathrm{H}_{44} \mathrm{O}_{3} \mathrm{Si}_{2} \mathrm{Na}^{+}[\mathrm{M}+\mathrm{Na}]^{+}$615.2829; found 615.2721.

\subsubsection{Preparation of 4,5-bis[(tert-butyldiphenylsilyl)oxy]pentyl 4-methylbenzene-1-} sulfonate 9

To a stirred solution of alcohol $8(870 \mathrm{mg}, 1.47 \mathrm{mmol})$ in dry ether $(10 \mathrm{~mL})$ at $0^{\circ} \mathrm{C}, p$ toluenesulfonyl chloride $(336 \mathrm{mg}, 1.76 \mathrm{mmol}$ ) and potassium hydroxide $(412 \mathrm{mg}, 7.34$ $\mathrm{mmol}$ ) were added. The reaction mixture was stirred and the temperature allowed to rise to r.t., after 16 hours all the starting material was consumed and water was added. The mixture was extracted with ether, dried with $\mathrm{Na}_{2} \mathrm{SO}_{4}$, filtered and concentrated under vacuum. Without further purification alkyne 9 was obtained $(1.04 \mathrm{~g}, 95 \%)$ as a colourless viscous oil.

${ }^{1} \mathrm{H}-\mathrm{NMR}\left(\mathrm{CDCl}_{3}\right), 400 \mathrm{MHz}: \delta$ 7.69-7.61 (m, 10H, Ar), 7.42-7.33 (m, 12H, Ar), $7.17(\mathrm{~d}$, $2 \mathrm{H}, \mathrm{J}=8.1 \mathrm{~Hz}, \mathrm{Ar}), 4.44\left(\mathrm{~s}, 2 \mathrm{H}, \mathrm{C} \equiv \mathrm{CC}_{2} \mathrm{OTs}\right), 4.43-4.40(\mathrm{~m}, 1 \mathrm{H}, \mathrm{C} \underline{\mathrm{HC}} \equiv \mathrm{C}), 3.65(\mathrm{dd}, 1 \mathrm{H}$, $\left.\mathrm{J}=6.6 \mathrm{~Hz}, \mathrm{~J}=10.1 \mathrm{~Hz}, 1 \times \mathrm{TBDPSOCH}_{2} \mathrm{CH}\right), 3.55(\mathrm{dd}, 1 \mathrm{H}, \mathrm{J}=5.1 \mathrm{~Hz}, \mathrm{~J}=10.0 \mathrm{~Hz}$, 1xTBDPSOC $\left.\underline{H}_{2} \mathrm{CH}\right), 2.32\left(\mathrm{~s}, 3 \mathrm{H}, \mathrm{PhC}_{3}\right), 1.05\left(\mathrm{~s}, 9 \mathrm{H}, \mathrm{C}\left(\mathrm{CH}_{3}\right)_{3}\right), 1.01\left(\mathrm{~s}, 9 \mathrm{H}, \mathrm{C}\left(\mathrm{CH}_{3}\right)_{3}\right)$ ppm. ${ }^{13}$ C-NMR $\left(\mathrm{CDCl}_{3}\right), 100 \mathrm{MHz}: \delta 144.9\left(\mathrm{C}_{\mathrm{q}} \mathrm{Ar}\right), 136.1$ (Ar), 135.9 (Ar), 135.61 (Ar), 135.59 (Ar), $133.24\left(C_{q} A r\right), 133.2\left(C_{q} A r\right), 133.18\left(C_{q}\right.$ Ar), $133.0\left(C_{q} A r\right), 129.8(A r)$, $129.7(\mathrm{Ar}), 128.1(\mathrm{Ar}), 127.7(\mathrm{Ar}), 127.6(\mathrm{Ar}), 127.4(\mathrm{Ar}), 88.6(\underline{\mathrm{C}} \equiv \mathrm{C}), 77.2(\mathrm{C} \equiv \underline{\mathrm{C}}), 67.7$ (TBDPSOC $\left.\left.\mathrm{H}_{2} \mathrm{CH}\right), 64.9(\underline{\mathrm{CHC}} \equiv \mathrm{C}), 57.8\left(\mathrm{C} \equiv \mathrm{C}_{\mathrm{CH}} \mathrm{OTs}\right), 26.8\left(\mathrm{C}\left(\mathrm{CH}_{3}\right)_{3}\right), 26.7\left(\mathrm{C}_{(\mathrm{CH}}\right)_{3}\right)$, $21.6\left(\mathrm{PhCH}_{3}\right), 19.22\left(\underline{\mathrm{C}}\left(\mathrm{CH}_{3}\right)_{3}\right), 19.19\left(\underline{\mathrm{C}}\left(\mathrm{CH}_{3}\right)_{3}\right)$ ppm. FTIR (Neat): $2158(\mathrm{C} \equiv \mathrm{C}), 1111$ and 1079 (C-O-C) $\mathrm{cm}^{-1}$. HRMS: calcd. for $\mathrm{C}_{44} \mathrm{H}_{50} \mathrm{O}_{5} \mathrm{SSi}_{2} \mathrm{Na}^{+}[\mathrm{M}+\mathrm{Na}]^{+} 769.2917$; found 769.2810 .

\subsubsection{Preparation of 5-(3-azidopropyl)-2,2,9,9-tetramethyl-3,3,8,8-tetraphenyl-4,7-dioxa-3,8- disiladecane 10}

To a stirred solution of alkyne $9(1.04 \mathrm{~g}, 1.39 \mathrm{mmol})$ in dry DMF $(10 \mathrm{~mL})$ at r.t., sodium azide $(0.45 \mathrm{~g}, 6.96 \mathrm{mmol})$ was added. After 2 hours all the starting material was consumed. The reaction mixture was diluted with $\mathrm{CH}_{2} \mathrm{Cl}_{2}$ and the obtained solid was 
filtered, the solvent was concentrated under vacuum. The residue was purified by flash column chromatography (90:10 Hexane/EtOAc) to afford the azide 10 (817 mg, 95\%) as a colourless viscous oil.

${ }^{1} \mathrm{H}-\mathrm{NMR}\left(\mathrm{CDCl}_{3}\right), 400 \mathrm{MHz}: \delta$ 7.75-7.64 (m, 8H, Ar), 7.42-7.36 (m, 12H, Ar), 4.59-4.56 $(\mathrm{m}, 1 \mathrm{H}, \mathrm{C} \underline{\mathrm{HC}} \equiv \mathrm{C}), 3.80\left(\mathrm{dd}, 1 \mathrm{H}, \mathrm{J}=6.5 \mathrm{~Hz}, \mathrm{~J}=10.1 \mathrm{~Hz}, 1 \times \operatorname{TBDPSOC}_{2} \mathrm{CH}\right), 3.71(\mathrm{dd}, 1 \mathrm{H}$, $\left.\mathrm{J}=5.3 \mathrm{~Hz}, \mathrm{~J}=10.0 \mathrm{~Hz}, 1 \times \operatorname{TBDPSOC} \underline{H}_{2} \mathrm{CH}\right), 3.66\left(\mathrm{~d}, 2 \mathrm{H}, \mathrm{J}=1.2 \mathrm{~Hz}, \mathrm{C} \equiv \mathrm{CC}_{2} \mathrm{~N}_{3}\right), 1.08(\mathrm{~s}$, $\left.9 \mathrm{H}, \mathrm{C}\left(\mathrm{CH}_{3}\right)_{3}\right), 1.03\left(\mathrm{~s}, 9 \mathrm{H}, \mathrm{C}\left(\mathrm{CH}_{3}\right)_{3}\right)$ ppm. ${ }^{13} \mathrm{C}-\mathrm{NMR}\left(\mathrm{CDCl}_{3}\right), 100 \mathrm{MHz}: \delta 136.1$ (Ar), $135.9(\mathrm{Ar}), 135.64(\mathrm{Ar}), 135.60(\mathrm{Ar}), 133.5\left(\mathrm{C}_{\mathrm{q}} \mathrm{Ar}\right), 133.33\left(\mathrm{C}_{\mathrm{q}} \mathrm{Ar}\right), 133.29\left(\mathrm{C}_{\mathrm{q}} \mathrm{Ar}\right)$, $133.26\left(\mathrm{C}_{\mathrm{q}} \mathrm{Ar}\right), 129.73(\mathrm{Ar}), 129.68(\mathrm{Ar}), 129.6(\mathrm{Ar}), 127.7(\mathrm{Ar}), 127.6(\mathrm{Ar}), 127.4(\mathrm{Ar})$, $86.7(\underline{\mathrm{C}} \equiv \mathrm{C}), 77.8(\mathrm{C} \equiv \underline{\mathrm{C}}), 68.1\left(\mathrm{TBDPSO} \mathrm{CH}_{2} \mathrm{CH}\right), 65.1(\underline{\mathrm{CHC}} \equiv \mathrm{C}), 39.9\left(\mathrm{C} \equiv \mathrm{C} \mathrm{CH}_{2} \mathrm{~N}_{3}\right)$, $\left.\left.26.9\left(\mathrm{C}\left(\mathrm{CH}_{3}\right)_{3}\right), 26.7\left(\mathrm{C}_{(\mathrm{C}}\right)_{3}\right)_{3}\right), 19.3\left(\underline{\mathrm{C}}\left(\mathrm{CH}_{3}\right)_{3}\right), 19.2\left(\underline{\mathrm{C}}\left(\mathrm{CH}_{3}\right)_{3}\right)$ ppm. FTIR (Neat): 2121 $(\mathrm{N}=\mathrm{N}=\mathrm{N}) \mathrm{cm}^{-1}$. HRMS: calcd. for $\mathrm{C}_{37} \mathrm{H}_{43} \mathrm{~N}_{3} \mathrm{O}_{2} \mathrm{Si}_{2} \mathrm{Na}^{+}[\mathrm{M}+\mathrm{Na}]^{+} 640.2787$; found 640,2786.

\subsubsection{Preparation of 5-azidopent-3-yne-1,2-diol 11}

To a stirred solution of azide $10(815 \mathrm{mg}, 1.32 \mathrm{mmol})$ in dry THF $(8 \mathrm{~mL})$ at room temperature, a $1 \mathrm{M}$ solution of TBAF in THF $(2.6 \mathrm{~mL}, 2.64 \mathrm{mmol})$ was added. After 3 hours all the starting material was consumed and the mixture was quenched with water (satured with $\mathrm{NaCl}, 10 \mathrm{~mL})$. The mixture was extracted with EtOAc $(3 \times 10 \mathrm{~mL})$, dried with $\mathrm{Na}_{2} \mathrm{SO}_{4}$, filtered and concentrated under vacuum. The residue was purified by flash column chromatography (20:80 Hexane/EtOAc) to afforded the diol 11 (142 mg, 76\%) as a colourless viscous oil.

${ }^{1} \mathrm{H}-\mathrm{NMR}\left(\mathrm{CDCl}_{3}\right), 400 \mathrm{MHz}: \delta$ 4.57-4.53 (m, 1H, C트 $\left.\equiv \mathrm{C}\right), 3.98(\mathrm{~d}, 2 \mathrm{H}, \mathrm{J}=1.4 \mathrm{~Hz}$, $\left.\mathrm{C} \equiv \mathrm{CC}_{2} \underline{\mathrm{N}}_{3}\right), 3.79\left(\mathrm{dd}, 1 \mathrm{H}, \mathrm{J}=3.7 \mathrm{~Hz}, \mathrm{~J}=11.5 \mathrm{~Hz}, 1 \mathrm{xHOC}_{2} \mathrm{CH}\right), 3.71(\mathrm{dd}, 1 \mathrm{H}, \mathrm{J}=6.6 \mathrm{~Hz}$, $\left.\mathrm{J}=11.5 \mathrm{~Hz}, 1 \times \mathrm{xHOC}_{2} \mathrm{CH}\right)$ ppm. ${ }^{13} \mathrm{C}-\mathrm{NMR}\left(\mathrm{CDCl}_{3}\right), 100 \mathrm{MHz}: \delta 85.2(\underline{\mathrm{C}} \equiv \mathrm{C}), 78.3(\mathrm{C} \equiv \underline{\mathrm{C}})$, $66.3\left(\mathrm{HOC} \mathrm{H}_{2} \mathrm{CH}\right), 63.1(\underline{\mathrm{C}} \mathrm{HC} \equiv \mathrm{C}), 39.9\left(\mathrm{C} \equiv \mathrm{C}^{\mathrm{C}} \mathrm{H}_{2} \mathrm{~N}_{3}\right)$ ppm. FTIR (Neat): $2112(\mathrm{~N}=\mathrm{N}=\mathrm{N})$, $3283(\mathrm{OH}) \mathrm{cm}^{-1}$.

\subsubsection{Preparation of 2-(3-azidoprop-1-yn-1-yl)-1,4-dioxaspiro[4.5]decane 12}

To a stirred solution of diol $11(94 \mathrm{mg}, 0.67 \mathrm{mmol})$ in dry DMF (3 mL) at r.t., cyclohexanone dimethyl ketal $(0.20 \mathrm{~mL}, 1.33 \mathrm{mmol})$ and two drops of sulfuric acid were added. After 16 hours all the starting material was consumed and the mixture was quenched with a saturated aqueous $\mathrm{NaHCO}_{3}$ solution $(5 \mathrm{~mL})$ and extracted with EtOAc $(3 \times 5 \mathrm{~mL})$. The combined organic layers were dried with anhydrous $\mathrm{Na}_{2} \mathrm{SO}_{4}$, the solvent was filtered and concentrated under vacuum. The residue was purified by flash column chromatography (95:05 Hexane/EtOAc) to afford the acetal 12 (123 mg, 84\%) as a colourless viscous oil.

${ }^{1} \mathrm{H}-\mathrm{NMR}\left(\mathrm{CDCl}_{3}\right), 400 \mathrm{MHz}: \delta$ 4.80-4.76 (m, 1H, C $\left.\underline{\mathrm{HC}} \equiv \mathrm{C}\right), 4.19$ (dd, $1 \mathrm{H}, \mathrm{J}=6.4 \mathrm{~Hz}, \mathrm{~J}=8.1$ $\left.\mathrm{Hz}, 1 \times \mathrm{HOCH}_{2} \mathrm{CH}\right), 3.96\left(\mathrm{~s}, 2 \mathrm{H}, \mathrm{C} \equiv \mathrm{CCH}_{2} \mathrm{~N}_{3}\right), 3.94(\mathrm{dd}, 1 \mathrm{H}, \mathrm{J}=6.3 \mathrm{~Hz}, \mathrm{~J}=8.0 \mathrm{~Hz}$, $\left.1 \times \mathrm{xHOCH}_{2} \mathrm{CH}\right), 1.76-1.39\left(\mathrm{~m}, 10 \mathrm{H}, \mathrm{CH}_{2}\right.$ from ketal) ppm. ${ }^{13} \mathrm{C}-\mathrm{NMR}\left(\mathrm{CDCl}_{3}\right), 100 \mathrm{MHz}: \delta$ $111.3\left(\mathrm{C}_{\mathrm{q}}\right), \quad 85.3 \quad(\underline{\mathrm{C}} \equiv \mathrm{C}), \quad 77.8 \quad(\mathrm{C} \equiv \underline{\mathrm{C}}), \quad 69.6 \quad\left(\mathrm{HO} \underline{\mathrm{C}} \mathrm{H}_{2} \mathrm{CH}\right), \quad 65.0 \quad(\underline{\mathrm{C}} \mathrm{HC} \equiv \mathrm{C}), \quad 39.9$ 
( $\left.\mathrm{C} \equiv \mathrm{C}_{\mathrm{CH}} \mathrm{N}_{3}\right), 35.7$ ( $\mathrm{CH}_{2}$ from ketal), 35.4 ( $\mathrm{CH}_{2}$ from ketal), 25.0 ( $\mathrm{CH}_{2}$ from acetal), 23.9 ( $2 \times \mathrm{CH}_{2}$ from acetal) ppm. FTIR (Neat): $2120(\mathrm{~N}=\mathrm{N}=\mathrm{N}), 1040(\mathrm{C}-\mathrm{O}-\mathrm{C}) \mathrm{cm}^{-1}$. HRMS: calcd. for $\mathrm{C}_{11} \mathrm{H}_{15} \mathrm{~N}_{3} \mathrm{O}_{2}{ }^{+}[\mathrm{M}]^{+}$222.1236; found 222.1237.

\subsubsection{Preparation of 3-\{1,4-dioxaspiro[4.5]decan-2-yl\}prop-2-yn-1-amine, 2}

To a stirred solution of acetal $12(120 \mathrm{mg}, 0.54 \mathrm{mmol})$ in dry THF $(5 \mathrm{~mL})$ at r.t., triphenylphosphine $(313 \mathrm{mg}, 1.19 \mathrm{mmol}$ ) was added. After 3 hours $45 \mu \mathrm{L}$ of water were added and the mixture was stirred overnight. The reaction mixture was concentrated under vacuum and the residue was purified by flash column chromatography $(100 \%$ EtOAc followed by $90: 10 \mathrm{CH}_{2} \mathrm{Cl}_{2} / \mathrm{MeOH}$ ) to afford the amine 2 (100 $\mathrm{mg}, 94 \%$ ) as a colourless viscous oil.

${ }^{1} \mathrm{H}-\mathrm{NMR}\left(\mathrm{CDCl}_{3}\right), 400 \mathrm{MHz}: \delta 4.74(\mathrm{t}, 1 \mathrm{H}, \mathrm{J}=6.2 \mathrm{~Hz}, \mathrm{C} \underline{\mathrm{HC}} \equiv \mathrm{C}), 4.14$ (dd, $1 \mathrm{H}, \mathrm{J}=6.2 \mathrm{~Hz}$, $\left.\mathrm{J}=8.0 \mathrm{~Hz}, 1 \mathrm{xHOCH}_{2} \mathrm{CH}\right), 3.88\left(\mathrm{dd}, 1 \mathrm{H}, \mathrm{J}=6.6 \mathrm{~Hz}, \mathrm{~J}=8.0 \mathrm{~Hz}, 1 \mathrm{xHOCH}_{2} \mathrm{CH}\right), 3.56(\mathrm{~d}, 2 \mathrm{H}$, $\left.\mathrm{C} \equiv \mathrm{CCH}_{2} \mathrm{NH}_{2}\right), 1.74-1.40\left(\mathrm{~m}, 10 \mathrm{H}, \mathrm{CH}_{2}\right.$ from ketal) ppm. ${ }^{13} \mathrm{C}-\mathrm{NMR}\left(\mathrm{CDCl}_{3}\right), 100 \mathrm{MHz}: \delta$ $111.0\left(\mathrm{C}_{\mathrm{q}}\right), 84.6(\underline{\mathrm{C}} \equiv \mathrm{C}), 80.9(\mathrm{C} \equiv \underline{\mathrm{C}}), 69.5\left(\mathrm{HOC} \mathrm{H}_{2} \mathrm{CH}\right), 65.2(\underline{\mathrm{CHC}} \equiv \mathrm{C}), 35.8\left(\underline{\mathrm{CH}}_{2}\right.$ from ketal), $35.4\left(\underline{\mathrm{CH}}_{2}\right.$ from ketal), $31.2\left(\mathrm{C} \equiv \mathrm{CCH}_{2} \mathrm{NH}_{2}\right), 25.0\left(\underline{\mathrm{CH}} \mathrm{H}_{2}\right.$ from ketal), $23.9\left(\mathrm{CH}_{2}\right.$ from ketal), $23.8\left(\mathrm{CH}_{2}\right.$ from ketal) ppm. FTIR (Neat): $2106(\mathrm{C} \equiv \mathrm{C}), 1099(\mathrm{C}-\mathrm{N}), 1590(\mathrm{~N}-\mathrm{H}) \mathrm{cm}^{-}$ ${ }^{1}$. HRMS: calcd. for $\mathrm{C}_{11} \mathrm{H}_{16} \mathrm{NO}_{2}^{+}[\mathrm{M}]^{+}$195.1259; found 196.1332 .

\subsubsection{Preparation of $\mathrm{N}$-(3-\{1,4-dioxaspiro[4.5]decan-2-yl\}prop-2-yn-1-yl)-6-(5-methyl-2- oxoimidazolidin-4-yl)hexanamide 13}

To a solution of D-desthiobiotin $(110 \mathrm{mg}, 0.51 \mathrm{mmol})$ in dry MeCN were added EDC (147 $\mathrm{mg}, 0.77 \mathrm{mmol}$ ) and HOBt $(69 \mathrm{mg}, 0.51 \mathrm{mmol})$. After stirred for $2 \mathrm{~h} 30 \mathrm{~min}$ the amine 2 $(100 \mathrm{mg}, 0.51 \mathrm{mmol})$ was added in dry $\mathrm{MeCN}$ and the reaction mixture was stirred overnight, at room temperature. The mixture was concentrated under vacuum and the crude residue was purified by flash column chromatography $\left(95: 05 \mathrm{CH}_{2} \mathrm{Cl}_{2} / \mathrm{MeOH}\right)$ to afford the amide 13 (91 $\mathrm{mg}, 46 \%)$.

${ }^{1} \mathrm{H}-\mathrm{NMR}\left(\mathrm{CDCl}_{3}\right), 400 \mathrm{MHz}: \delta 6.40(\mathrm{~s}, 1 \mathrm{H}, \mathrm{NH}), 4.71\left(\mathrm{t}, 1 \mathrm{H}, \mathrm{J}=6.4 \mathrm{~Hz}, \mathrm{C} \equiv \mathrm{CC}^{\mathrm{H}} \mathrm{CH}_{2}\right), 4.13$ (dd, $\left.1 \mathrm{H}, \mathrm{J}=4.3 \mathrm{~Hz}, \mathrm{~J}=8.0 \mathrm{~Hz}, 1 \times \mathrm{C} \equiv \mathrm{CCHCH}_{2}\right), 4.08\left(\mathrm{~s}, 2 \mathrm{H}, \mathrm{HNCH}_{2} \mathrm{C} \equiv \mathrm{C}\right), 3.88-3.84(\mathrm{~m}$, $2 \mathrm{H}, 1 \times \mathrm{C} \equiv \mathrm{CCHCH}_{2}$ and $\mathrm{CH}_{3} \mathrm{CHNH}$ D-desthiobiotin), 3.74-3.67 (m, 1H, $\mathrm{HNCHCH}_{2} \mathrm{D}-$ desthiobiotin), $2.20\left(\mathrm{t}, 2 \mathrm{H}, \mathrm{J}=7.4 \mathrm{~Hz}, \mathrm{CH}_{2}(\mathrm{C}=\mathrm{O}) \mathrm{NH}\right.$ ), 1.73-1.24 (m, $\mathrm{CH}_{2}$ from Ddesthiobiotin and ketal), $1.14\left(\mathrm{~d}, 3 \mathrm{H}, \mathrm{J}=6.5 \mathrm{~Hz}, \mathrm{CH}_{3}\right)$ ppm. ${ }^{13} \mathrm{C}-\mathrm{NMR}\left(\mathrm{CDCl}_{3}\right), 100 \mathrm{MHz}: \delta$ $172.7(\underline{\mathrm{C}}=\mathrm{O}), 163.9(\underline{\mathrm{C}}=\mathrm{O}), 111.0\left(\mathrm{C}_{\mathrm{q}}\right.$ from ketal), $82.00(\underline{\mathrm{C}} \equiv \mathrm{C}), 81.96(\underline{\mathrm{C}} \equiv \mathrm{C}), 80.52$ $(\mathrm{C} \equiv \underline{\mathrm{C}}), 80.49(\mathrm{C} \equiv \underline{\mathrm{C}}), 69.4\left(\mathrm{C} \equiv \mathrm{CCH}_{\underline{C}} \mathrm{H}_{2}\right), 65.1\left(\mathrm{C} \equiv \mathrm{C} \underline{\mathrm{C}} \mathrm{HCH}_{2}\right), 56.1\left(\mathrm{CH}_{3} \underline{\mathrm{CHNH}}\right), 51.5$ $\left(\mathrm{HNCHCH}{ }_{2}\right), 35.8\left(\underline{C H}_{2}\right), 35.62\left(\underline{C H}_{2}\right), 35.59\left(\underline{C H}_{2}\right), 35.3\left(\underline{C H}_{2}(\mathrm{C}=\mathrm{O}) \mathrm{NH}\right), 29.4\left(\underline{C H}_{2}\right)$, $29.3\left(\mathrm{CH}_{2}\right), 29.2\left(\mathrm{HNCH}_{2} \mathrm{C} \equiv \mathrm{C}\right), 28.5\left(\mathrm{CH}_{2}\right), 28.4\left(\underline{\mathrm{CH}}_{2}\right), 25.73\left(\underline{\mathrm{CH}}_{2}\right), 25.71\left(\mathrm{CH}_{2}\right), 25.03$ $\left(\underline{\mathrm{CH}}_{2}\right), 24.99\left(\mathrm{CH}_{2}\right), 23.9\left(\mathrm{CH}_{2}\right), 23.8\left(\underline{\mathrm{CH}}_{2}\right), 15.7\left(\underline{\mathrm{CH}}_{3}\right)$ ppm. HRMS: calcd. for $\mathrm{C}_{20} \mathrm{H}_{34} \mathrm{~N}_{3} \mathrm{O}_{4}{ }^{+}[\mathrm{M}]^{+}$392.2543; found 392.2544. 


\subsubsection{Preparation of $\mathbf{N}$-(3-\{1,4-dioxaspiro[4.5]decan-2-yl\}-2,3-dioxopropyl)-6-(5-methyl-2-}

oxoimidazolidin-4-yl)hexanamide 14

To a solution of amide 13 (15 mg, $0.38 \mathrm{mmol})$ in $2 \mathrm{~mL}$ of $\mathrm{H}_{2} \mathrm{O}: \mathrm{Et}_{2} \mathrm{O}$ (1:1.5) was added $\mathrm{KClO}_{3}(12 \mathrm{mg}, 0.96 \mathrm{mmol}), \mathrm{OsO}_{4}(195 \mu \mathrm{L}, 0.15 \mathrm{mmol}, 2 \%$ aqueous solution) and $t-\mathrm{BuOH}$ $(195 \mu \mathrm{L})$. After $24 \mathrm{~h}$, at room temperature, the reaction mixture was quenched with a saturated aqueous $\mathrm{NH}_{4} \mathrm{Cl}$ solution $(2 \mathrm{~mL})$ and extracted with $\mathrm{CH}_{2} \mathrm{Cl}_{2}(3 \times 2 \mathrm{~mL})$. The combined organic layers were dried with anhydrous $\mathrm{Na}_{2} \mathrm{SO}_{4}$, filtered and concentrated under vacuum. The amide 14 (16 mg, quant. yield) was afforded without further purification as a colourless viscous oil.

${ }^{1} \mathrm{H}-\mathrm{NMR}\left(\mathrm{CDCl}_{3}\right), 400 \mathrm{MHz}: \delta 4.92\left(\mathrm{t}, 1 \mathrm{H}, \mathrm{J}=6.5 \mathrm{~Hz},(\mathrm{C}=\mathrm{O}) \mathrm{CHCH}_{2}\right), 4.26(\mathrm{t}, 1 \mathrm{H}, \mathrm{J}=8.0$ $\left.\mathrm{Hz}, 1 \times \mathrm{xHNC}_{2}(\mathrm{C}=\mathrm{O})\right), 4.15-4.08\left(\mathrm{~m}, 2 \mathrm{H}, 1 \mathrm{xHNC}_{2}(\mathrm{C}=\mathrm{O})\right.$ and $\left.1 \mathrm{x}(\mathrm{C}=\mathrm{O}) \mathrm{CHC}_{2}\right), 3.90-3.85$ $\left(1 \times(\mathrm{C}=\mathrm{O}) \mathrm{CHCH}_{2}\right.$ and $\mathrm{CH}_{3} \underline{\mathrm{CHNH}}$ D-desthiobiotin), 3.76-3.65 (m, 1H, $\mathrm{HNCHCH}_{2} \mathrm{D}-$ desthiobiotin), 2.45-2.18 (m, $\left.\mathrm{CH}_{2}(\mathrm{C}=\mathrm{O}) \mathrm{NH}\right), 1.74-1.25\left(\mathrm{~m}, \mathrm{CH}_{2}\right.$ from D-desthiobiotin and ketal), 1.13 (d, 3H, J=6.3 Hz, $\left.\mathrm{CH}_{3}\right)$ ppm. ${ }^{13} \mathrm{C}-\mathrm{NMR}\left(\mathrm{CDCl}_{3}\right), 100 \mathrm{MHz}$ : $\delta 206.7(\mathrm{C}=\mathrm{O})$, $192.4(\mathrm{C}=\mathrm{O}), 174.7(\mathrm{C}=\mathrm{O}), 164.8(\mathrm{C}=\mathrm{O}), 134.1\left(\mathrm{C}_{\mathrm{q}}\right.$ from ketal), $76.7\left((\mathrm{C}=\mathrm{O}) \underline{\mathrm{C}} \mathrm{HCH}_{2}\right)$, $69.4\left((\mathrm{C}=\mathrm{O}) \mathrm{CHCH}_{2}\right), 66.9\left(\mathrm{HNCH}_{2}(\mathrm{C}=\mathrm{O})\right), 56.2\left(\mathrm{HNCHCH}_{2} \quad\right.$ D-desthiobiotin $), \quad 56.1$ $\left(\mathrm{CH}_{3} \underline{\mathrm{C}} H N H\right.$ D-desthiobiotin), $42.0\left(\underline{\mathrm{CH}}_{2}(\mathrm{C}=\mathrm{O}) \mathrm{NH}\right), 35.8\left(\mathrm{CH}_{2}\right), 35.4\left(\underline{\mathrm{CH}}_{2}\right), 35.3\left(\mathrm{CH}_{2}\right)$, $\left.\left.34.8\left(\underline{\mathrm{CH}}_{2}\right), 29.7\left(\mathrm{CH}_{2}\right), 29.3\left(\underline{\mathrm{CH}}_{2}\right), 28.6\left(\underline{\mathrm{CH}}_{2}\right), 27.0\left(\underline{\mathrm{CH}}_{2}\right), 26.6(\underline{\mathrm{CH}})_{2}\right), 25.7(\underline{\mathrm{CH}})_{2}\right), 25.0$ $\left(\underline{\mathrm{CH}}_{2}\right), 24.6\left(\mathrm{CH}_{2}\right), 23.9\left(\mathrm{CH}_{2}\right), 23.8\left(\mathrm{CH}_{2}\right), 23.0\left(\underline{\mathrm{CH}}_{2}\right), 15.7\left(\mathrm{CH}_{3}\right)$ ppm. HRMS: calcd. for $\mathrm{C}_{21} \mathrm{H}_{33} \mathrm{~N}_{3} \mathrm{O}_{6}^{+}[\mathrm{M}]^{+}$424.2440; found 424.2442.

\subsubsection{Preparation of $\mathbf{N}$-(4,5-dihydroxy-2,3-dioxopentyl)-6-(5-methyl-2-oxoimidazolidin-4- yl)hexanamide 1}

To a solution of amide $14(9.6 \mathrm{mg}, 0.023 \mathrm{mmol})$ in $750 \mu \mathrm{L}$ of DMSO- $d_{6}: \mathrm{D}_{2} \mathrm{O}(1: 4)$ was added $\mathrm{D}_{2} \mathrm{SO}_{4}\left(10 \mu \mathrm{L}\right.$ of a $10 \%$ solution in $\left.\mathrm{D}_{2} \mathrm{O}\right)$. The solution was sonicated during 15 minutes, in a cooled ultrasounds bath, and stirring for $24 \mathrm{~h}$ at $800 \mathrm{rpm}$. The mixture was quenched with $\mathrm{CDCl}_{3}$ (3x500 $\mu \mathrm{L})$ and the aqueous phase was recovered. The complex D-desthiobiotin-Al-2 1 (7.8 $\mathrm{mg}$, quant. yield) was obtained in solution without further purification.

${ }^{1} \mathrm{H}-\mathrm{NMR}\left(\mathrm{D}_{2} \mathrm{O}\right), 400 \mathrm{MHz}$ : $\delta 8.15(\mathrm{~s}, \mathrm{NH}), 4.27$ (t, J=4.1 Hz, CH from Al-2), 3.86-3.76 (m, $1 \mathrm{H}, \mathrm{CH}_{3} \mathrm{CHNH}$ D-desthiobiotin), $3.76\left(\mathrm{~d}, \mathrm{~J}=4.2 \mathrm{~Hz}, \mathrm{CH}_{2}\right.$ from Al-2), 3.72-3.65 (m, $1 \mathrm{H}$, $\mathrm{HNCHCH}_{2}$ D-desthiobiotin), 3.58-3.49 (m, $\left.(\mathrm{C}=\mathrm{O}) \mathrm{HNCH}_{2}(\mathrm{C}=\mathrm{O})\right), 2.21-2.16(\mathrm{~m}, 2 \mathrm{H}$, $\left.\mathrm{C}_{2}(\mathrm{C}=\mathrm{O}) \mathrm{NH}\right), 1.62-1.50\left(\mathrm{~m}, 2 \mathrm{H}, \mathrm{CH}_{2}\right.$ from D-desthiobiotin), 1.47-1.39 (m, $2 \mathrm{H}, \mathrm{CH}_{2}$ from D-desthiobiotin), 1.35-1.18 ( $\mathrm{m}, 4 \mathrm{H}, \mathrm{CH}_{2}$ from D-desthiobiotin), 1.03 (d, 3H, J=6.5 Hz, $\mathrm{CH}_{3}$ ) ppm. Other peacks are present, come from the cyclic forms of $\mathrm{Al}-2 .{ }^{13} \mathbf{C}-\mathrm{NMR}$ $\left(\mathrm{D}_{2} \mathrm{O}\right), 100 \mathrm{MHz}: \delta 71.4$ ( $\underline{\mathrm{CH}}$ from Al-2), $65.1\left((\mathrm{C}=\mathrm{O}) \mathrm{HNCH}_{2}(\mathrm{C}=\mathrm{O})\right.$ ), $63.3\left(\underline{\mathrm{CH}}_{2}\right.$ from Al-2), $55.9\left(\mathrm{HNCHCH}_{2}\right.$ D-desthiobiotin), $51.4\left(\mathrm{CH}_{3} \underline{\mathrm{CHNH}}\right.$ D-desthiobiotin), $35.4\left(\mathrm{CH}_{2}\right), 35.0$ $\left.\left(\underline{\mathrm{CH}}_{2}\right), 28.8\left(\underline{\mathrm{CH}}_{2}\right), 28.7\left(\underline{\mathrm{CH}}_{2}\right), 28.2(\underline{\mathrm{CH}})_{2}\right), 28.1\left(\underline{\mathrm{CH}}_{2}\right), 25.3\left(\underline{\mathrm{CH}_{2}}\right), 25.1\left(\underline{\mathrm{CH}}_{2}\right), 25.0$ $\left(\mathrm{CH}_{2}\right), 14.6\left(\mathrm{CH}_{3}\right) \mathrm{ppm}$.

\subsubsection{Protein expression and purification}


Escherichia coli BL21 ( $\triangle /$ luxS) transformed with the plasmid pQE30 (carrying LuXP protein from Vibrio harveyi fused to cyan (CFP) and yellow (YFP) fluorescent proteins) - pQE30-CLPY- was kindly provided by Richard Sayre (The Ohio State University, Ohio, USA). Expression and purification of this protein was carried out as previously described. ${ }^{27}$ Briefly, protein expression was induced at an optical density $\left(\mathrm{OD}_{600}\right)$ of 0.6 with $0.3 \mathrm{mM}$ of isopropyl $\beta$-Dthiogalactopyranoside (IPTG) and grown for $6 \mathrm{~h}$, at $28{ }^{\circ} \mathrm{C}$ before cell harvesting by centrifugation. The resulting pellet was resuspended in $25 \mathrm{mM}$ sodium phosphate buffer $\mathrm{pH}$ 8.0, $35 \mathrm{mM} \mathrm{NaCl}, 1: 100$ protease inhibitor cocktail (Roche) and cells were lysed by passing them three times through a french press. Cell debris were removed by centrifugation and LuxP was purified from clarified supernatants through Nickel-nitrilotriacetic ( $\left.\mathrm{Ni}^{+}-\mathrm{NTA}\right)$ acid affinity chromatography (Qiagen). The protein was eluted in $25 \mathrm{mM}$ sodium phosphate buffer $\mathrm{pH}$ 8.0, $35 \mathrm{mM} \mathrm{NaCl}, 40 \%$ glycerol, $250 \mathrm{mM}$ imidazole, 1:100 protease inhibitor cocktail. The expression and purification of Clostridium saccharobutylicum DSM13864 and E. coli K-12 MG1655 LsrB proteins (CsLsrB and EcLsr, respectively) were carried out as previously described. ${ }^{12,28}$ Concisely, E. coli BL21 ( $\Delta /$ /uXS) cells transformed with the constructs pProEcLsrB and pDEST-CsLsrB were grown in LB with $1 \mu \mathrm{g} / \mathrm{mL}$ ampicillin at $37^{\circ} \mathrm{C}$ until the $\mathrm{OD}_{600}$ was 0.3 . At this point, temperature was decreased to $22^{\circ} \mathrm{C}$. At $\mathrm{OD}_{600}=0.9$, protein expression was induced with $0.1 \mathrm{mM}$ or $0.3 \mathrm{mM}$ of IPTG for the expression of EcLsr and CsLsrB, respectively. Cells grew for $6 \mathrm{~h}$ after induction and were harvested by centrifugation. The resulting pellets were resuspended in $50 \mathrm{mM} \mathrm{NaH} \mathrm{PO}_{4}(\mathrm{pH} 8.0), 300 \mathrm{mM} \mathrm{NaCl}, 10 \mathrm{mM}$ imidazole, $2.5 \mu \mathrm{g} / \mathrm{mL}$ DNase and $2.5 \mu \mathrm{g} / \mathrm{mL}$ leupeptin and cells were lysed by passing thrice through a french press. Centrifugation was employed to remove cell debris and the taggedproteins were purified by $\mathrm{Ni}^{+}$-NTA affinity chromatography. EcLsrB and CsLsrB were eluted in $50 \mathrm{mM} \mathrm{NaH}_{2} \mathrm{PO}_{4}$ (pH 8.0), $300 \mathrm{mM} \mathrm{NaCl}, 250 \mathrm{mM}$ imidazole and subsequently dialyzed (SlideA-Lyzer, ThermoFisher Scientific) into $25 \mathrm{mM}$ Tris buffer pH 8.0, $150 \mathrm{mM} \mathrm{NaCl}, 1 \mathrm{mM}$ DTT. CLPY-LuxP, EcLsrB and CsLsrB have a molecular weight of approximately 98,40 and 37.5 $\mathrm{kDa}$, respectively. The higher molecular weight of CPLY-LuxP when compared with the other receptors is due to its fusion to CFP and YFP.

\subsubsection{Native PAGE and western-blot}

Approximately $125 \mu \mathrm{g}$ of partially purified CPLY (CFP-LuxP-YFP; $\sim 1 \mathrm{nmol})$, CsLsrB $(\sim 3 \mathrm{nmol})$, and EcLsrB $(\sim 3 \mathrm{nmol})$ were incubated with approximately $59 \mu \mathrm{g}$ of desthiobiotin-Al-2 ( 172 $\mathrm{nmol}$ ) overnight under gentle agitation at $4^{\circ} \mathrm{C}$. These quantities ensured the presence of at least 50 times more probe than receptors. As a control $125 \mu \mathrm{g}$ of the protein samples were incubated with desthiobiotin alone $(59 \mu \mathrm{g})$ or with buffer in the same conditions $(25 \mathrm{mM}$ sodium phosphate buffer $\mathrm{pH}$ 8.0, $35 \mathrm{mM} \mathrm{NaCl}, 1 \mathrm{mM}$ boric acid for CPLY and $25 \mathrm{mM}$ Tris buffer pH 8.0, $150 \mathrm{mM}$ $\mathrm{NaCl}, 1 \mathrm{mM}$ DTT for CsLsrB and EcLsrB). $20 \mu \mathrm{L}$ of all the samples were mixed with $5 \mu \mathrm{L}$ of $5 \mathrm{X}$ sample buffer $(0.31 \mathrm{M}$ Tris- $\mathrm{HCl}$ buffer $\mathrm{pH} 6.8,0.05 \%$ bromophenol blue and $50 \%$ glycerol) and $11 \mu \mathrm{L}$ of these mixes were loaded into each of two $10 \%$ polyacrylamide non-denaturing gels. 5 $\mu \mathrm{L}$ of protein standards (All Blue Standards, Bio-Rad) was also added. The gel was run in Tris- 
glycine buffer ( $25 \mathrm{mM}$ Tris, $192 \mathrm{mM}$ glycine, $\mathrm{pH} 8.3$ ), at $160 \mathrm{~V}, 4^{\circ} \mathrm{C}$ for approximately $1 \mathrm{~h} 30$. One of the gels was stained with Comassie blue and the presence of the bands assessed. The second gel was used for a western-blot. Transfer was performed at $90 \mathrm{~mA}, 4^{\circ} \mathrm{C}$, overnight in 25 $\mathrm{mM}$ Tris, $192 \mathrm{mM}$ glycine and $0.05 \%$ SDS to a PVDF membrane. The membrane was incubated in a 1:5000 dilution of an anti-biotin, HRP conjugated antibody (PA1-30595, Invitrogen) for $1 \mathrm{~h}$ at room temperature. An ECL chemiluminescent substrate was added (SuperSignal West Pico, Pierce) and signal detection was performed in a blot imager (Amersham Imager 680).

\subsubsection{Pull-down of LuxP receptor}

Magnetic Dynabeads with protein G (Invitrogen, 10003D) were conjugated with the antibiotin antibody (\#31852, Pierce) as per the manufacturers instructions. Briefly, $50 \mu \mathrm{L}$ of Dynabeads $(1.5 \mathrm{mg})$ were added to a $1.5 \mathrm{~mL}$ eppendorf and the storage solution was removed through magnetic separation. $10 \mu \mathrm{g}$ of antibody diluted in $200 \mu \mathrm{L}$ of wash buffer (PBS buffer $\mathrm{pH} 7.4,0.02 \%$ Tween-20) was added to the beads and the mixture was incubated for $10 \mathrm{~min}$, at room temperature with agitation. The unbound antibody was then removed by magnetic separation and the beads were washed with $200 \mu \mathrm{L}$ of wash buffer. Next, the sample was added to the anti-biotin antibody conjugated magnetic beads. The sample used for the pull down of CLPY was incubated following the conditions mentioned above and included approximately $76,5 \mu \mathrm{g}$ of DB-Al-2 and $265 \mu \mathrm{g}$ of partially purified CLPY. The mixture sample/antibody-conjugated beads was incubated for $1 \mathrm{~h}$ at room temperature with agitation followed by three washes with $200 \mu \mathrm{L}$ of wash buffer to remove unbound protein. CPLY, complexed with the Al-2 probe and retained by the antibody conjugated magnetic beads, was eluted by denaturation. The final volume was heated for 10 minutes at $70^{\circ} \mathrm{C}$ in $20 \mu \mathrm{L}$ of $50 \mathrm{mM}$ glycine $\mathrm{pH} 2.8$ and $10 \mu \mathrm{L}$ of 240 $\mathrm{mM}$ Tris- $\mathrm{HCl} \mathrm{pH} 6.8,40 \%$ glycerol, $8 \%$ SDS, $0.04 \%$ bromophenol blue and $5 \% \beta-$ mercaptoethanol. $10 \mu \mathrm{L}$ of the wash and elution steps were mixed with $5 \mu \mathrm{L}$ of $200 \mathrm{mM}$ Tris- $\mathrm{HCl} \mathrm{pH} 6.8,8 \%$ SDS, $0.4 \%$ bromophenol blue and $40 \%$ glycerol and added to a denaturing gel composed of $15 \%$ acrylamide in the separating gel and $5 \%$ in the stacking gel. As protein standards, $5 \mu \mathrm{L}$ of All Blue Standards (Bio-Rad) were loaded. The gel was run in SDS running buffer at room temperature, $180 \mathrm{~V}$ for approximately 70 minutes and stained with Comassie blue.

\section{Acknowledgements}

We thank the Fundação para a Ciência e Tecnologia (FCT) and MostMicro Research Unit (financially supported by LISBOA-01-0145-FEDER-007660 funded by FEDER funds through COMPETE2020 (POCI) and by national funds through FCT. The NMR data was acquired at CERMAX, ITQB-NOVA, Oeiras, Portugal with equipment funded by FCT, project AAC 01/SAICT/2016. The work performed in the laboratory of M.R.V. was supported by Portuguese National funds from FCT, project PTDC/BIABQM/29668/2017 and V.M. acknowledges FCT individual PhD grant SFRH/BD/102159/2014. The work performed in the laboratory of K.B.X. was supported by Portuguese National funds from FCT, project 
PTDC/BIA-MIC/4188/14. K.B.X. and I.M.T. acknowledge FCT for individual grants IF/00831/2015 and $\mathrm{PD} / \mathrm{BD} / 105736 / 2014$, being the latter within the scope of the PhD program Molecular Biosciences PD/00133/2012. We thank Bárbara A. Rebelo for repeating some experiments. We thank Paulo Duarte for helpful tips regarding the immunoprecipitation protocol, Mónica Dias for generously providing the magnetic Dynabeads, Adriano O. Henriques and Stephen Miller for helpful discussions.

\section{References}

(1) Waters, C. M.; Bassler, B. L. Annu. Rev. Cell Dev. Biol. 2005, 21 (1), 319-346.

(2) Pereira, C. S.; Thompson, J. A.; Xavier, K. B. FEMS Microbiol. Rev. 2013, 37 (2), 156181.

(3) Mukherjee, S.; Bassler, B. L. Nat. Rev. Microbiol. 2019.

(4) Chen, X.; Schauder, S.; Potier, N.; Van Dorsselaer, A.; Pelczer, I.; Bassler, B. L.; Hughson, F. M. Nature 2002, 415 (6871), 545-549.

(5) Miller, S. T.; Xavier, K. B.; Campagna, S. R.; Taga, M. E.; Semmelhack, M. F.; Bassler, B. L.; Hughson, F. M. Mol. Cell 2004, 15 (5), 677-687.

(6) Papenfort, K.; Bassler, B. L. Nat Rev Microbiol 2016, 14 (9), 576-588.

(7) Bassler, B. L.; Greenberg, E. P.; Stevens, A. M. J. Bacteriol. 1997, 179 (12), 4043-4045.

(8) Bassler, B. L.; Wright, M.; Showalter, R. E.; Silverman, M. R. Mol. Microbiol. 1993, 9 (4), 773-786.

(9) Jung, S. A.; Chapman, C. A.; Ng, W. L. PLoS Pathog. 2015, 11 (4), 1-19.

(10) Garner, A. L.; Park, J.; Zakhari, J. S.; Lowery, C. A.; Struss, A. K.; Sawada, D.; Kaufmann, G. F.; Janda, K. D. J. Am. Chem. Soc. 2011, 133 (40), 15934-15937.

(11) Xavier, K. B.; Bassler, B. L. Nature 2005, 437 (7059), 750-753.

(12) Pereira, C. S.; De Regt, A. K.; Brito, P. H.; Miller, S. T.; Xavier, K. B. J. Bacteriol. 2009, 191 (22), 6975-6987.

(13) Rossmann, F. S; Racek, T.; Wobser, D.; Puchalka, J.; Rabener, E. M.; Reiger, M.; Hendrickx, A. P. A.; Diederich, AK.; Jung, K.; Klein, C.; Huebner, J. PLOS Pathogens 2015, 11(2): e1004653.

(14) Maa, R.; Quub, S.; Qiu, J.; Suna, H.; Xueb, T.; Caib, G.; Sun, B. Int J Med Microbiol 2017, 307: 257-267.

(15) Dubinsky, L.; Delago, A.; Amara, N.; Krief, P.; Rayo, J.; Zor, T.; Kravchenko, V. V.; Meijler, M. M. Chem. Commun. 2013, 49 (52), 5826-5828.

(16) Welsh, M. A.; Blackwell, H. E. FEMS Microbiol. Rev. 2016, 40 (5), 774-794.

(17) Wilchek, M.; Bayer, E. A.; Livnah, O. Immunol. Lett. 2006, 103 (1), 27-32.

(18) Nimse, S. B.; Song, K.; Sonawane, M. D.; Sayyed, D. R.; Kim, T. Sensors (Switzerland) 2014, 14 (12), 22208-22229.

(19) Bednarek, S.; Madan, V.; Sikorski, P. J.; Bartenschlager, R.; Kowalska, J.; Jemielity, J. Philos. Trans. R. Soc. B Biol. Sci. 2018, 373 (1762).

(20) Wu, S. C.; Wang, C.; Hansen, D.; Wong, S. L. Sci. Rep. 2017, 7 (January), 1-10.

(21) Ngo, C.; Mehta, R.; Aggarwal, K.; Fikes, A. G.; Santos, I. C.; Greer, S. M.; Que, E. L. 
ChemBioChem 2019, 20 (8), 1003-1007.

(22) Goujon, A.; Straková, K.; Sakai, N.; Matile, S. Chem. Sci. 2019, 10 (1), 310-319.

(23) Ascenso, O. S.; Marques, J. C.; Santos, A. R.; Xavier, K. B.; Rita Ventura, M.; Maycock, C. D. Bioorganic Med. Chem. 2011, 19 (3), 1236-1241.

(24) Mori, Y.; Mitsuoka, S.; Furukawa, H. Tetrahedron Lett. 2000, 41, 4161-4164.

(25) Tsuchikama, K.; Zhu, J.; Lowery, C. A.; Kaufmann, G. F.; Janda, K. D. J. Am. Chem. Soc. 2012, 134 (33), 13562-13564.

(26) Ascenso, O. S.; Torcato, I. M.; Sofia, A.; Marques, J. C.; Xavier, K. B.; Ventura, M. R.; Maycock, C. D. Bioorg. Chem. 2019, 85, 75-81.

(27) Rajamani, S.; Zhu, J.; Pei, D.; Sayre, R. Biochemistry 2007, 3990-3997.

(28) Torcato, I. M.; Kasal, M. R.; Brito, P. H.; Miller, S. T.; Xavier, K. B. J. Biol. Chem. 2019, 294 (12), 4450-4463.

(29) Eslamizar, L.; Haugland, R. P.; Hirsch, J. D.; Malekzadeh, N.; Beechem, J. M.; Haugland, R. P.; Filanoski, B. J. Anal. Biochem. 2002, 308 (2), 343-357.

(30) Armarego, W. L. F.; Chai, C. L. L. Purification of Laboratory Chemicals, 5th Editio.; Elsevier, Ed.; 2003.

(31) Allegretti, P. A.; Ferreira, E. M. Org. Lett. 2011, 13 (21), 5924-5927. 
Synthesis of D-desthiobiotin-Al-2 as a novel chemical probe for autoinducer-2 quorum sensing receptors

Vanessa Miranda, ${ }^{a}$ Inês M. Torcato, ${ }^{a, b}$ Karina B. Xavier ${ }^{b}$ and M. Rita Ventura ${ }^{a} *$

a. Instituto de Tecnologia Química e Biológica António Xavier, Universidade Nova de Lisboa, Apartado 127, 2780-901 Oeiras, Portugal. E-mail: rventura@itqb.unl.pt

${ }^{b}$ Instituto Gulbenkian da Ciência, 2781-901 Oeiras, Portugal.

\section{Electronic Supporting Information}

\section{Table of contents}

1. Material and Methods $\quad 2$

1.1 Synthesis 2

1.2 Characterisation of compounds 2

$\begin{array}{ll}1.3 \text { Protein expression and purification } & 6\end{array}$

$\begin{array}{ll}1.4 \text { Native PAGE and western-blot } & 7\end{array}$

$\begin{array}{ll}1.5 \text { Pull-down of LuxP receptor } & 7\end{array}$

$\begin{array}{lr}\text { 2. NMR Spectra } & 9\end{array}$

$\begin{array}{lr}\text { 3. References } & 21\end{array}$ 


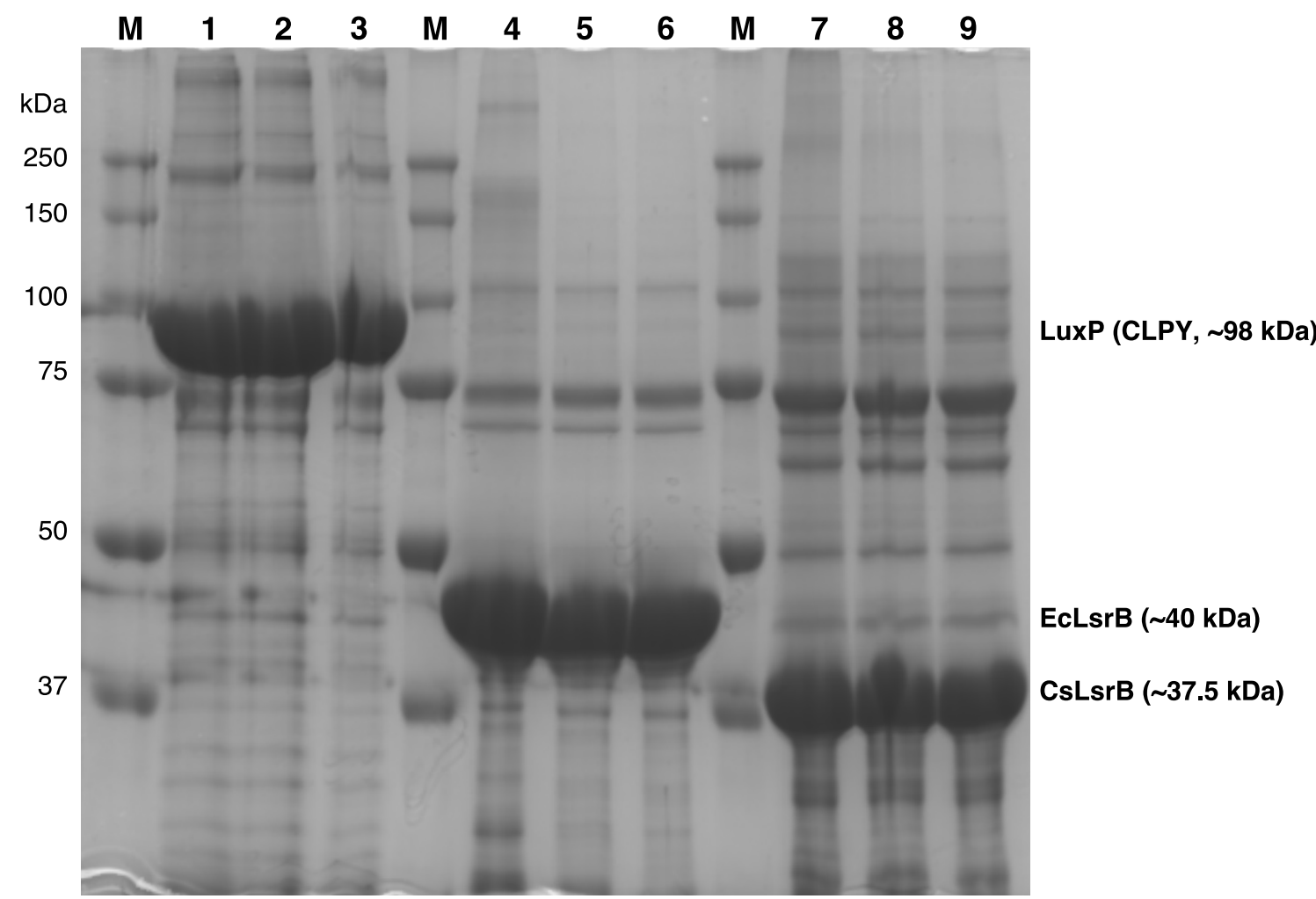

Figure S1 Loading control of the samples ran in the native gel. The samples were heated at $95^{\circ} \mathrm{C}$ for 5 min and loaded into a denaturing gel composed of $15 \%$ acrylamide in the separating gel and $5 \%$ in the stacking gel. $5 \mu \mathrm{L}$ of All Blue Standards (Bio-Rad) were loaded as protein standards. The gel was run in SDS running buffer at room temperature, $180 \mathrm{~V}$ for approximately 70 minutes and stained with Comassie blue. Protein standards (M), CLPYLuxP incubated with DB-Al-2 (1), desthiobiotin (2) and buffer (3); EcLsrB incubated with DB-Al-2 (4), with desthiobiotin (5) and buffer (6); CsLsrB incubated with DB-Al-2 (7), desthiobiotin (8) and buffer (9).

\section{Material and Methods}

\subsection{Synthesis}

${ }^{1} \mathrm{H}$ NMR spectra were obtained with a Bruker Avance II+ $(400 \mathrm{MHz})$ spectrometer, at $400 \mathrm{MHz}$ in $\mathrm{CDCl}_{3}$ or $\mathrm{D}_{2} \mathrm{O}$ with chemical shift values $(\delta)$ in ppm downfield from tetramethylsilane in the case of $\mathrm{CDCl}_{3}$, and ${ }^{13} \mathrm{C}$ NMR spectra were obtained at $100 \mathrm{MHz}$ in $\mathrm{CDCl}_{3}$ or $\mathrm{D}_{2} \mathrm{O}$. Assignments are supported by $2 \mathrm{D}$ correlation NMR spectroscopy studies. Preparative chromatographic separations were carried out by flash chromatography using Kieselgel 60, $(0.032-0.063 \mathrm{~mm})$. Analytical TLC was performed on aluminum-backed Merck $60 \mathrm{~F}_{254}$ silica gel plates. Reagents and solvents were purified and dried according to ref. ${ }^{1}$ All the reactions were carried out under an inert atmosphere (argon), except when the solvents were not dried.

\subsection{Characterisation of compounds}

\section{Synthesis of 2-(ethynyloxy)oxane 3}

ОтнР Propyne 3 was prepared and characterised according to the literature. ${ }^{2}$

\section{Synthesis of $N$-Methoxy- $N$-methyl-2-(tert-butyldiphenylsilyloxy)acetamide 4}


TBDPSO $\overbrace{\mathrm{O}}^{\mathrm{N}}$ OMe

Weinreb amide 4 was prepared and characterised according to the literature. ${ }^{3}$

\section{Synthesis of 1-[(tert-butyldiphenylsilyl)oxy]-5-(oxan-2-yloxy)pent-3-yn-2-one 5}<smiles>CC(C)[Mg]OCC(=O)C#CC[OH+]</smiles>

To a solution of DIPA (1.6 mL, $11.2 \mathrm{mmol})$ in THF $(8 \mathrm{~mL}), 1.6 \mathrm{M}$ solution of $\mathrm{n}$-BuLi in hexane $(6.3 \mathrm{~mL}, 10.7 \mathrm{mmol})$ was added dropwise at $-78^{\circ} \mathrm{C}$ and the mixture stirred at $0^{\circ} \mathrm{C}$ for 15 minutes. At $-78{ }^{\circ} \mathrm{C}$, a solution of propyne $3(1.57 \mathrm{~g}, 11.2 \mathrm{mmol})$ in THF

$(8 \mathrm{~mL})$ was added and the mixture stirred for 30 minutes. Still at $-78{ }^{\circ} \mathrm{C}$, a solution of Weinreb amide $4(2.00 \mathrm{~g}, 5.6 \mathrm{mmol})$ in THF $(10 \mathrm{~mL})$ was added. The mixture was stirred at $-78^{\circ} \mathrm{C}$ for 20 minutes and then at $0{ }^{\circ} \mathrm{C}$ until all starting material had been consumed (TLC), approximately 2 hours. The mixture was quenched with a saturated aqueous $\mathrm{NH}_{4} \mathrm{Cl}$ solution $(20 \mathrm{~mL})$ and extracted with $\mathrm{CH}_{2} \mathrm{Cl}_{2}$ $(3 \times 20 \mathrm{~mL})$. The combined organic layers were dried with anhydrous $\mathrm{Na}_{2} \mathrm{SO}_{4}$, the solvent was filtered and concentrated under vacuum. The residue was purified by flash column chromatography (90:10 Hexane/EtOAc) to afford the ketone 5 (2.20 g, $90 \%)$ as a colourless viscous oil.

${ }^{1} \mathrm{H}-\mathrm{NMR}\left(\mathrm{CDCl}_{3}\right), 400 \mathrm{MHz}: \delta$ 7.68-7.66 (m, 4H, Ar), 7.44-7.37 (m, 6H, Ar), 4.77 (t, $1 \mathrm{H}, \mathrm{J}=3.2 \mathrm{~Hz}, \mathrm{CH}$ from THP), $4.39\left(\mathrm{~d}, 2 \mathrm{H}, \mathrm{J}=1.7 \mathrm{~Hz}, \mathrm{C} \equiv \mathrm{CCH}_{2}\right), 4.32\left(\mathrm{~s}, 2 \mathrm{H}, \mathrm{TBDPSOCH}_{2} \mathrm{C}=\mathrm{O}\right), 3.81-3.76\left(\mathrm{~m}, 1 \mathrm{H}, 1 \times \mathrm{xCH}_{2}\right.$ from THP),

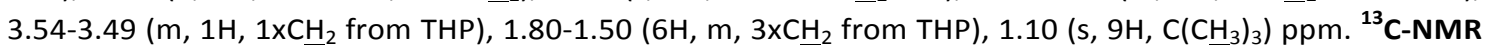
$\left(\mathrm{CDCl}_{3}\right), 100 \mathrm{MHz}: \delta 185.4(\mathrm{C}=\mathrm{O}), 135.6(\mathrm{Ar}), 132.6\left(\mathrm{C}_{\mathrm{q}} \mathrm{Ar}\right.$ ), $130.0(\mathrm{Ar}), 127.9(\mathrm{Ar}), 97.2$ ( $\mathrm{CH}$ from THP), 91.0 $(\underline{C} \equiv C), 83.0(\mathrm{C} \equiv \underline{C}), 70.5\left(\mathrm{TBDPSO} \underline{C H}_{2} \mathrm{C}=\mathrm{O}\right), 62.0\left(\underline{\mathrm{CH}}_{2}\right.$ from THP), $53.8\left(\mathrm{C} \equiv \mathrm{C}^{\mathrm{CH}} \mathrm{H}_{2}\right), 30.0\left(\underline{\mathrm{CH}}_{2}\right.$ from THP), 26.7 $\left(\mathrm{C}\left(\mathrm{CH}_{3}\right)_{3}\right), 25.2\left(\underline{\mathrm{CH}}_{2}\right.$ from THP), $19.3\left(\underline{\mathrm{C}}\left(\mathrm{CH}_{3}\right)_{3}\right), 18.8\left(\underline{\mathrm{CH}}_{2}\right.$ from THP). FTIR (Neat): $1720(\mathrm{C}=\mathrm{O}), 2155(\mathrm{C} \equiv \mathrm{C})$ $\mathrm{cm}^{-1}$. HRMS: calcd. for $\mathrm{C}_{26} \mathrm{H}_{32} \mathrm{O}_{4} \mathrm{SiNa}^{+}[\mathrm{M}+\mathrm{Na}]^{+}$459.2070; found 459.1962.

\section{Synthesis of 1-[(tert-butyldiphenylsilyl)oxy]-5-(oxan-2-yloxy)pent-3-yn-2-ol 6}<smiles>O=C(O)[Mg]OCC(O)C#CC[OH+]</smiles>

To a solution of ketone $5(0.790 \mathrm{~g}, 1.8 \mathrm{mmol})$ in dry $\mathrm{CH}_{2} \mathrm{Cl}_{2}(5 \mathrm{~mL})$, at $0{ }^{\circ} \mathrm{C}$, was added tert-butyldimethylsilylchloride $(0.60 \mathrm{~mL}, 2.7 \mathrm{mmol})$, diisopropylethylamine $(0.63 \mathrm{~mL}, 3.6 \mathrm{mmol})$ and a catalytic amount of DMAP. The reaction mixture was stirred allowing the temperature to rise until r.t., after 16 hours all the starting material was consumed and water was added. The mixture was extracted with $\mathrm{CH}_{2} \mathrm{Cl}_{2}$, dried with $\mathrm{Na}_{2} \mathrm{SO}_{4}$, the solvent was filtered and concentrated under vacuum. Without further purification, alcohol 6 was obtained ( $0.819 \mathrm{~g}$, quantitative yield) as a colourless viscous oil.

${ }^{1} \mathrm{H}-\mathrm{NMR}\left(\mathrm{CDCl}_{3}\right), 400 \mathrm{MHz}$ : $\delta$ 7.69-7.65 (m, 4H, Ar), 7.44-7.38 (m, 6H, Ar), $4.77(\mathrm{t}, 1 \mathrm{H}, \mathrm{J}=3.37 \mathrm{~Hz}, \mathrm{CH}$ from THP), 4.52-4.50 (m, $1 \mathrm{H}, \mathrm{C} \underline{\mathrm{HC}} \equiv \mathrm{C}$ ), 4.27 (qdd, $2 \mathrm{H}, \mathrm{J}=16.0 \mathrm{~Hz}, \mathrm{~J}=1.7 \mathrm{~Hz}, \mathrm{~J}=3.5 \mathrm{~Hz}, \mathrm{C} \equiv \mathrm{CC}_{\mathrm{H}_{2}}$ ), 3.82-3.70 (m, $3 \mathrm{H}$, TBDPSOCH$\underline{H}_{2} \mathrm{CH}$ and $1 \times \mathrm{CH}_{2}$ from THP), 3.51-3.47 (m, $1 \mathrm{H}, 1 \times \mathrm{xH}_{2}$ from THP), 1.63-1.49 (m, $6 \mathrm{H}, 3 \times \underline{H}_{2}$ from THP), $1.07\left(\mathrm{~s}, 9 \mathrm{H}, \mathrm{C}\left(\mathrm{CH}_{3}\right)_{3}\right) \mathrm{ppm} .{ }^{13} \mathrm{C}-\mathrm{NMR}\left(\mathrm{CDCl}_{3}\right), 100 \mathrm{MHz}: \delta 135.6(\mathrm{Ar}), 135.5(\mathrm{Ar}), 132.9\left(\mathrm{C}_{\mathrm{q}} \mathrm{Ar}\right), 132.8\left(\mathrm{C}_{\mathrm{q}}\right.$ $\mathrm{Ar}$ ), 129.92 (Ar), 129.91 (Ar), $127.84(\mathrm{Ar}), 127.82$ (Ar), 96.8 ( $\underline{\mathrm{CH}}$ from THP), 67.4 (TBDPSOCH$\left.{ }_{2} \mathrm{CH}\right), 63.2$ $(\underline{\mathrm{C}} \mathrm{HC} \equiv \mathrm{C}), 61.9\left(\underline{\mathrm{CH}}_{2}\right.$ from THP), $54.2\left(\mathrm{C} \equiv \mathrm{CCH}_{2}\right), 30.2\left(\underline{\mathrm{CH}} \mathrm{CH}_{2}\right.$ from THP), $26.8\left(\mathrm{C}\left(\mathrm{CH}_{3}\right)_{3}\right), 25.3\left(\mathrm{C}\left(\underline{\mathrm{C}} \mathrm{H}_{3}\right)_{3}\right), 19.3$ $\left(\underline{\mathrm{C}}\left(\mathrm{CH}_{3}\right)_{3}\right)$ ppm. FTIR (Neat): $2158(\mathrm{C} \equiv \mathrm{C}), 1022(\mathrm{C}-\mathrm{O}-\mathrm{C}) \mathrm{cm}^{-1}$. HRMS: calcd. for $\mathrm{C}_{26} \mathrm{H}_{34} \mathrm{O}_{4} \mathrm{SiNa}^{+}[\mathrm{M}+\mathrm{Na}]^{+}$ 461.2226; found 461.2119 .

Synthesis of 2,2,9,9-tetramethyl-5-[3-(oxan-2-yloxy)prop-1-yn-1-yl]-3,3,8,8-tetraphenyl-4,7-dioxa-3,8disiladecane 7

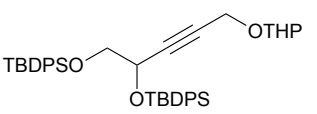

To a solution of alcohol $6(0.815 \mathrm{~g}, 1.9 \mathrm{mmol})$ in dry $\mathrm{MeOH}(5 \mathrm{~mL})$, at $0{ }^{\circ} \mathrm{C}$, was added $\mathrm{NaBH}_{4}(0.141 \mathrm{~g}, 3.7 \mathrm{mmol})$. The reaction mixture was stirred allowing the temperature to rise to r.t., after 3 hours all the starting material was consumed and water was added. The mixture was extracted with EtOAc, dried with $\mathrm{Na}_{2} \mathrm{SO}_{4}$, the solvent was filtered and concentrated under vacuum. The crude residue was purified by flash column chromatography (90:10 Hexane/EtOAc) to afford the alkyne 7 ( $1.160 \mathrm{~g}, 95 \%)$ as a colourless viscous oil. 
${ }^{1} \mathrm{H}-\mathrm{NMR}\left(\mathrm{CDCl}_{3}\right), 400 \mathrm{MHz}: \delta 7.75(\mathrm{~d}, 2 \mathrm{H}, \mathrm{J}=6.90 \mathrm{~Hz}, \mathrm{Ar}), 7.71(\mathrm{~d}, 2 \mathrm{H}, \mathrm{J}=7.3 \mathrm{~Hz}, \mathrm{Ar}), 7.65(\mathrm{t}, 4 \mathrm{H}, \mathrm{J}=6.2 \mathrm{~Hz}, \mathrm{Ar})$, 7.40-7.32 (m, $12 \mathrm{H}, \mathrm{Ar}), 4.64-4.56(\mathrm{~m}, 2 \mathrm{H}, \mathrm{CH}$ from THP and $\mathrm{CHC} \equiv \mathrm{C}), 4.11-4.02\left(\mathrm{~m}, 2 \mathrm{H}, \mathrm{C} \equiv \mathrm{CC}_{2}\right), 3.81-3-68$ (m, $3 \mathrm{H}$, TBDPSOC $\underline{H}_{2} \mathrm{CH}$ and $1 \times \mathrm{CC}_{2}$ from THP), 3.44-3.40 (m, $1 \mathrm{H}, 1 \times \mathrm{C}_{2}$ from THP), 1.78-1.45 (m, $6 \mathrm{H}, 3 \times \mathrm{C}_{2}$ from THP), $1.08\left(\mathrm{~s}, 9 \mathrm{H}, \mathrm{C}\left(\mathrm{CH}_{3}\right)_{3}\right), 1.02\left(\mathrm{~s}, 9 \mathrm{H}, \mathrm{C}\left(\mathrm{CH}_{3}\right)_{3}\right)$ ppm. ${ }^{13} \mathrm{C}-\mathrm{NMR}\left(\mathrm{CDCl}_{3}\right), 100 \mathrm{MHz}: \delta 136.1(\mathrm{Ar}), 135.9$ $(\mathrm{Ar}), 135.7(\mathrm{Ar}), 135.6(\mathrm{Ar}), 133.6\left(\mathrm{C}_{\mathrm{q}} \mathrm{Ar}\right), 133.5\left(\mathrm{C}_{\mathrm{q}} \mathrm{Ar}\right), 133.4\left(\mathrm{C}_{\mathrm{q}} \mathrm{Ar}\right), 133.3\left(\mathrm{C}_{\mathrm{q}} \mathrm{Ar}\right), 129.62(\mathrm{Ar}), 129.58(\mathrm{Ar})$,

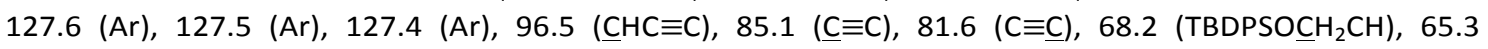
$(\underline{\mathrm{CHC}} \equiv \mathrm{C}), 61.9\left(\underline{\mathrm{CH}}_{2}\right.$ from THP), $54.0\left(\mathrm{C} \equiv \mathrm{CCH}_{2}\right), 30.2\left(\underline{\mathrm{CH}}_{2}\right.$ from THP), $26.9\left(\mathrm{C}\left(\underline{\mathrm{CH}}_{3}\right)_{3}\right), 26.7\left(\mathrm{C}(\underline{\mathrm{CH}})_{3}\right), 25.4\left(\underline{\mathrm{CH}} \mathrm{H}_{2}\right.$ from THP), $19.3\left(\underline{\mathrm{C}}\left(\mathrm{CH}_{3}\right)_{3}\right), 19.2\left(\underline{\mathrm{C}}\left(\mathrm{CH}_{3}\right)_{3}\right), 19.1\left(\mathrm{CH}_{2}\right.$ from THP) ppm. FTIR (Neat): $2170(\mathrm{C} \equiv \mathrm{C}), 1111$ and 1079 (C-O-C) $\mathrm{cm}^{-1}$. HRMS: calcd. for $\mathrm{C}_{42} \mathrm{H}_{52} \mathrm{O}_{4} \mathrm{Si}_{2} \mathrm{Na}^{+}[\mathrm{M}+\mathrm{Na}]^{+}$699.3404; found 699.3296.

\section{Synthesis of 4,5-bis[(tert-butyldiphenylsilyl)oxy]pent-2-yn-1-ol 8}

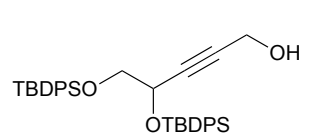

To a stirred solution of alkyne $7(0.57 \mathrm{~g}, 0.84 \mathrm{mmol})$ in dry $\mathrm{MeOH}(5 \mathrm{~mL})$ at r.t., $p$ toluenesulfonic acid monohydrate $(11 \mathrm{mg}, 0.06 \mathrm{mmol}$ ) was added. After 2 hours all the starting material had been consumed and the reaction mixture was quenched with a satured aqueous $\mathrm{NaHCO}_{3}$ solution $(10 \mathrm{~mL})$ and extracted with EtOAc $(3 \times 10 \mathrm{~mL})$. The combined organic layers were dried with anhydrous $\mathrm{Na}_{2} \mathrm{SO}_{4}$, the solvent was filtered and concentrated under vacuum. The residue was purified by flash column chromatography (95:05 Hexane/EtOAc) to afford the alcohol 8 ( $473 \mathrm{mg}, 95 \%)$ as a colourless viscous oil.

${ }^{1} \mathrm{H}-\mathrm{NMR}\left(\mathrm{CDCl}_{3}\right), 400 \mathrm{MHz}: \delta$ 7.78-7.65 (m, 8H, Ar), 7.44-7.33 (m, 12H, Ar), 4.62-4.59 (m, 1H, CHC $\left.\equiv \mathrm{C}\right), 3.93$ (d, $\left.2 \mathrm{H}, \mathrm{J}=1.4 \mathrm{~Hz}, \mathrm{C} \equiv \mathrm{CC}_{2} \mathrm{OH}\right), 3.81\left(\mathrm{dd}, 1 \mathrm{H}, \mathrm{J}=6.9 \mathrm{~Hz}, \mathrm{~J}=10.2 \mathrm{~Hz}, 1 \times \operatorname{TBDPSOCH}_{2} \mathrm{CH}\right.$ ), $3.71(\mathrm{dd}, 1 \mathrm{H}, \mathrm{J}=4.7 \mathrm{~Hz}$, $\left.\mathrm{J}=10.1 \mathrm{~Hz}, 1 \times \mathrm{XTDPSOCH}_{2} \mathrm{CH}\right), 1.08\left(\mathrm{~s}, 9 \mathrm{H}, \mathrm{C}\left(\mathrm{CH}_{3}\right)_{3}\right), 1.05\left(\mathrm{~s}, 9 \mathrm{H}, \mathrm{C}\left(\mathrm{CH}_{3}\right)_{3}\right) \mathrm{ppm} .{ }^{13} \mathrm{C}-\mathrm{NMR}\left(\mathrm{CDCl}_{3}\right), 100 \mathrm{MHz}: \delta$ $136.3(\mathrm{Ar}), 136.0(\mathrm{Ar}), 135.7(\mathrm{Ar}), 134.1\left(\mathrm{C}_{\mathrm{q}} \mathrm{Ar}\right), 133.3\left(\mathrm{C}_{\mathrm{q}} \mathrm{Ar}\right), 129.71(\mathrm{Ar}), 129.66(\mathrm{Ar}), 129.64(\mathrm{Ar}), 129.61$

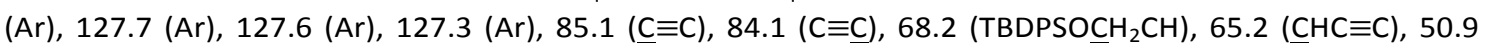
$\left(\mathrm{C} \equiv \mathrm{CCH}_{2} \mathrm{OH}\right), 26.9\left(\mathrm{C}\left(\underline{\mathrm{CH}}_{3}\right)_{3}\right), 26.7\left(\mathrm{C}\left(\mathrm{CH}_{3}\right)_{3}\right), 19.2\left(\underline{\mathrm{C}}\left(\mathrm{CH}_{3}\right)_{3}\right) \mathrm{ppm}$. FTIR (Neat): $2156(\mathrm{C} \equiv \mathrm{C}), 3673(\mathrm{OH}) \mathrm{cm}^{-1}$. HRMS: calcd. for $\mathrm{C}_{37} \mathrm{H}_{44} \mathrm{O}_{3} \mathrm{Si}_{2} \mathrm{Na}^{+}[\mathrm{M}+\mathrm{Na}]^{+}$615.2829; found 615.2721.

\section{Synthesis of 4,5-bis[(tert-butyldiphenylsilyl)oxy]pentyl 4-methylbenzene-1-sulfonate 9}

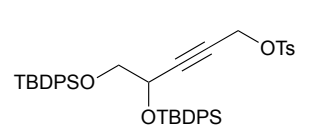

To a stirred solution of alcohol $8(870 \mathrm{mg}, 1.47 \mathrm{mmol})$ in dry ether $(10 \mathrm{~mL})$ at $0{ }^{\circ} \mathrm{C}$, p-toluenesulfonyl chloride (336 $\mathrm{mg}, 1.76 \mathrm{mmol}$ ) and potassium hydroxide $(412 \mathrm{mg}$, $7.34 \mathrm{mmol}$ ) were added. The reaction mixture was stirred and the temperature allowed to rise to r.t., after 16 hours all the starting material was consumed and water was added. The mixture was extracted with ether, dried with $\mathrm{Na}_{2} \mathrm{SO}_{4}$, the solvent was filtered and concentrated under vacuum. Without further purification alkyne 9 was obtained (1.04 g, 95 \%) as a colourless viscous oil.

${ }^{1} \mathrm{H}-\mathrm{NMR}\left(\mathrm{CDCl}_{3}\right), 400 \mathrm{MHz}: \delta$ 7.69-7.61 (m, 10H, Ar), 7.42-7.33 (m, 12H, Ar), 7.17 (d, 2H, J=8.1 Hz, Ar), 4.44 (s, $\left.2 \mathrm{H}, \mathrm{C} \equiv \mathrm{CCH}_{2} \mathrm{OTs}\right), 4.43-4.40(\mathrm{~m}, 1 \mathrm{H}, \mathrm{CHC} \equiv \mathrm{C}), 3.65$ (dd, $\left.1 \mathrm{H}, \mathrm{J}=6.6 \mathrm{~Hz}, \mathrm{~J}=10.1 \mathrm{~Hz}, 1 \times \mathrm{TBDPSOCH}_{2} \mathrm{CH}\right), 3.55$ (dd, $\left.1 \mathrm{H}, \mathrm{J}=5.1 \mathrm{~Hz}, \mathrm{~J}=10.0 \mathrm{~Hz}, 1 \times \operatorname{XTBDPSOC}_{2} \mathrm{CH}\right), 2.32\left(\mathrm{~s}, 3 \mathrm{H}, \mathrm{PhCH}_{3}\right), 1.05\left(\mathrm{~s}, 9 \mathrm{H}, \mathrm{C}\left(\mathrm{CH}_{3}\right)_{3}\right), 1.01(\mathrm{~s}, 9 \mathrm{H}$, $\left.\mathrm{C}\left(\mathrm{CH}_{3}\right)_{3}\right) \mathrm{ppm} .{ }^{13} \mathrm{C}-\mathrm{NMR}\left(\mathrm{CDCl}_{3}\right), 100 \mathrm{MHz}: \delta 144.9\left(\mathrm{C}_{\mathrm{q}} \mathrm{Ar}\right), 136.1(\mathrm{Ar}), 135.9(\mathrm{Ar}), 135.61(\mathrm{Ar}), 135.59(\mathrm{Ar})$, $133.24\left(C_{q} A r\right), 133.2\left(C_{q} A r\right), 133.18\left(C_{q} A r\right), 133.0\left(C_{q}\right.$ Ar), $129.8(\mathrm{Ar}), 129.7(\mathrm{Ar}), 128.1(\mathrm{Ar}), 127.7(\mathrm{Ar})$, $127.6(\mathrm{Ar}), 127.4(\mathrm{Ar}), 88.6(\underline{\mathrm{C}} \equiv \mathrm{C}), 77.2(\mathrm{C} \equiv \underline{\mathrm{C}}), 67.7\left(\mathrm{TBDPSO} \mathrm{CH}_{2} \mathrm{CH}\right), 64.9(\underline{\mathrm{C}} \mathrm{HC} \equiv \mathrm{C}), 57.8\left(\mathrm{C} \equiv \mathrm{C}_{\underline{C}} \mathrm{H}_{2} \mathrm{OTs}\right), 26.8$ $\left(\mathrm{C}\left(\underline{\mathrm{CH}}_{3}\right)_{3}\right), 26.7\left(\mathrm{C}\left(\mathrm{CH}_{3}\right)_{3}\right), 21.6\left(\mathrm{PhCH}_{3}\right), 19.22\left(\underline{\mathrm{C}}\left(\mathrm{CH}_{3}\right)_{3}\right), 19.19\left(\underline{\mathrm{C}}\left(\mathrm{CH}_{3}\right)_{3}\right)$ ppm. FTIR (Neat): $2158(\mathrm{C} \equiv \mathrm{C}), 1111$ and 1079 (C-O-C) cm ${ }^{-1}$. HRMS: calcd. for $\mathrm{C}_{44} \mathrm{H}_{50} \mathrm{O}_{5} \mathrm{SSi}_{2} \mathrm{Na}^{+}[\mathrm{M}+\mathrm{Na}]^{+} 769.2917$; found 769.2810. 


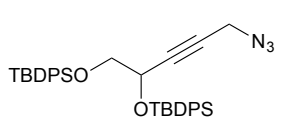

To a stirred solution of alkyne 9 (1.04 g, $1.39 \mathrm{mmol})$ in dry DMF $(10 \mathrm{~mL})$ at r.t., sodium azide $(0.45 \mathrm{~g}, 6.96 \mathrm{mmol})$ was added. After 2 hours all the starting material was consumed. The reaction mixture was diluted with $\mathrm{CH}_{2} \mathrm{Cl}_{2}$ and the obtained solid chromatography (90:10 Hexane/EtOAc) to afford the azide $\mathbf{1 0}(817 \mathrm{mg}, 95 \%)$ as a colourless viscous oil.

${ }^{1}$ H-NMR $\left(\mathrm{CDCl}_{3}\right), 400 \mathrm{MHz}: \delta$ 7.75-7.64 (m, 8H, Ar), 7.42-7.36 (m, 12H, Ar), 4.59-4.56 (m, $\left.1 \mathrm{H}, \mathrm{CHC} \equiv \mathrm{C}\right), 3.80$ (dd, $1 \mathrm{H}, \mathrm{J}=6.5 \mathrm{~Hz}, \mathrm{~J}=10.1 \mathrm{~Hz}, 1 \times \mathrm{TBDPSOCH}_{2} \mathrm{CH}$ ), 3.71 (dd, $1 \mathrm{H}, \mathrm{J}=5.3 \mathrm{~Hz}, \mathrm{~J}=10.0 \mathrm{~Hz}, 1 \times \operatorname{TBDPSOCH}_{2} \mathrm{CH}$ ), 3.66 (d, $\left.2 \mathrm{H}, \mathrm{J}=1.2 \mathrm{~Hz}, \mathrm{C} \equiv \mathrm{CCH}_{2} \mathrm{~N}_{3}\right), 1.08\left(\mathrm{~s}, 9 \mathrm{H}, \mathrm{C}\left(\mathrm{CH}_{3}\right)_{3}\right), 1.03\left(\mathrm{~s}, 9 \mathrm{H}, \mathrm{C}\left(\mathrm{CH}_{3}\right)_{3}\right) \mathrm{ppm} .{ }^{13} \mathrm{C}-\mathrm{NMR}\left(\mathrm{CDCl}_{3}\right), 100 \mathrm{MHz}: \delta$ 136.1 (Ar), $135.9(\mathrm{Ar}), 135.64(\mathrm{Ar}), 135.60(\mathrm{Ar}), 133.5\left(\mathrm{C}_{\mathrm{q}} \mathrm{Ar}\right), 133.33\left(\mathrm{C}_{\mathrm{q}} \mathrm{Ar}\right), 133.29\left(\mathrm{C}_{\mathrm{q}} \mathrm{Ar}\right), 133.26\left(\mathrm{C}_{\mathrm{q}} \mathrm{Ar}\right)$, 129.73 (Ar), 129.68 (Ar), 129.6 (Ar), 127.7 (Ar), 127.6 (Ar), $127.4(\mathrm{Ar}), 86.7(\mathrm{C} \equiv \mathrm{C}), 77.8(\mathrm{C} \equiv \mathrm{C}), 68.1$ (TBDPSOCH$\left.{ }_{2} \mathrm{CH}\right), 65.1(\underline{\mathrm{CHC}} \equiv \mathrm{C}), \quad 39.9\left(\mathrm{C} \equiv \mathrm{CCCH}_{2} \mathrm{~N}_{3}\right), 26.9\left(\mathrm{C}\left(\mathrm{CH}_{3}\right)_{3}\right), 26.7\left(\mathrm{C}\left(\underline{C H}_{3}\right)_{3}\right), 19.3\left(\underline{\mathrm{C}}\left(\mathrm{CH}_{3}\right)_{3}\right), 19.2$ $\left(\mathrm{C}\left(\mathrm{CH}_{3}\right)_{3}\right)$ ppm. FTIR (Neat): $2121(\mathrm{~N}=\mathrm{N}=\mathrm{N}) \mathrm{cm}^{-1}$. HRMS: calcd. for $\mathrm{C}_{37} \mathrm{H}_{43} \mathrm{~N}_{3} \mathrm{O}_{2} \mathrm{Si}_{2} \mathrm{Na}^{+}[\mathrm{M}+\mathrm{Na}]^{+}$640.2787; found 640,2786 .

\section{Synthesis of 5-azidopent-3-yne-1,2-diol 11}

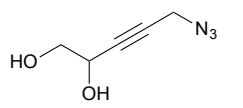

To a stirred solution of azide $10(815 \mathrm{mg}, 1.32 \mathrm{mmol})$ in dry THF $(8 \mathrm{~mL})$ at r.t., sodium azide $(0.45 \mathrm{~g}, 6.96 \mathrm{mmol})$ was added. After 2 hours all the starting material was consumed and the mixture was quenched with water. The mixture was extracted with EtOAc, dried with $\mathrm{Na}_{2} \mathrm{SO}_{4}$, the solvent was filtered and concentrated under vacuum. Without further purification diol 11 (142 mg, $76 \%$ ) was obtained as a colourless viscous oil.

${ }^{1} \mathrm{H}-\mathrm{NMR}\left(\mathrm{CDCl}_{3}\right), 400 \mathrm{MHz}: \delta$ 4.57-4.53 (m, $\left.1 \mathrm{H}, \mathrm{CHC} \equiv \mathrm{C}\right), 3.98\left(\mathrm{~d}, 2 \mathrm{H}, \mathrm{J}=1.4 \mathrm{~Hz}, \mathrm{C} \equiv \mathrm{CC}_{2} \mathrm{~N}_{3}\right), 3.79$ (dd, $1 \mathrm{H}$, $\left.\mathrm{J}=3.7 \mathrm{~Hz}, \mathrm{~J}=11.5 \mathrm{~Hz}, 1 \times \mathrm{HOCH}_{2} \mathrm{CH}\right), 3.71\left(\mathrm{dd}, 1 \mathrm{H}, \mathrm{J}=6.6 \mathrm{~Hz}, \mathrm{~J}=11.5 \mathrm{~Hz}, 1 \times \mathrm{HOCH}_{2} \mathrm{CH}\right) \mathrm{ppm} .{ }^{13} \mathrm{C}-\mathrm{NMR}\left(\mathrm{CDCl}_{3}\right)$, $100 \mathrm{MHz}: \delta 85.2(\underline{\mathrm{C}} \equiv \mathrm{C}), 78.3(\mathrm{C} \equiv \underline{\mathrm{C}}), 66.3\left(\mathrm{HOCH}_{2} \mathrm{CH}\right), 63.1(\underline{\mathrm{CHC}} \equiv \mathrm{C}), 39.9\left(\mathrm{C} \equiv \mathrm{C}_{\mathrm{CH}} \mathrm{N}_{3}\right)$ ppm. FTIR (Neat): $2112(\mathrm{~N}=\mathrm{N}=\mathrm{N}), 3283(\mathrm{OH}) \mathrm{cm}^{-1}$. HRMS: calcd. for $\mathrm{C}_{44} \mathrm{H}_{50} \mathrm{O}_{5} \mathrm{SSi}_{2} \mathrm{Na}^{+}[\mathrm{M}+\mathrm{Na}]^{+}$.

\section{Synthesis of 2-(3-azidoprop-1-yn-1-yl)-1,4-dioxaspiro[4.5]decane 12}

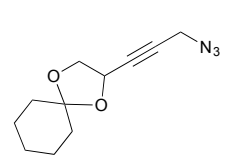

To a stirred solution of diol $11(94 \mathrm{mg}, 0.67 \mathrm{mmol}$ ) in dry DMF (3 mL) at r.t., cyclohexanone dimethyl ketal $(0.20 \mathrm{~mL}, 1.33 \mathrm{mmol})$ and two drops of sulfuric acid were added. After 16 hours all the starting material was consumed and the mixture was quenched with a saturated aqueous $\mathrm{NaHCO}_{3}$ solution $(5 \mathrm{~mL})$ and extracted with EtOAc $(3 \times 5 \mathrm{~mL})$. The combined organic layers were dried with anhydrous $\mathrm{Na}_{2} \mathrm{SO}_{4}$, the solvent was filtered and concentrated under vacuum. The residue was purified by flash column chromatography (95:05 Hexane/EtOAc) to afford the acetal 12 (123 mg, $84 \%$ ) as a colourless viscous oil.

${ }^{1} \mathrm{H}-\mathrm{NMR}\left(\mathrm{CDCl}_{3}\right), 400 \mathrm{MHz}: \delta$ 4.80-4.76 (m, $\left.1 \mathrm{H}, \mathrm{CHC} \equiv \mathrm{C}\right), 4.19$ (dd, $\left.1 \mathrm{H}, \mathrm{J}=6.4 \mathrm{~Hz}, \mathrm{~J}=8.1 \mathrm{~Hz}, 1 \mathrm{xHOCH}_{2} \mathrm{CH}\right), 3.96$ $\left(\mathrm{s}, 2 \mathrm{H}, \mathrm{C} \equiv \mathrm{CCH}_{2} \mathrm{~N}_{3}\right), 3.94\left(\mathrm{dd}, 1 \mathrm{H}, \mathrm{J}=6.3 \mathrm{~Hz}, \mathrm{~J}=8.0 \mathrm{~Hz}, 1 \mathrm{xHOCH}_{2} \mathrm{CH}\right), 1.76-1.39\left(\mathrm{~m}, 10 \mathrm{H}, \mathrm{CH}_{2}\right.$ from ketal) ppm. ${ }^{13} \mathrm{C}-\mathrm{NMR}\left(\mathrm{CDCl}_{3}\right), 100 \mathrm{MHz}: \delta 111.3\left(\mathrm{C}_{\mathrm{q}}\right), 85.3(\underline{\mathrm{C}} \equiv \mathrm{C}), 77.8(\mathrm{C} \equiv \underline{\mathrm{C}}), 69.6\left(\mathrm{HOCH}_{2} \mathrm{CH}\right), 65.0(\underline{\mathrm{CHC}} \equiv \mathrm{C}), 39.9$ $\left(\mathrm{C} \equiv \mathrm{CCH}_{2} \mathrm{~N}_{3}\right), 35.7\left(\underline{\mathrm{CH}}_{2}\right.$ from ketal), $35.4\left(\underline{\mathrm{CH}}_{2}\right.$ from ketal), $25.0\left(\mathrm{CH}_{2}\right.$ from acetal), 23.9 (2x $\underline{\mathrm{CH}}_{2}$ from acetal) ppm. FTIR (Neat): $2120(\mathrm{~N}=\mathrm{N}=\mathrm{N}), 1040(\mathrm{C}-\mathrm{O}-\mathrm{C}) \mathrm{cm}^{-1}$. HRMS: calcd. for $\mathrm{C}_{11} \mathrm{H}_{15} \mathrm{~N}_{3} \mathrm{O}_{2}^{+}[\mathrm{M}]^{+}$222.1236; found 222.1237. 


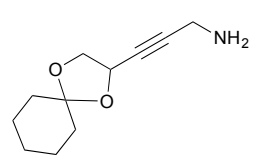

To a stirred solution of acetal $12(120 \mathrm{mg}, 0.54 \mathrm{mmol})$ in dry THF $(5 \mathrm{~mL})$ at r.t., triphenylphosphine (313 mg, $1.19 \mathrm{mmol}$ ) was added. After 3 hours $45 \mu \mathrm{L}$ of water were added and the mixture was stirred overnight. The reaction mixture was concentrated under vacuum and the residue was purified by flash column chromatography (100\% EtOAc followed by $\left.90: 10 \mathrm{CH}_{2} \mathrm{Cl}_{2} / \mathrm{MeOH}\right)$ to afford the amine 2 (100 mg, $94 \%$ ) as a colourless viscous oil.

${ }^{1} \mathrm{H}-\mathrm{NMR}\left(\mathrm{CDCl}_{3}\right), 400 \mathrm{MHz}: \delta 4.74(\mathrm{t}, 1 \mathrm{H}, \mathrm{J}=6.2 \mathrm{~Hz}, \mathrm{CHC} \equiv \mathrm{C}), 4.14$ (dd, $1 \mathrm{H}, \mathrm{J}=6.2 \mathrm{~Hz}, \mathrm{~J}=8.0 \mathrm{~Hz}, 1 \times \mathrm{HOCH}_{2} \mathrm{CH}$ ), $3.88\left(\mathrm{dd}, 1 \mathrm{H}, \mathrm{J}=6.6 \mathrm{~Hz}, \mathrm{~J}=8.0 \mathrm{~Hz}, 1 \times \mathrm{HOCH}_{2} \mathrm{CH}\right), 3.56\left(\mathrm{~d}, 2 \mathrm{H}, \mathrm{C} \equiv \mathrm{CCH}_{2} \mathrm{NH}_{2}\right), 1.74-1.40\left(\mathrm{~m}, 10 \mathrm{H}, \mathrm{CH}_{2}\right.$ from ketal) ppm. ${ }^{13} \mathrm{C}-\mathrm{NMR}\left(\mathrm{CDCl}_{3}\right), 100 \mathrm{MHz}: \delta 111.0\left(\mathrm{C}_{\mathrm{q}}\right), 84.6(\underline{\mathrm{C}} \equiv \mathrm{C}), 80.9(\mathrm{C} \equiv \mathrm{C}), 69.5\left(\mathrm{HOCH}_{2} \mathrm{CH}\right), 65.2(\underline{\mathrm{CHC}} \equiv \mathrm{C}), 35.8$ ( $\underline{C H}_{2}$ from ketal), 35.4 ( $\underline{C H}_{2}$ from ketal), $31.2\left(\mathrm{C} \equiv \mathrm{CCH}_{2} \mathrm{NH}_{2}\right), 25.0\left(\mathrm{CH}_{2}\right.$ from ketal), $23.9\left(\mathrm{CH}_{2}\right.$ from ketal), 23.8 ( $\mathrm{CH}_{2}$ from ketal) ppm. FTIR (Neat): $2106(\mathrm{C} \equiv \mathrm{C}), 1099(\mathrm{C}-\mathrm{N}), 1590(\mathrm{~N}-\mathrm{H}) \mathrm{cm}^{-1}$. HRMS: calcd. for $\mathrm{C}_{11} \mathrm{H}_{16} \mathrm{NO}_{2}{ }^{+}$ $[\mathrm{M}]^{+}$195.1259; found 196.1332 .

Synthesis of $\boldsymbol{N}$-(3-\{1,4-dioxaspiro[4.5]decan-2-yl\}prop-2-yn-1-yl)-6-(5-methyl-2-oxoimidazolidin-4yl)hexanamide 13

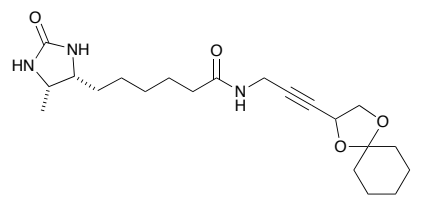

To a solution of D-desthiobiotin (110 $\mathrm{mg}, 0.51 \mathrm{mmol}$ ) in dry MeCN were added EDC (147 mg, $0.77 \mathrm{mmol})$ and HOBt (69 mg, $0.51 \mathrm{mmol})$. After stirred for $2 \mathrm{~h} 30 \mathrm{~min}$ the amine $2(100 \mathrm{mg}, 0.51 \mathrm{mmol})$ was added in dry $\mathrm{MeCN}$ and the reaction mixture was stirred overnight, at room temperature. The mixture was concentrated under vacuum and the crude residue was purified by flash column chromatography $\left(95: 05 \mathrm{CH}_{2} \mathrm{Cl}_{2} / \mathrm{MeOH}\right)$ to afford the amide 13 (91 mg, $46 \%)$.

${ }^{1} \mathrm{H}-\mathrm{NMR}\left(\mathrm{CDCl}_{3}\right), 400 \mathrm{MHz}: \delta 6.40(\mathrm{~s}, 1 \mathrm{H}, \mathrm{NH}), 4.71\left(\mathrm{t}, 1 \mathrm{H}, \mathrm{J}=6.4 \mathrm{~Hz}, \mathrm{C} \equiv \mathrm{CCHCH}_{2}\right), 4.13$ (dd, $1 \mathrm{H}, \mathrm{J}=4.3 \mathrm{~Hz}, \mathrm{~J}=8.0$ $\left.\mathrm{Hz}, 1 \times \mathrm{CC} \equiv \mathrm{CCHC}_{2}\right), 4.08\left(\mathrm{~s}, 2 \mathrm{H}, \mathrm{HNC}_{2} \mathrm{C} \equiv \mathrm{C}\right), 3.88-3.84\left(\mathrm{~m}, 2 \mathrm{H}, 1 \times \mathrm{C} \equiv \mathrm{CCHCH}_{2}\right.$ and $\mathrm{CH}_{3} \mathrm{CHNH}$ D-desthiobiotin), 3.74-3.67 (m, $1 \mathrm{H}, \mathrm{HNCHCH}_{2}$ D-desthiobiotin), 2.20 (t, $\left.2 \mathrm{H}, \mathrm{J}=7.4 \mathrm{~Hz}, \mathrm{CH}_{2}(\mathrm{C}=\mathrm{O}) \mathrm{NH}\right), 1.73-1.24\left(\mathrm{~m}, \mathrm{CH}_{2}\right.$ from Ddesthiobiotin and ketal), $1.14\left(\mathrm{~d}, 3 \mathrm{H}, \mathrm{J}=6.5 \mathrm{~Hz}, \mathrm{CH}_{3}\right)$ ppm. ${ }^{13} \mathrm{C}-\mathrm{NMR}\left(\mathrm{CDCl}_{3}\right), 100 \mathrm{MHz}: \delta 172.7(\underline{\mathrm{C}}=\mathrm{O}), 163.9$ $(\underline{\mathrm{C}}=\mathrm{O}), 111.0\left(\mathrm{C}_{\mathrm{q}}\right.$ from ketal), $82.00(\underline{\mathrm{C}} \equiv \mathrm{C}), 81.96(\underline{\mathrm{C}} \equiv \mathrm{C}), 80.52(\mathrm{C} \equiv \underline{\mathrm{C}}), 80.49(\mathrm{C} \equiv \underline{\mathrm{C}}), 69.4\left(\mathrm{C} \equiv \mathrm{CCHCH}_{2}\right), 65.1$ $\left(\mathrm{C} \equiv \mathrm{CCHCH}_{2}\right), 56.1\left(\mathrm{CH}_{3} \underline{\mathrm{CHNH}}\right), 51.5\left(\mathrm{HNCHCH}_{2}\right), 35.8\left(\underline{\mathrm{CH}}_{2}\right), 35.62\left(\underline{\mathrm{CH}}_{2}\right), 35.59\left(\underline{\mathrm{CH}}_{2}\right), 35.3\left(\underline{C H}_{2}(\mathrm{C}=\mathrm{O}) \mathrm{NH}\right)$, $29.4\left(\underline{C H}_{2}\right), 29.3\left(\underline{C H}_{2}\right), 29.2\left(\mathrm{HNCH}_{2} \mathrm{C} \equiv \mathrm{C}\right), 28.5\left(\underline{\mathrm{CH}}_{2}\right), 28.4\left(\underline{\mathrm{CH}}_{2}\right), 25.73\left(\underline{\mathrm{CH}}_{2}\right), 25.71\left(\underline{\mathrm{CH}}_{2}\right), 25.03\left(\underline{\mathrm{CH}}_{2}\right), 24.99$ $\left.(\underline{\mathrm{CH}})_{2}\right), 23.9\left(\mathrm{CH}_{2}\right), 23.8\left(\underline{\mathrm{CH}}_{2}\right), 15.7\left(\mathrm{CH}_{3}\right)$ ppm. HRMS: calcd. for $\mathrm{C}_{20} \mathrm{H}_{34} \mathrm{~N}_{3} \mathrm{O}_{4}{ }^{+}[\mathrm{M}]^{+}$392.2543; found 392.2544.

Synthesis of $\mathrm{N}$-(3-\{1,4-dioxaspiro[4.5]decan-2-yl\}-2,3-dioxopropyl)-6-(5-methyl-2-oxoimidazolidin-4yl)hexanamide 14

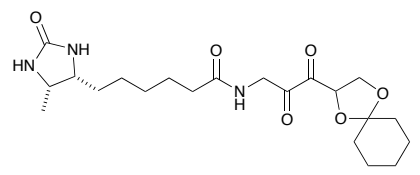

To a solution of amide 13 (15 mg, $0.38 \mathrm{mmol}$ ) in $2 \mathrm{~mL}$ of $\mathrm{H}_{2} \mathrm{O}: \mathrm{Et}_{2} \mathrm{O}$ (1:1.5) was added $\mathrm{KClO}_{3}(12 \mathrm{mg}, 0.96 \mathrm{mmol}), \mathrm{OsO}_{4}(195 \mu \mathrm{L}, 0.15 \mathrm{mmol}, 2 \%$ aqueous solution) and $t$-BuOH $(195 \mu \mathrm{L})$. After $24 \mathrm{~h}$, at room temperature, the reaction mixture was quenched with a saturated aqueous $\mathrm{NH}_{4} \mathrm{Cl}$ solution ( $2 \mathrm{~mL}$ ) and extracted with $\mathrm{CH}_{2} \mathrm{Cl}_{2}(3 \times 2 \mathrm{~mL})$. The combined organic layers were dried with anhydrous $\mathrm{Na}_{2} \mathrm{SO}_{4}$, the solvent was filtered and concentrated under vacuum. The amide $\mathbf{1 4}$ (16 mg, quant. yield) was afforded without further purification as a colourless viscous oil.

${ }^{1} \mathrm{H}-\mathrm{NMR}\left(\mathrm{CDCl}_{3}\right), 400 \mathrm{MHz}: \delta 4.92\left(\mathrm{t}, 1 \mathrm{H}, \mathrm{J}=6.5 \mathrm{~Hz},(\mathrm{C}=\mathrm{O}) \mathrm{CHCH}_{2}\right), 4.26\left(\mathrm{t}, 1 \mathrm{H}, \mathrm{J}=8.0 \mathrm{~Hz}, 1 \mathrm{xHNCH}_{2}(\mathrm{C}=0)\right)$, 4.15$4.08\left(\mathrm{~m}, 2 \mathrm{H}, 1 \times \mathrm{HNCH}_{2}(\mathrm{C}=\mathrm{O})\right.$ and $\left.1 \times(\mathrm{C}=\mathrm{O}) \mathrm{CHCH}_{2}\right), 3.90-3.85\left(1 \times(\mathrm{C}=\mathrm{O}) \mathrm{CHCH}_{2}\right.$ and $\mathrm{CH}_{3} \mathrm{CHNH}$ D-desthiobiotin), 3.76-3.65 (m, $1 \mathrm{H}, \mathrm{HNCHCH}_{2}$ D-desthiobiotin), 2.45-2.18 (m, $\left.\mathrm{CH}_{2}(\mathrm{C}=\mathrm{O}) \mathrm{NH}\right), 1.74-1.25\left(\mathrm{~m}, \mathrm{CH}_{2}\right.$ from Ddesthiobiotin and ketal), $1.13\left(\mathrm{~d}, 3 \mathrm{H}, \mathrm{J}=6.3 \mathrm{~Hz}, \mathrm{CH}_{3}\right)$ ppm. ${ }^{13} \mathrm{C}-\mathrm{NMR}\left(\mathrm{CDCl}_{3}\right), 100 \mathrm{MHz}$ : $\delta 206.7(\mathrm{C}=\mathrm{O}), 192.4$ $(\mathrm{C}=\mathrm{O}), 174.7(\mathrm{C}=\mathrm{O}), 164.8(\mathrm{C}=\mathrm{O}), 134.1\left(\mathrm{C}\right.$ from ketal), $76.7\left((\mathrm{C}=\mathrm{O}) \underline{\mathrm{CHCH}_{2}}\right), 69.4\left((\mathrm{C}=\mathrm{O}) \mathrm{CH}_{\underline{C}} \mathrm{H}_{2}\right), 66.9$ 


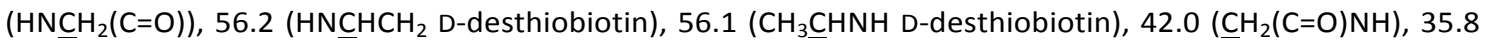
$\left(\underline{C H}_{2}\right), 35.4\left(\underline{C H}_{2}\right), 35.3\left(\underline{C H}_{2}\right), 34.8\left(\underline{C H}_{2}\right), 29.7\left(\underline{C H}_{2}\right), 29.3\left(\underline{C H}_{2}\right), 28.6\left(\underline{C H}_{2}\right), 27.0\left(\underline{C H}_{2}\right), 26.6\left(\underline{C} \mathrm{CH}_{2}\right), 25.7\left(\underline{\mathrm{CH}_{2}}\right)$, $25.0\left(\underline{C H}_{2}\right), 24.6\left(\underline{C H}_{2}\right), 23.9\left(\underline{C H}_{2}\right), 23.8\left(\underline{C H}_{2}\right), 23.0\left(\underline{C H}_{2}\right), 15.7\left(\underline{C H}_{3}\right)$ ppm. HRMS: calcd. for $\mathrm{C}_{21} \mathrm{H}_{33} \mathrm{~N}_{3} \mathrm{O}_{6}{ }^{+}[\mathrm{M}]^{+}$ 424.2440; found 424.2442 .

\section{Synthesis of N-(4,5-dihydroxy-2,3-dioxopentyl)-6-(5-methyl-2-oxoimidazolidin-4-yl)hexanamide 1}

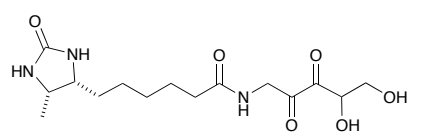

To a solution of amide 14 (9.6 mg, $0.023 \mathrm{mmol})$ in $750 \mu \mathrm{L}$ of DMSO- $d_{6}: \mathrm{D}_{2} \mathrm{O}(1: 4)$ was added $\mathrm{D}_{2} \mathrm{SO}_{4}\left(10 \mu \mathrm{L}\right.$ of a $10 \%$ solution in $\left.\mathrm{D}_{2} \mathrm{O}\right)$. The solution was sonicated during 15 minutes, in a cooled ultrasounds bath, and stirring for $24 \mathrm{~h}$ at $800 \mathrm{rpm}$. The mixture was quenched with $\mathrm{CDCl}_{3}(3 \times 500 \mu \mathrm{L})$ and the aqueous phase was recovered. The complex D-desthiobiotin-Al-2 1 (7.8 mg, quant. yield) was obtained in solution without further purification.

${ }^{1} \mathrm{H}-\mathrm{NMR}\left(\mathrm{D}_{2} \mathrm{O}\right), 400 \mathrm{MHz}: \delta 8.15(\mathrm{~s}, \mathrm{NH}), 4.27(\mathrm{t}, \mathrm{J}=4.1 \mathrm{~Hz}, \mathrm{CH}$ from Al-2), 3.86-3.76 (m, 1H, CH $\mathrm{CH} \mathrm{HH}$ Ddesthiobiotin), 3.76 (d, J=4.2 Hz, $\mathrm{CH}_{2}$ from Al-2), 3.72-3.65 (m, 1H, $\mathrm{HNCHCH}_{2}$ D-desthiobiotin), 3.58-3.49 (m, $\left.(\mathrm{C}=\mathrm{O}) \mathrm{HNCH}_{2}(\mathrm{C}=\mathrm{O})\right), 2.21-2.16\left(\mathrm{~m}, 2 \mathrm{H}, \mathrm{CH}_{2}(\mathrm{C}=\mathrm{O}) \mathrm{NH}\right), 1.62-1.50\left(\mathrm{~m}, 2 \mathrm{H}, \mathrm{CH}_{2}\right.$ from D-desthiobiotin), 1.47-1.39 ( $\mathrm{m}, 2 \mathrm{H}, \mathrm{CH}_{2}$ from D-desthiobiotin), 1.35-1.18 ( $\mathrm{m}, 4 \mathrm{H}, \mathrm{CH}_{2}$ from D-desthiobiotin), 1.03 (d, 3H, J=6.5 Hz, $\mathrm{CH}_{3}$ ) ppm. Other peacks are present, come from the cyclic forms of Al-2. ${ }^{13} \mathrm{C}-\mathrm{NMR}\left(\mathrm{D}_{2} \mathrm{O}\right), 100 \mathrm{MHz}: \delta 71.4(\mathrm{CH}$ from Al-2), $65.1\left((\mathrm{C}=\mathrm{O}) \mathrm{HNCH}_{2}(\mathrm{C}=\mathrm{O})\right), 63.3\left(\mathrm{CH}_{2}\right.$ from Al-2), $55.9\left(\mathrm{HNCHCH}_{2}\right.$ D-desthiobiotin), $51.4\left(\mathrm{CH}_{3} \mathrm{CHNH}\right.$ D-desthiobiotin), $\left.\left.35.4\left(\underline{\mathrm{C}} \mathrm{H}_{2}\right), 35.0\left(\underline{\mathrm{CH}}_{2}\right), 28.8(\underline{\mathrm{CH}})_{2}\right), 28.7\left(\underline{\mathrm{CH}}_{2}\right), 28.2\left(\underline{\mathrm{C}} \mathrm{H}_{2}\right), 28.1\left(\underline{\mathrm{CH}}_{2}\right), 25.3(\underline{\mathrm{CH}})_{2}\right), 25.1\left(\underline{\mathrm{C}} \mathrm{H}_{2}\right)$, $25.0\left(\mathrm{CH}_{2}\right), 14.6\left(\mathrm{CH}_{3}\right)$ ppm.

\subsection{Protein expression and purification}

Escherichia coli BL21 ( $\triangle$ /UXS) transformed with the plasmid pQE30 (carrying LuxP protein from Vibrio harveyi fused to cyan (CFP) and yellow (YFP) fluorescent proteins) - pQE30-CLPY- was kindly provided by Richard Sayre (The Ohio State University, Ohio, USA). Expression and purification of this protein was carried out as previously described. ${ }^{4}$ Briefly, protein expression was induced at an optical density $\left(O D_{600}\right)$ of 0.6 with $0.3 \mathrm{mM}$ of isopropyl $\beta$-Dthiogalactopyranoside (IPTG) and grown for $6 \mathrm{~h}$, at $28^{\circ} \mathrm{C}$ before cell harvesting by centrifugation. The resulting pellet was resuspended in $25 \mathrm{mM}$ sodium phosphate buffer $\mathrm{pH} 8.0,35 \mathrm{mM} \mathrm{NaCl}, 1: 100$ protease inhibitor cocktail (Roche) and cells were lysed by passing them three times through a french press. Cell debris were removed by centrifugation and LuxP was purified from clarified supernatants through Nickel-nitrilotriacetic (Ni ${ }^{+}$-NTA) acid affinity chromatography (Qiagen). The protein was eluted in $25 \mathrm{mM}$ sodium phosphate buffer $\mathrm{pH} 8.0,35 \mathrm{mM} \mathrm{NaCl}$, 40\% glycerol, $250 \mathrm{mM}$ imidazole, 1:100 protease inhibitor cocktail. The expression and purification of Clostridium saccharobutylicum DSM13864 and E. coli K-12 MG1655 LsrB proteins (CsLsrB and EcLsr, respectively) were carried out as previously described. ${ }^{5,6}$ Concisely, E. coli BL21 ( $\left.\Delta / u x S\right)$ cells transformed with the constructs pPro-EcLsrB and pDEST-CsLsrB were grown in $L B$ with $1 \mu \mathrm{g} / \mathrm{mL}$ ampicillin at $37^{\circ} \mathrm{C}$ until the $\mathrm{OD}_{600}$ was 0.3 . At this point, temperature was decreased to $22^{\circ} \mathrm{C}$. At $\mathrm{OD}_{600}=0.9$, protein expression was induced with $0.1 \mathrm{mM}$ or $0.3 \mathrm{mM}$ of IPTG for the expression of EcLsr and CsLsrB, respectively. Cells grew for $6 \mathrm{~h}$ after induction and were harvested by centrifugation. The resulting pellets were resuspended in $50 \mathrm{mM} \mathrm{NaH}{ }_{2} \mathrm{PO}_{4}(\mathrm{pH} 8.0), 300 \mathrm{mM} \mathrm{NaCl}, 10 \mathrm{mM}$ imidazole, $2.5 \mu \mathrm{g} / \mathrm{mL}$ DNase and $2.5 \mu \mathrm{g} / \mathrm{mL}$ leupeptin and cells were lysed by passing thrice through a french press. Centrifugation was employed to remove cell debris and the tagged-proteins were purified by Ni ${ }^{+} \mathrm{NTA}$ affinity chromatography. EcLsrB and CsLsrB were eluted in $50 \mathrm{mM} \mathrm{NaH}_{2} \mathrm{PO}_{4}(\mathrm{pH} 8.0), 300 \mathrm{mM} \mathrm{NaCl}, 250 \mathrm{mM}$ imidazole and subsequently dialyzed (Slide-A-Lyzer, ThermoFisher Scientific) into $25 \mathrm{mM}$ Tris buffer pH 8.0, $150 \mathrm{mM} \mathrm{NaCl}, 1 \mathrm{mM}$ DTT. CLPY-LuxP, EcLsrB and CsLsrB have a molecular weight of approximately 98,40 and $37.5 \mathrm{kDa}$, respectively. The higher molecular weight of CPLY-LuxP when compared with the other receptors is due to its fusion to CFP and YFP. 


\subsection{Native PAGE and western-blot}

Approximately $125 \mu \mathrm{g}$ of partially purified CPLY (CFP-LuxP-YFP; $\sim 1 \mathrm{nmol})$, CsLsrB ( $3 \mathrm{nmol}$ ), and EcLsrB ( 3 nmol) were incubated with approximately $59 \mathrm{\mu g}$ of desthiobiotin-AI-2 ( 172 nmol) overnight under gentle agitation at $4^{\circ} \mathrm{C}$. These quantities ensured the presence of at least 50 times more probe than receptors. As a control $125 \mu \mathrm{g}$ of the protein samples were incubated with desthiobiotin alone $(59 \mu \mathrm{g})$ or with buffer in the same conditions $(25 \mathrm{mM}$ sodium phosphate buffer $\mathrm{pH}$ 8.0, $35 \mathrm{mM} \mathrm{NaCl}, 1 \mathrm{mM}$ boric acid for CPLY and $25 \mathrm{mM}$ Tris buffer pH 8.0, $150 \mathrm{mM}$ $\mathrm{NaCl}, 1 \mathrm{mM}$ DTT for CsLsrB and EcLsrB). $20 \mu \mathrm{L}$ of all the samples were mixed with $5 \mu \mathrm{L}$ of $5 \mathrm{X}$ sample buffer $(0.31 \mathrm{M}$ Tris- $\mathrm{HCl}$ buffer $\mathrm{pH} 6.8,0.05 \%$ bromophenol blue and $50 \%$ glycerol) and $11 \mu \mathrm{L}$ of these mixes were loaded into each of two $10 \%$ polyacrylamide non-denaturing gels. $5 \mu \mathrm{L}$ of protein standards (All Blue Standards, Bio-Rad) was also added. The gel was run in Tris-glycine buffer ( $25 \mathrm{mM}$ Tris, $192 \mathrm{mM}$ glycine, $\mathrm{pH} 8.3$ ), at $160 \mathrm{~V}, 4^{\circ} \mathrm{C}$ for approximately 1h30. One of the gels was stained with Comassie blue and the presence of the bands assessed. The second gel was used for a western-blot. Transfer was performed at $90 \mathrm{~mA}, 4^{\circ} \mathrm{C}$, overnight in $25 \mathrm{mM}$ Tris, $192 \mathrm{mM}$ glycine and $0.05 \%$ SDS to a PVDF membrane. The membrane was incubated in a 1:5000 dilution of an anti-biotin, HRP conjugated antibody (PA1-30595, Invitrogen) for $1 \mathrm{~h}$ at room temperature. An ECL chemiluminescent substrate was added (SuperSignal West Pico, Pierce) and signal detection was performed in a blot imager (Amersham Imager 680).

\subsection{Pull-down of LuxP receptor}

Magnetic Dynabeads with protein G (Invitrogen, 10003D) were conjugated with the anti-biotin antibody (\#31852, Pierce) as per the manufacturers instructions. Briefly, $50 \mu \mathrm{L}$ of Dynabeads (1.5 mg) were added to a $1.5 \mathrm{~mL}$ eppendorf and the storage solution was removed through magnetic separation. $10 \mu \mathrm{g}$ of antibody diluted in $200 \mu \mathrm{L}$ of wash buffer (PBS buffer pH 7.4, 0.02\% Tween-20) was added to the beads and the mixture was incubated for 10 $\mathrm{min}$, at room temperature with agitation. The unbound antibody was then removed by magnetic separation and the beads were washed with $200 \mu \mathrm{L}$ of wash buffer. Next, the sample was added to the anti-biotin antibody conjugated magnetic beads. The sample used for the pull down of CLPY was incubated following the conditions mentioned above and included approximately $76,5 \mu \mathrm{g}$ of DB-Al-2 and $265 \mu \mathrm{g}$ of partially purified CLPY. The mixture sample/antibody-conjugated beads was incubated for $1 \mathrm{~h}$ at room temperature with agitation followed by three washes with $200 \mu \mathrm{L}$ of wash buffer to remove unbound protein. CPLY, complexed with the Al-2 probe and retained by the antibody conjugated magnetic beads, was eluted by denaturation. The final volume was heated for 10 minutes at $70^{\circ} \mathrm{C}$ in $20 \mu \mathrm{L}$ of $50 \mathrm{mM}$ glycine $\mathrm{pH} 2.8$ and $10 \mu \mathrm{L}$ of $240 \mathrm{mM}$ Tris- $\mathrm{HCl} \mathrm{pH} 6.8,40 \%$ glycerol, $8 \%$ SDS, $0.04 \%$ bromophenol blue and $5 \% \beta$-mercaptoethanol. $10 \mu \mathrm{L}$ of the wash and elution steps were mixed with $5 \mu \mathrm{L}$ of 200 $\mathrm{mM}$ Tris- $\mathrm{HCl} \mathrm{pH} 6.8,8 \%$ SDS, $0.4 \%$ bromophenol blue and $40 \%$ glycerol and added to a denaturing gel composed of $15 \%$ acrylamide in the separating gel and $5 \%$ in the stacking gel. As protein standards, $5 \mu \mathrm{L}$ of All Blue Standards (Bio-Rad) were loaded. The gel was run in SDS running buffer at room temperature, $180 \mathrm{~V}$ for approximately 70 minutes and stained with Comassie blue. 


\section{NMR Spectra}

a.

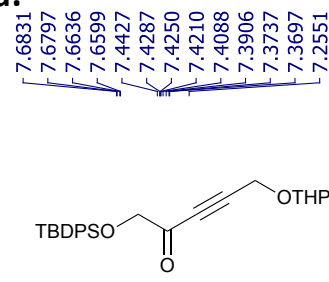

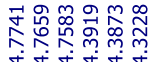

نं
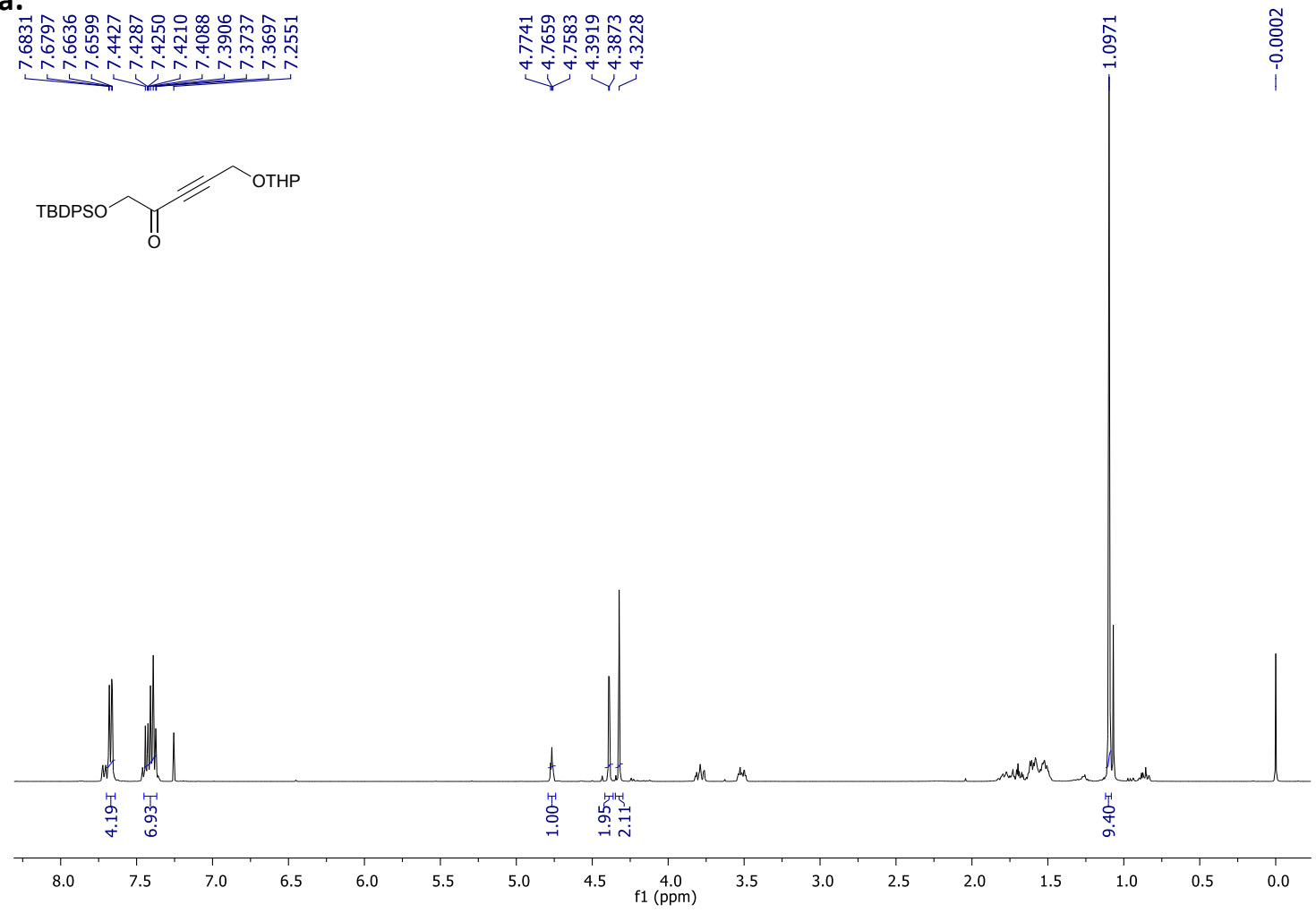

b.

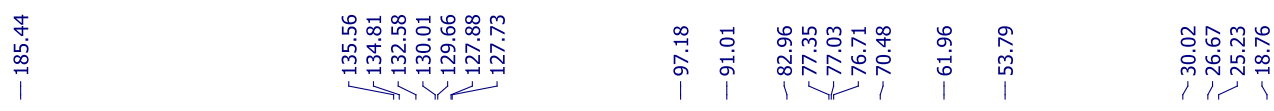

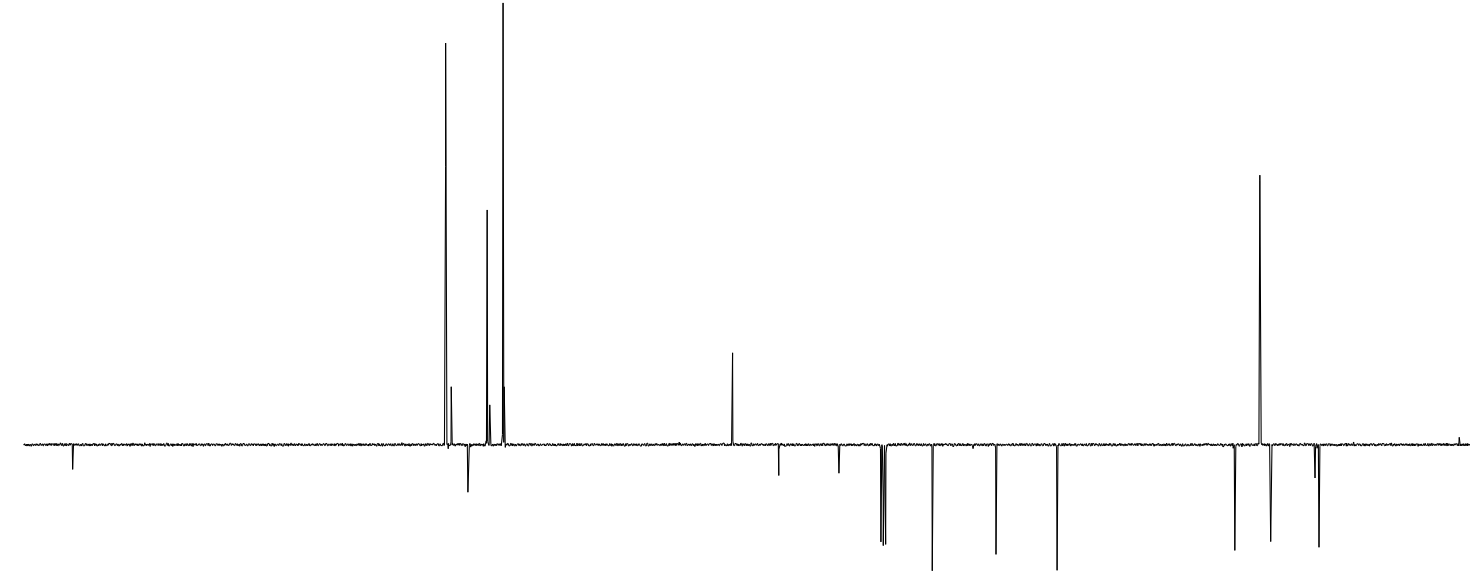

$\begin{array}{lllllllllllllllllll}190 & 180 & 170 & 160 & 150 & 140 & 130 & 120 & 110 & \begin{array}{c}100 \\ \mathrm{f} 1(\mathrm{ppm})\end{array} & 80 & 70 & 60 & 50 & 40 & 30 & 20 & 10 & 0\end{array}$

Figure S2 $-{ }^{1} \mathrm{H}$ NMR spectra of compound $\mathbf{5}(\mathrm{a}) ;{ }^{13} \mathrm{C}$ NMR spectra of compound $\mathbf{5}$ (b). 
a.

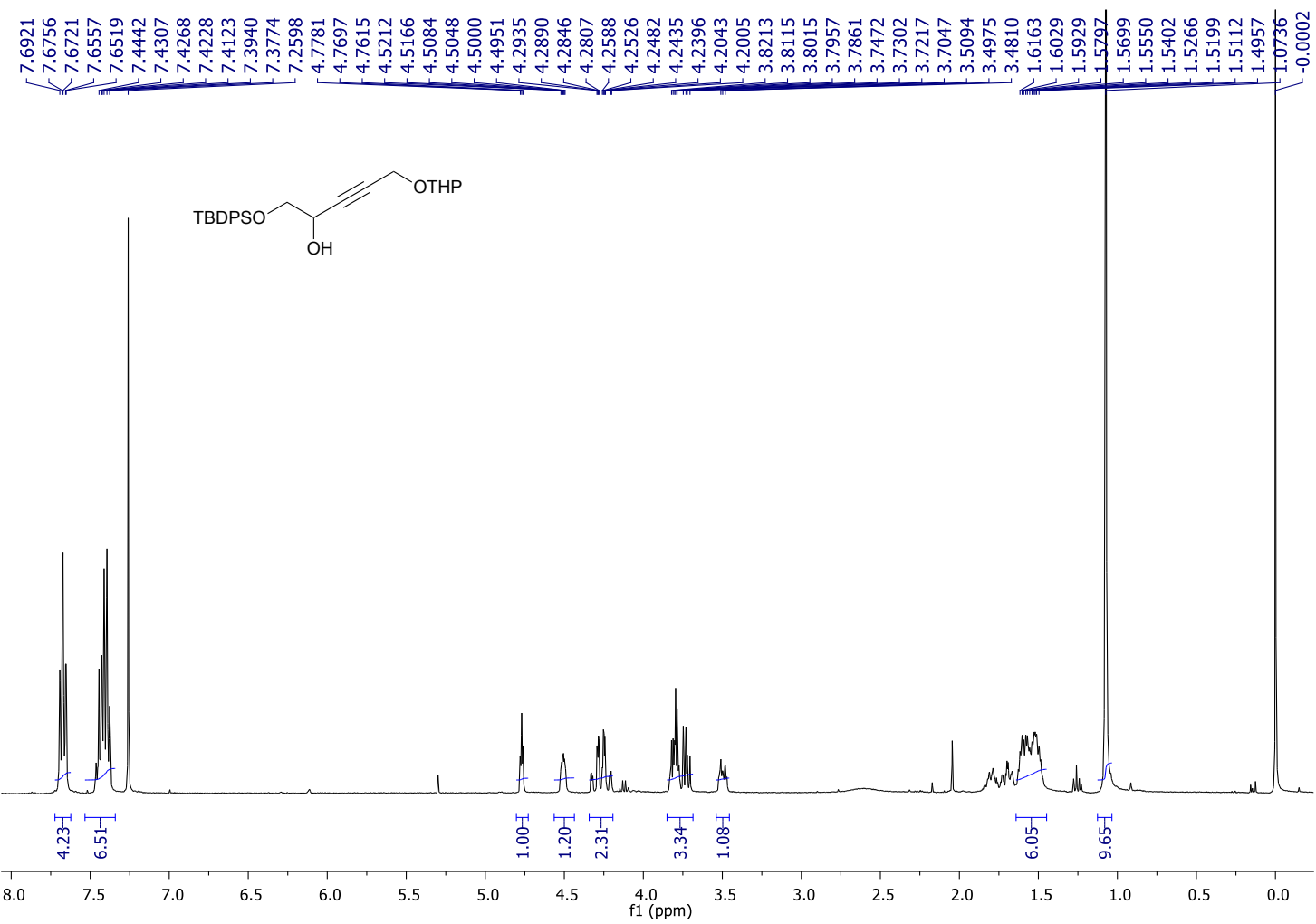

b.

\begin{tabular}{|c|c|c|c|c|c|}
\hline 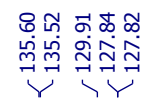 & $\begin{array}{l}\hat{\widehat{o}} \\
\hat{\sigma} \\
\hat{i}\end{array}$ & 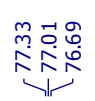 & 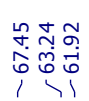 & $\begin{array}{l}0 \\
\dot{+} \\
1 \\
1\end{array}$ & 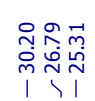 \\
\hline
\end{tabular}

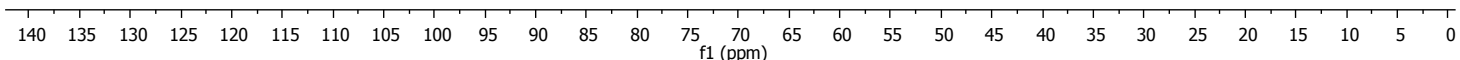

Figure S3 - ${ }^{1} \mathrm{H}$ NMR spectra of compound $\mathbf{6}(\mathrm{a}) ;{ }^{13} \mathrm{C}$ NMR spectra of compound $\mathbf{6}(\mathrm{b})$. 


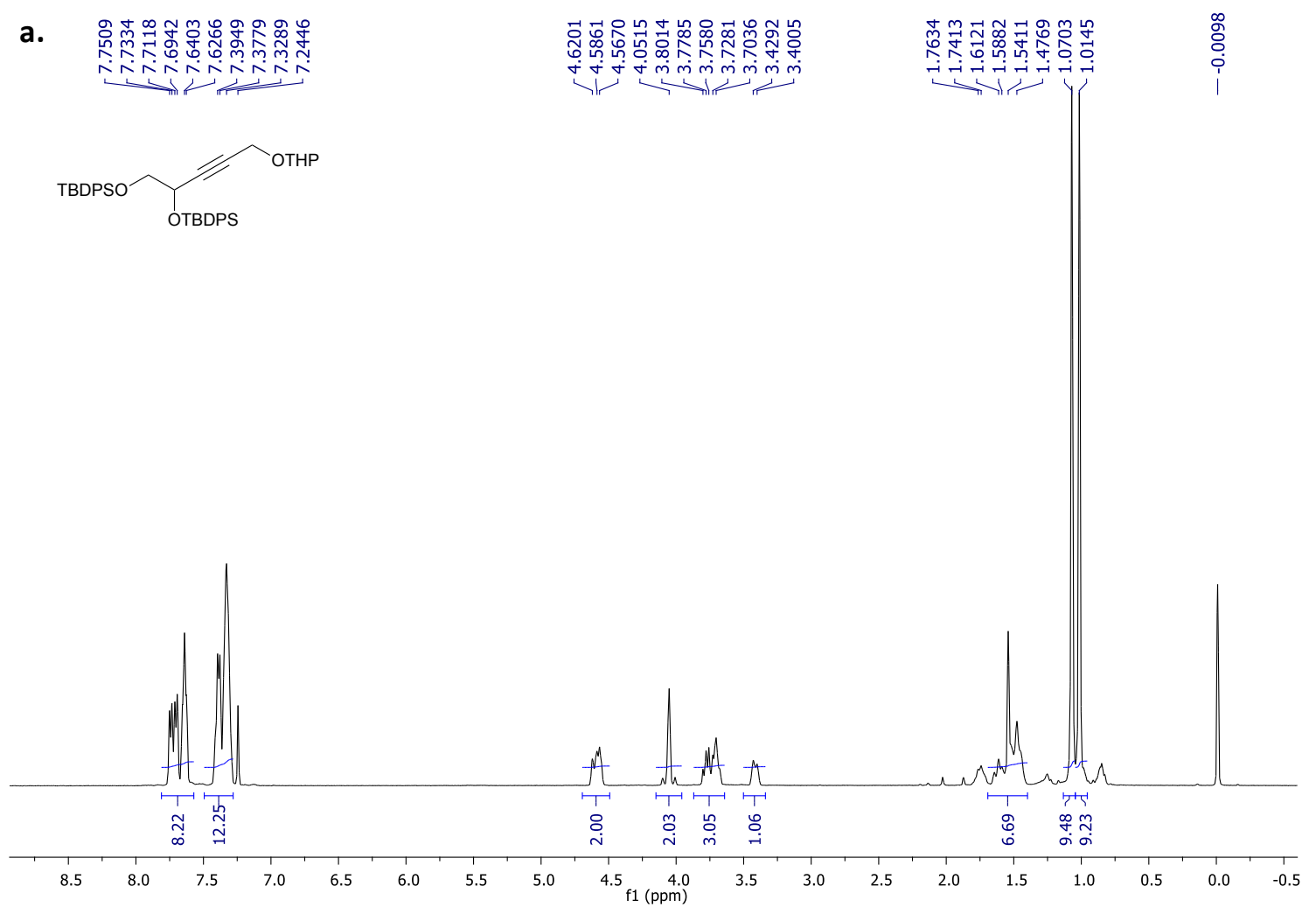

b.

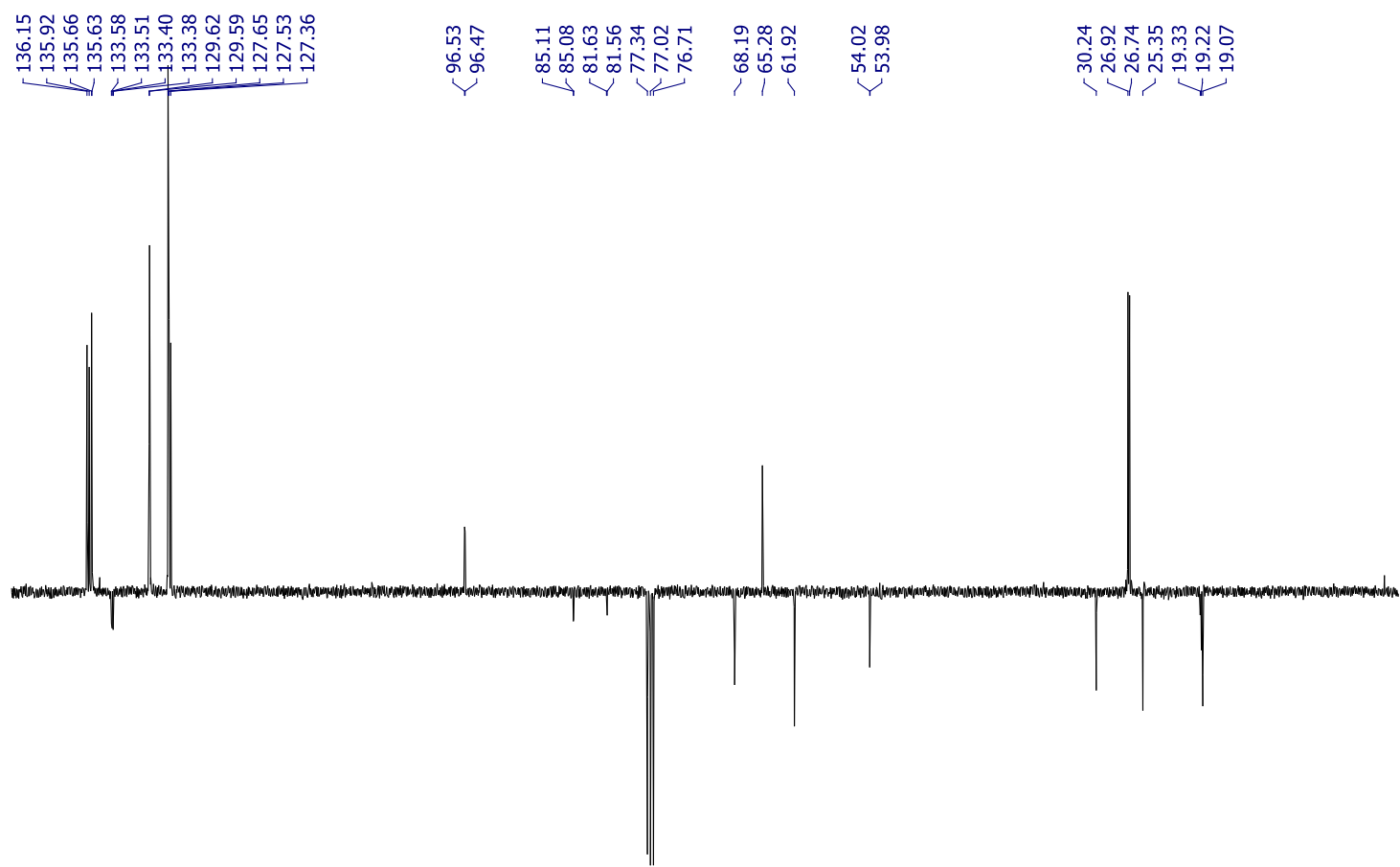

$\begin{array}{lllllllllllllllllllllllllllll}140 & 135 & 130 & 125 & 120 & 115 & 110 & 105 & 100 & 95 & 90 & 85 & 80 & 75 & 70 & 65 & 60 & 55 & 50 & 45 & 40 & 35 & 30 & 25 & 20 & 15 & 10 & 5 & 0\end{array}$

Figure $S 4-{ }^{1} H$ NMR spectra of compound $\mathbf{7}(a) ;{ }^{13} \mathrm{C}$ NMR spectra of compound $\mathbf{7}(\mathrm{b})$. 
a.

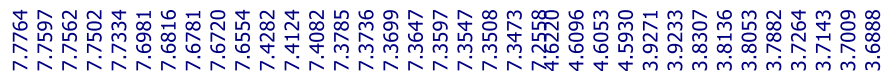

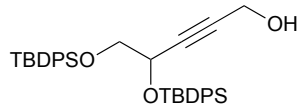

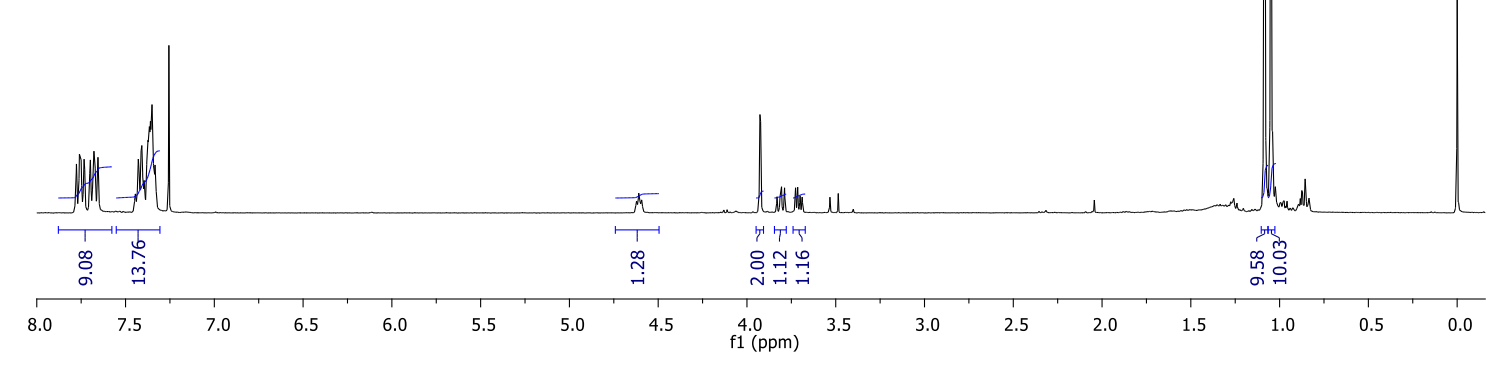

b.

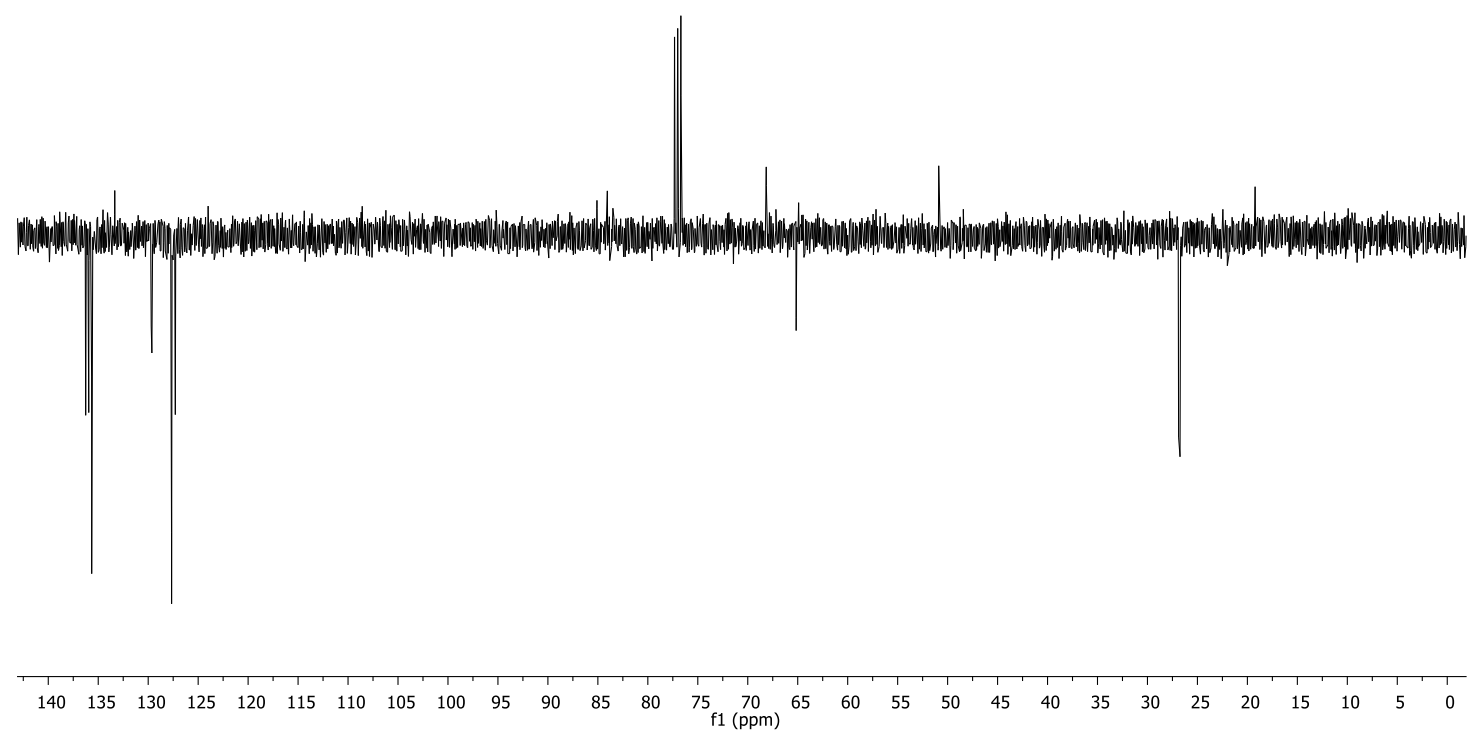

Figure S5 $-{ }^{1} \mathrm{H}$ NMR spectra of compound $8(\mathrm{a}) ;{ }^{13} \mathrm{C}$ NMR spectra of compound $\mathbf{8}(\mathrm{b})$. 
a.

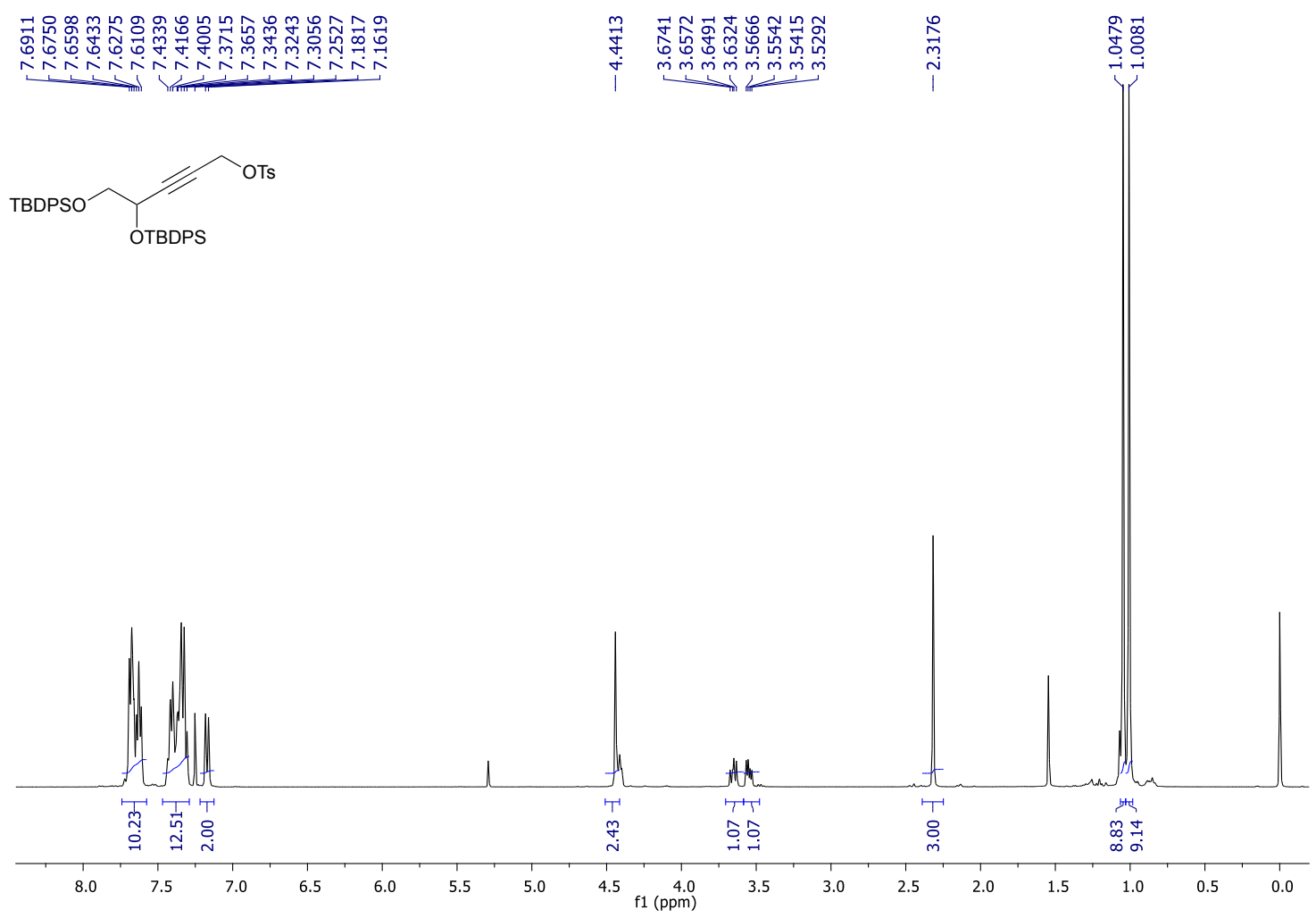

b.

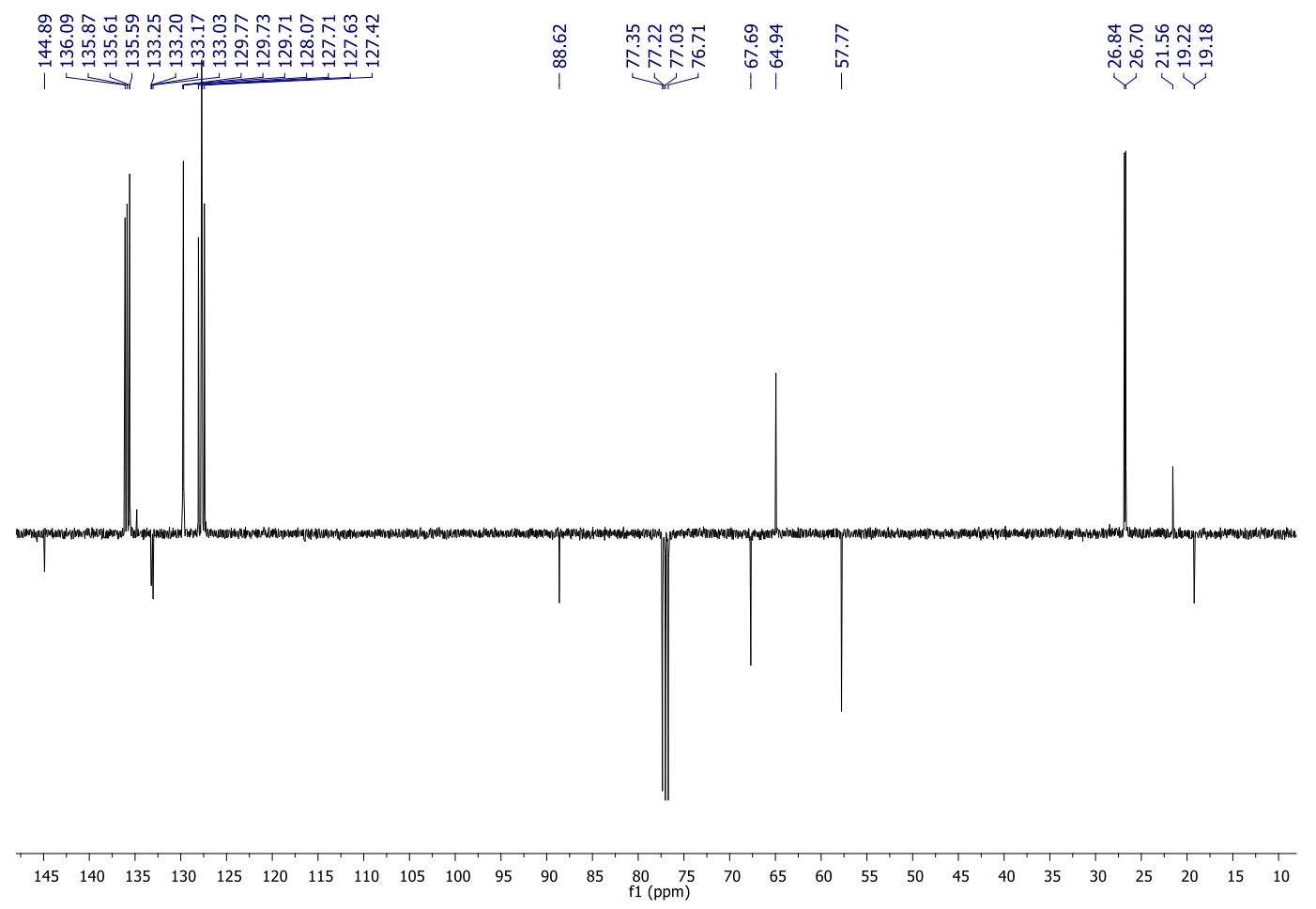

Figure S6 - ${ }^{1} \mathrm{H}$ NMR spectra of compound $\mathbf{9}(\mathrm{a}) ;{ }^{13} \mathrm{C}$ NMR spectra of compound $\mathbf{9}(\mathrm{b})$. 
a.

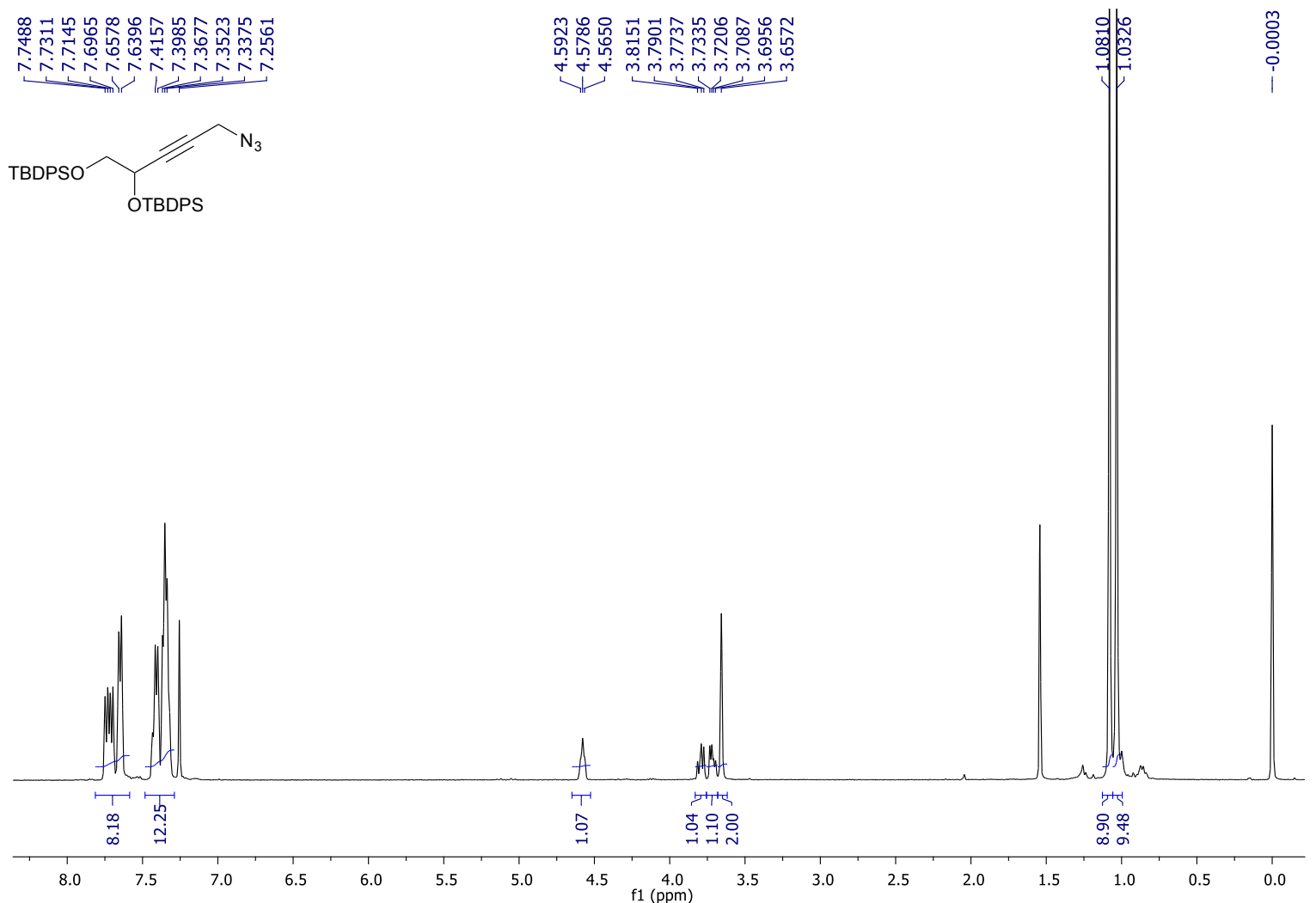

b.

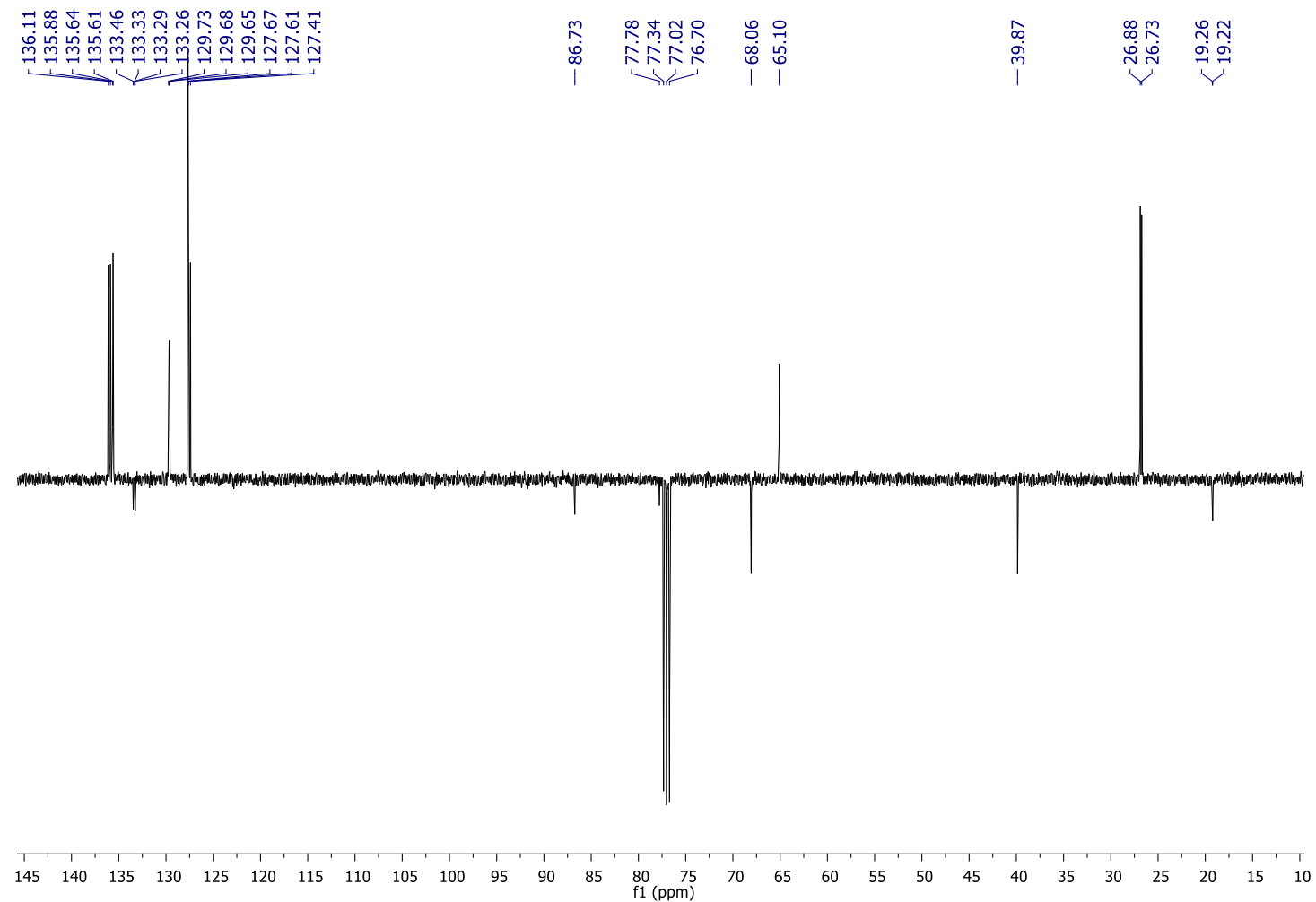

Figure S7 - ${ }^{1} \mathrm{H}$ NMR spectra of compound $\mathbf{1 0}(\mathrm{a}) ;{ }^{13} \mathrm{C}$ NMR spectra of compound $\mathbf{1 0}(\mathrm{b})$. 
a.

ڤ્ڤ

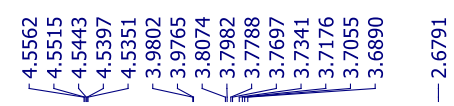<smiles>[N]CC#CC(O)CO</smiles>

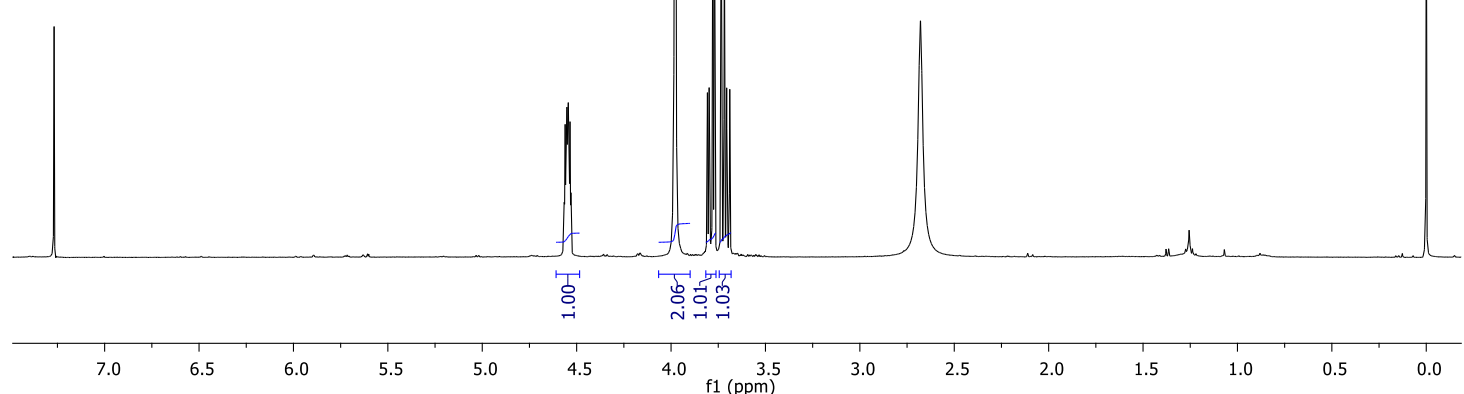

b.

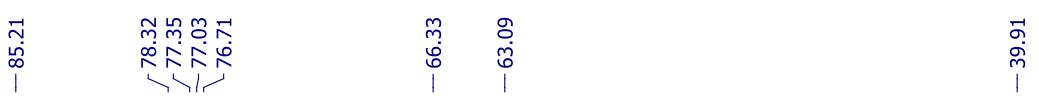

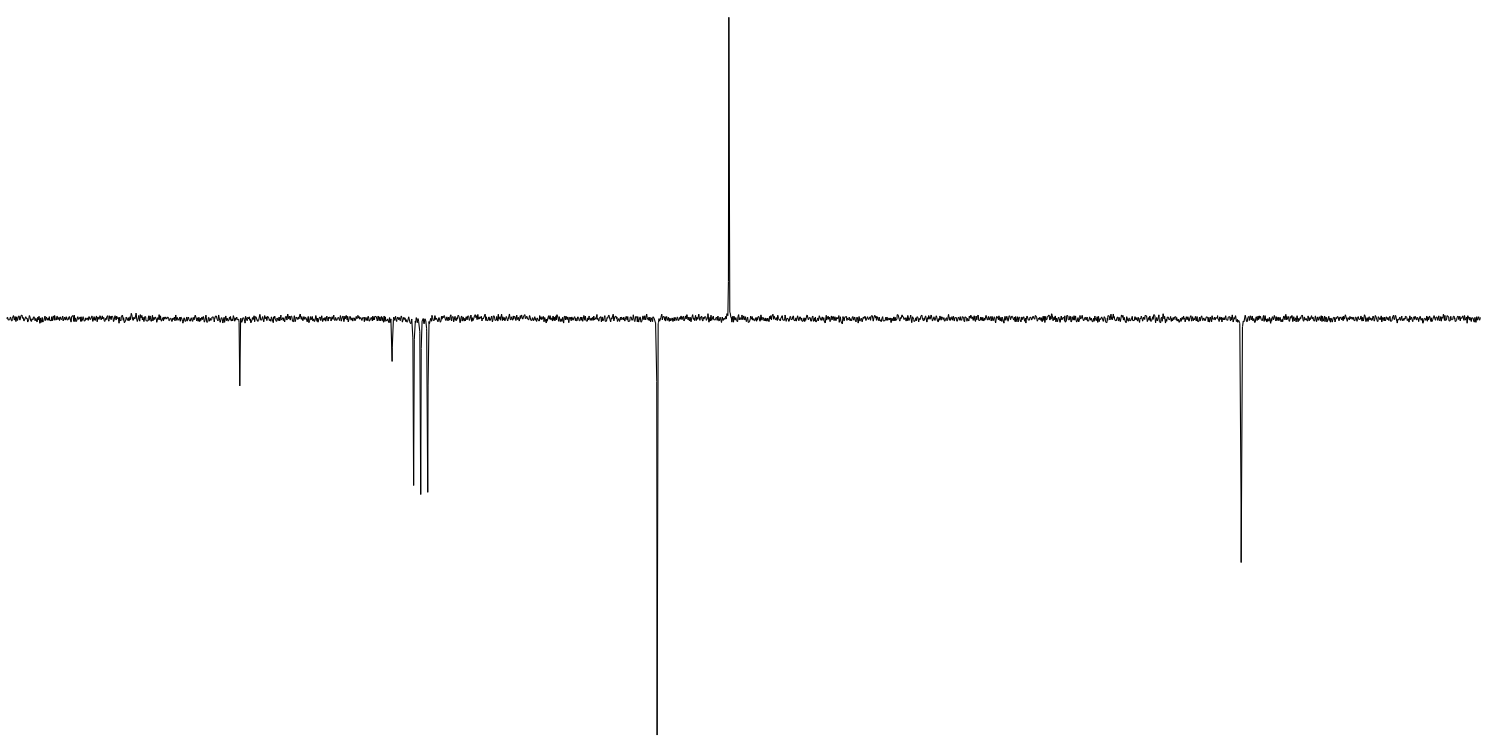

$\begin{array}{llllllllllllllllllllllllllllllllllllllllll}94 & 92 & 90 & 88 & 86 & 84 & 82 & 80 & 78 & 76 & 74 & 72 & 70 & 68 & 66 & 64 & 62 & 60 & 58 & 56 & 54 & 52 & 50 & 48 & 46 & 44 & 42 & 40 & 38 & 36 & 34 & 32 & 30\end{array}$

Figure $\mathbf{S 8}-{ }^{1} \mathrm{H}$ NMR spectra of compound $\mathbf{1 1}(\mathrm{a}) ;{ }^{13} \mathrm{C}$ NMR spectra of compound $\mathbf{1 1}(\mathrm{b})$. 
a.

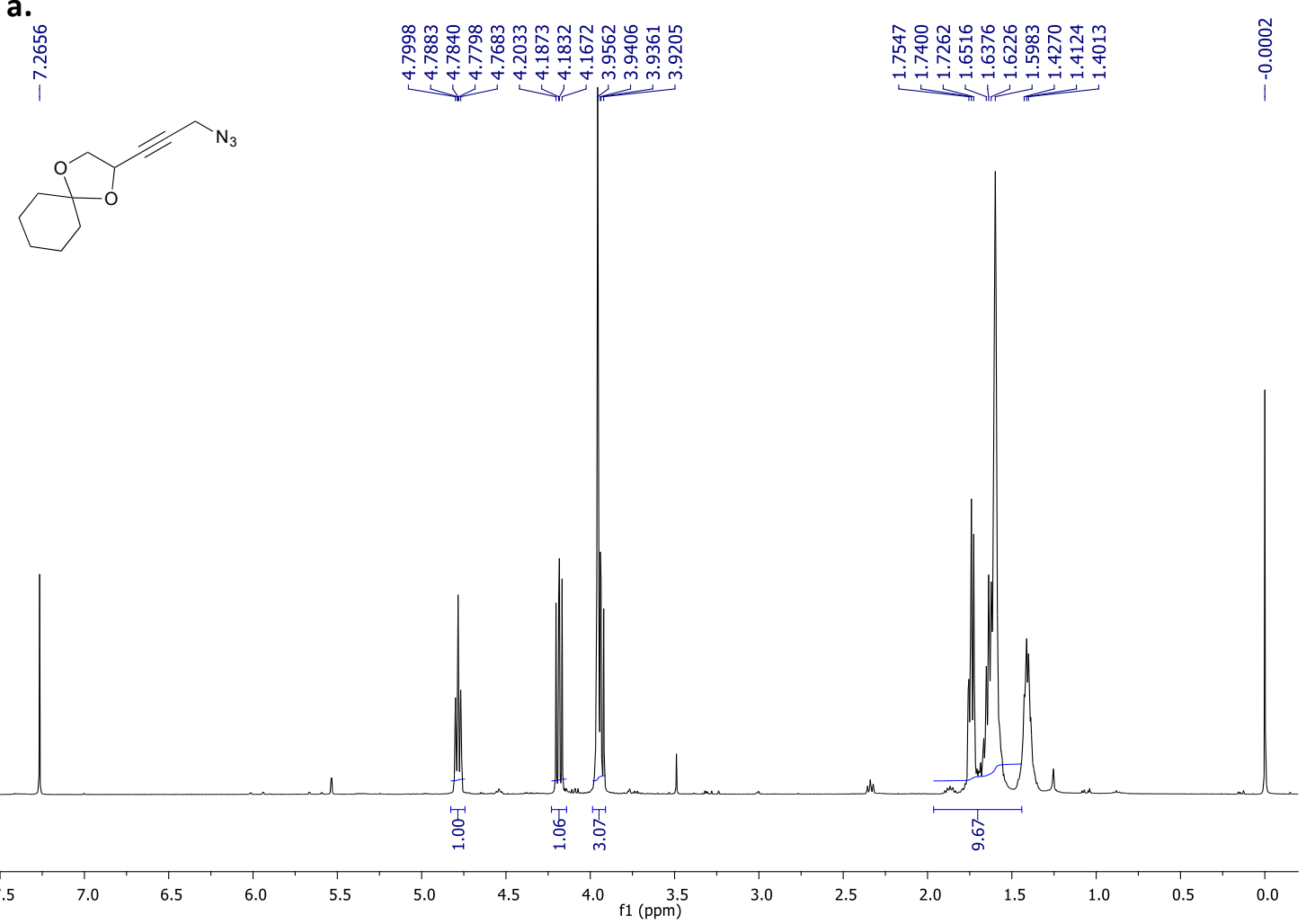

b.

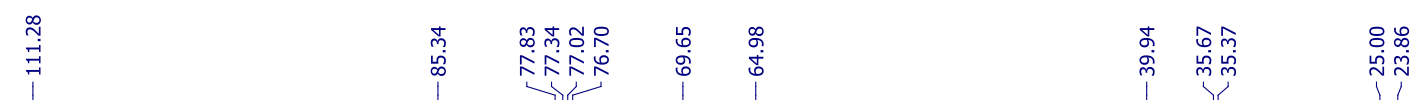

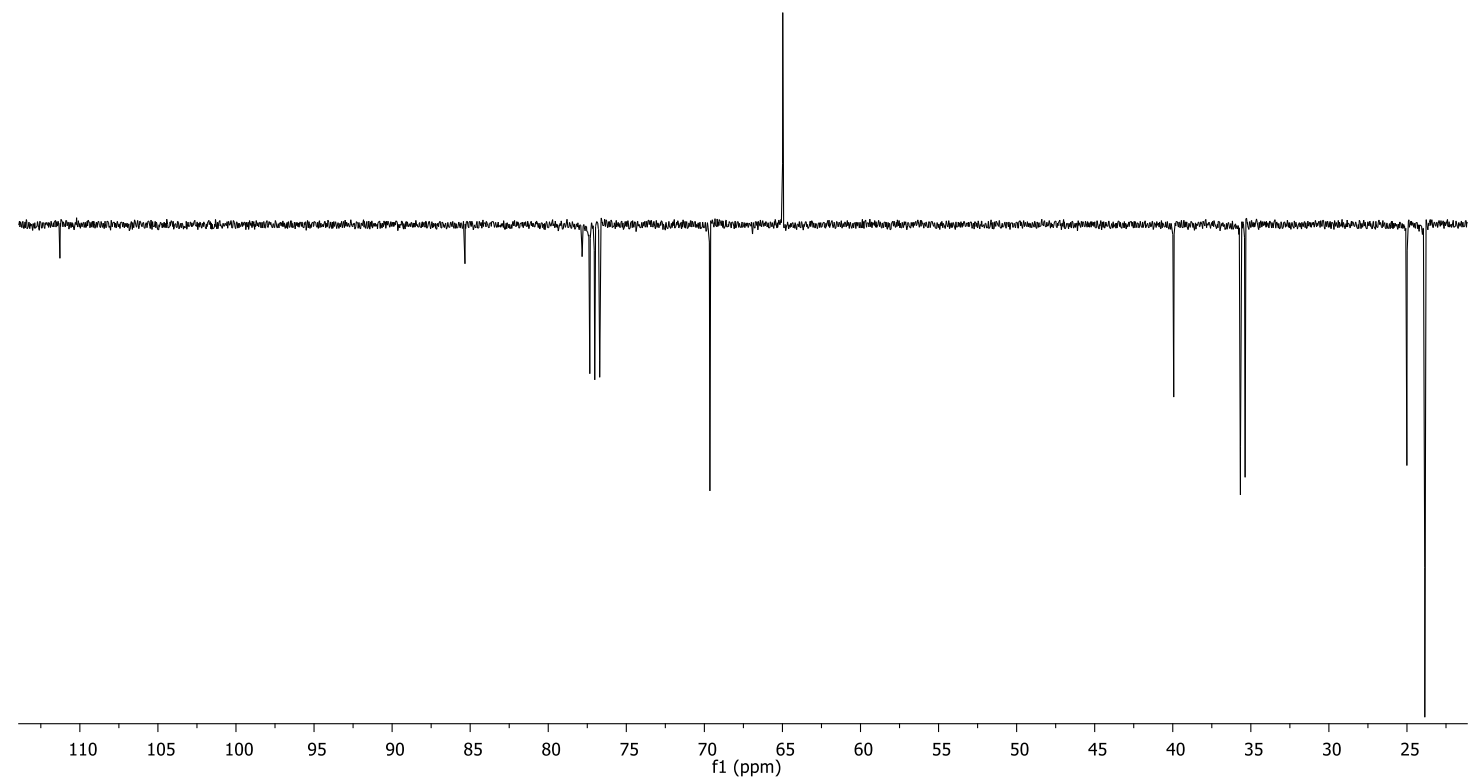

Figure S9 $-{ }^{1} \mathrm{H}$ NMR spectra of compound 12 (a); ${ }^{13} \mathrm{C}$ NMR spectra of compound 12 (b). 
a.

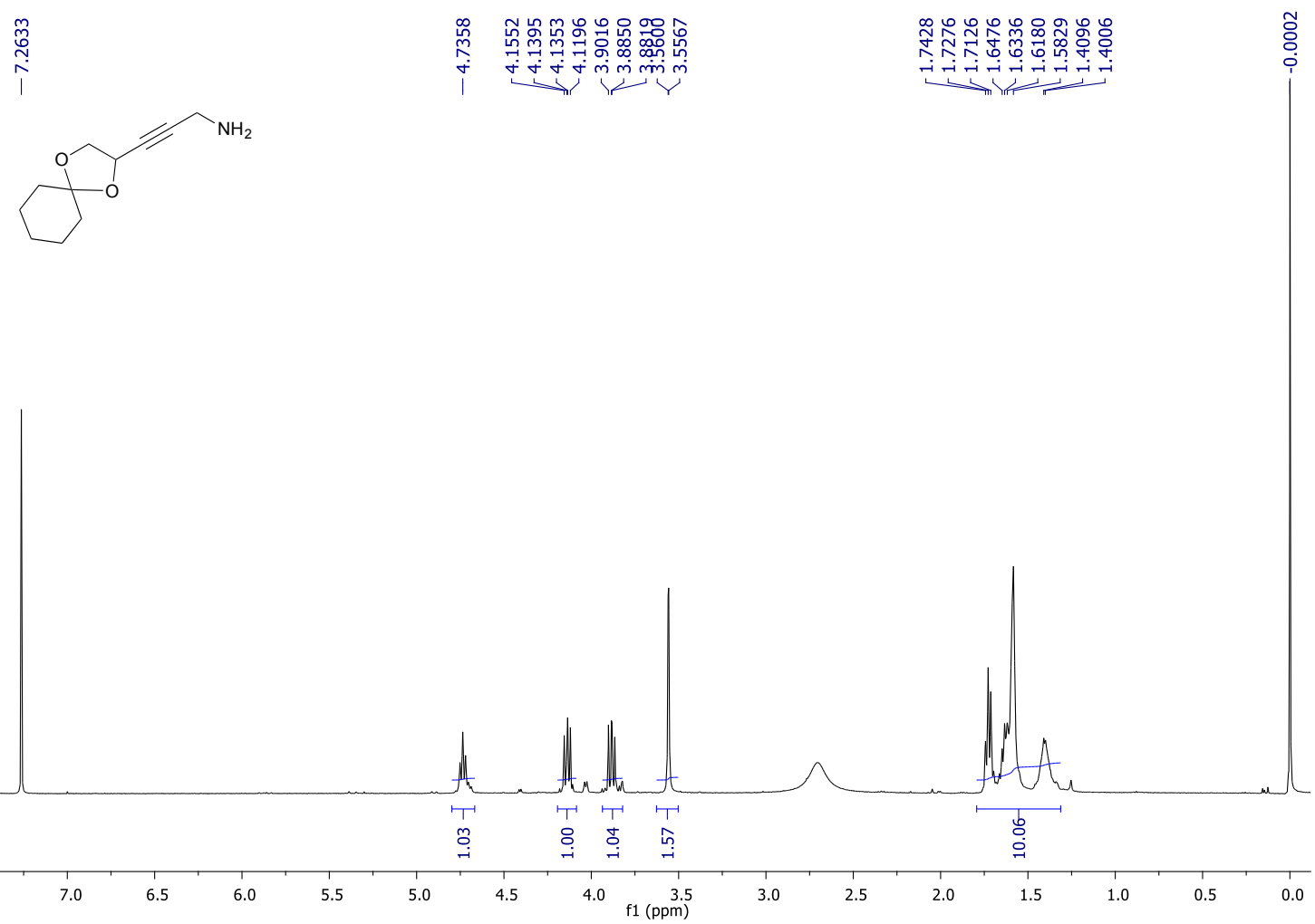

b.

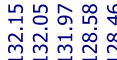

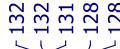

\begin{tabular}{l}
0 \\
$\circ$ \\
0 \\
\hdashline
\end{tabular}

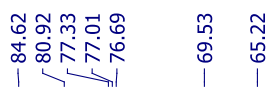

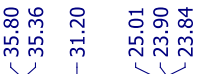

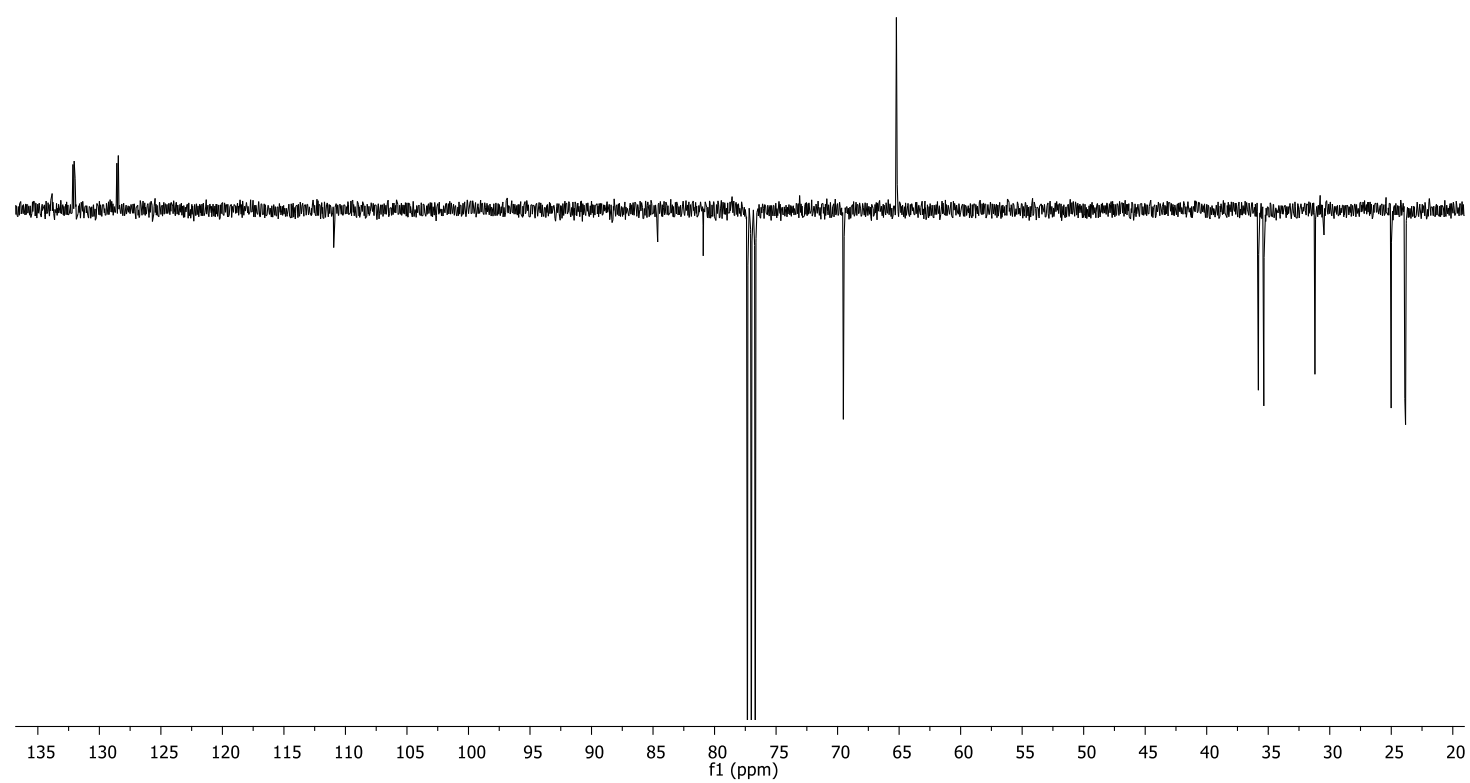

Figure $\mathbf{S 1 0}-{ }^{1} \mathrm{H}$ NMR spectra of compound $\mathbf{2}(\mathrm{a}) ;{ }^{13} \mathrm{C}$ NMR spectra of compound $\mathbf{2}(\mathrm{b})$. 
a.

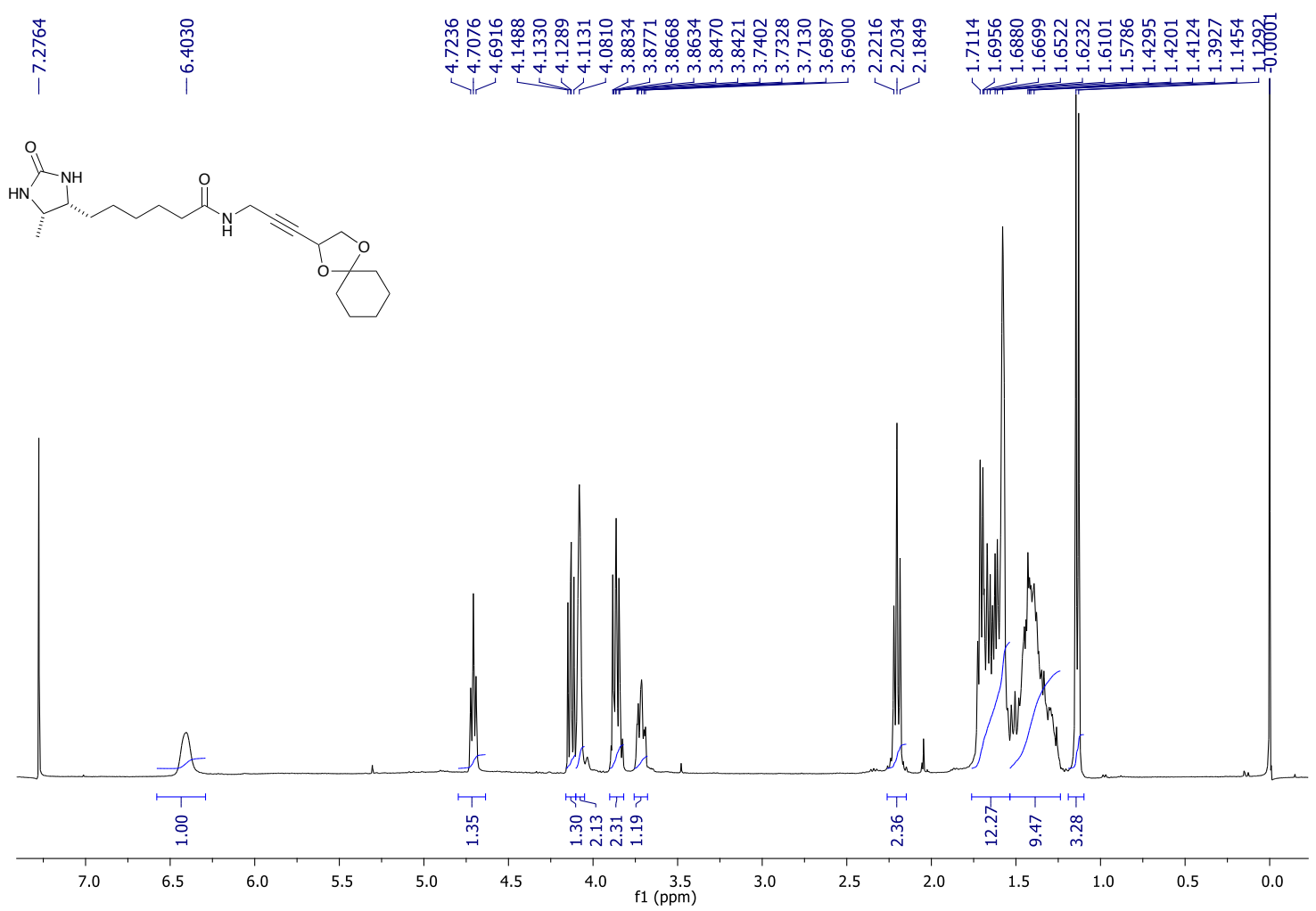

b.

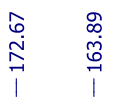

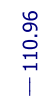

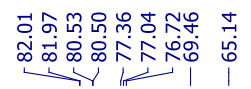
옹

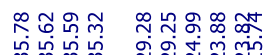

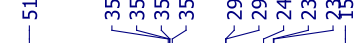

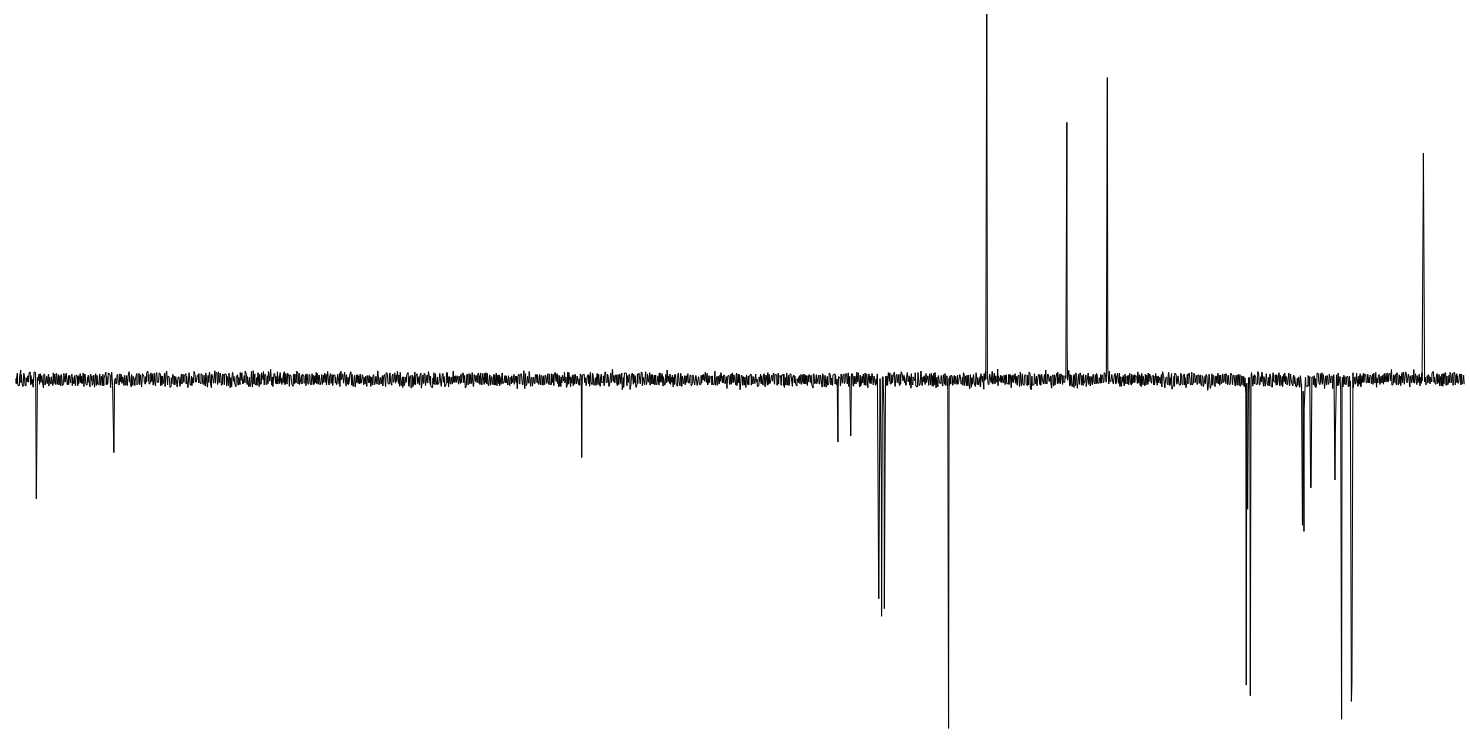

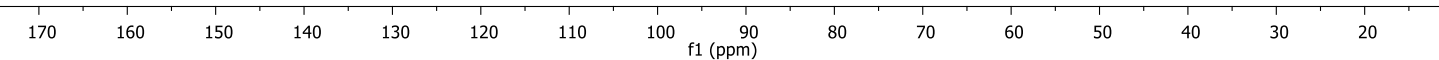

Figure S11 - ${ }^{1} \mathrm{H}$ NMR spectra of compound $13(a) ;{ }^{13} \mathrm{C}$ NMR spectra of compound $\mathbf{1 3}$ (b). 
a.
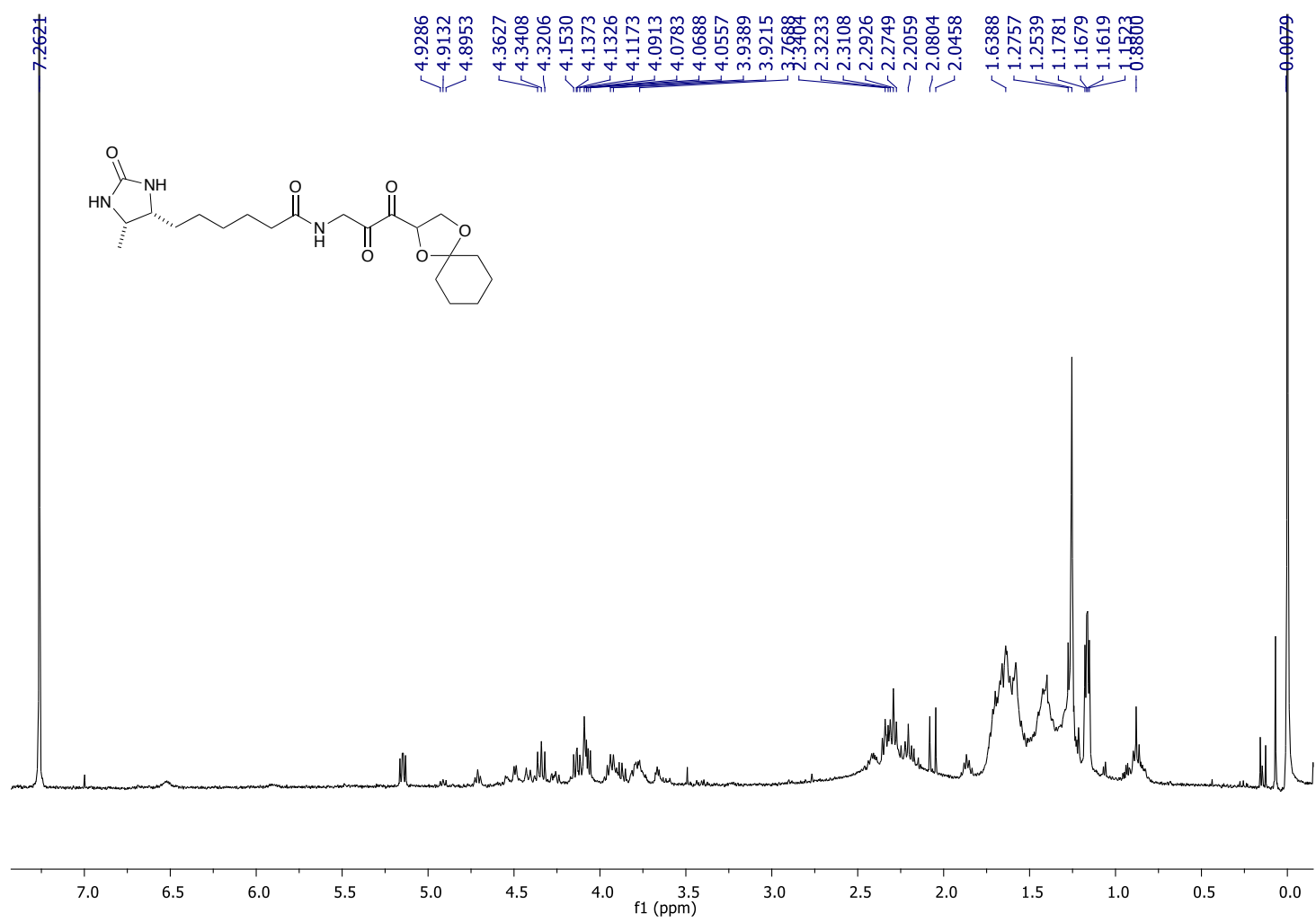

b.

\begin{tabular}{|c|c|c|c|c|}
\hline $\begin{array}{l}\stackrel{\text { N }}{\text { న }} \\
\text { }\end{array}$ & 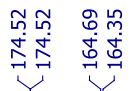 & $\stackrel{\substack{n \\
\dot{m}}}{\stackrel{m}{+}}$ & 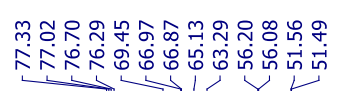 & 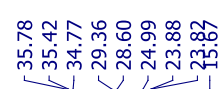 \\
\hline
\end{tabular}

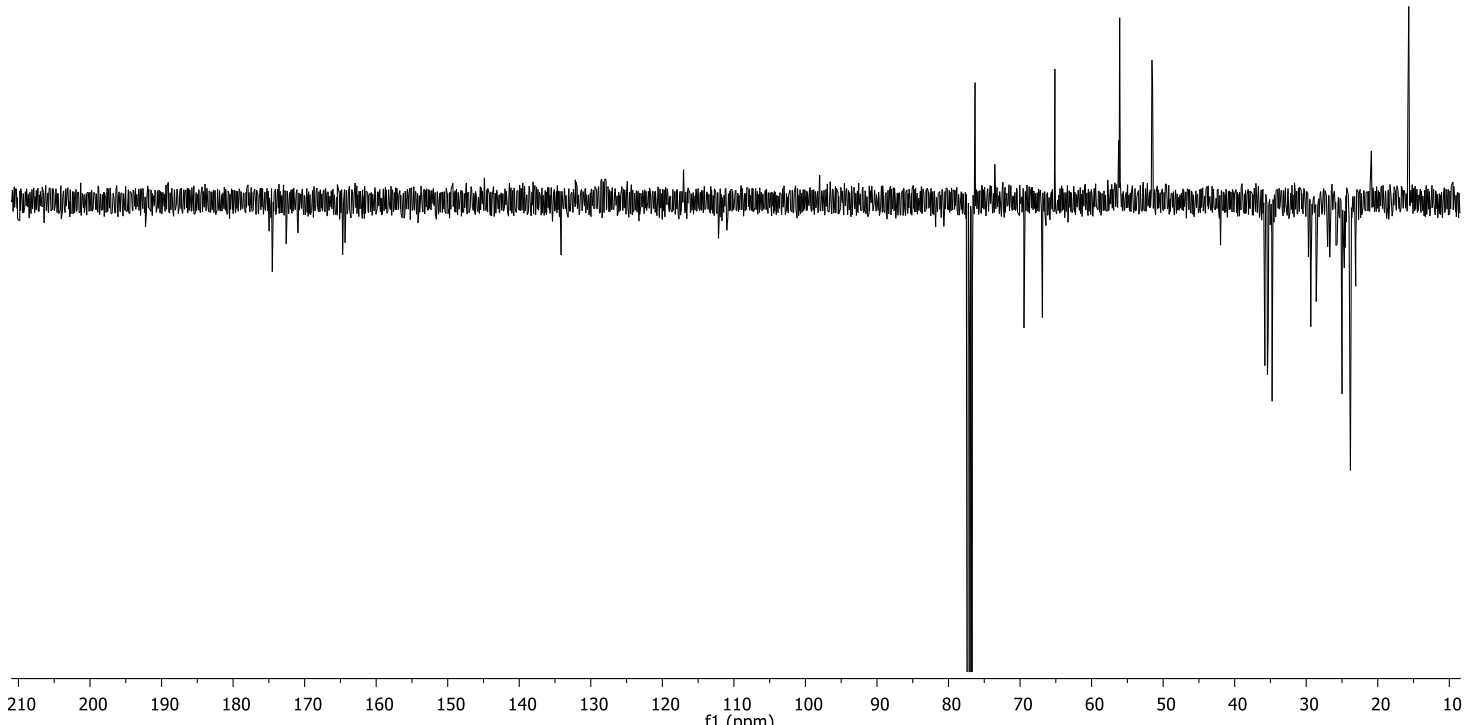

Figure $\mathbf{S 1 2}-{ }^{1} \mathrm{H}$ NMR spectra of compound $\mathbf{1 4}(\mathrm{a}) ;{ }^{13} \mathrm{C}$ NMR spectra of compound $\mathbf{1 4}$ (b). 
a.

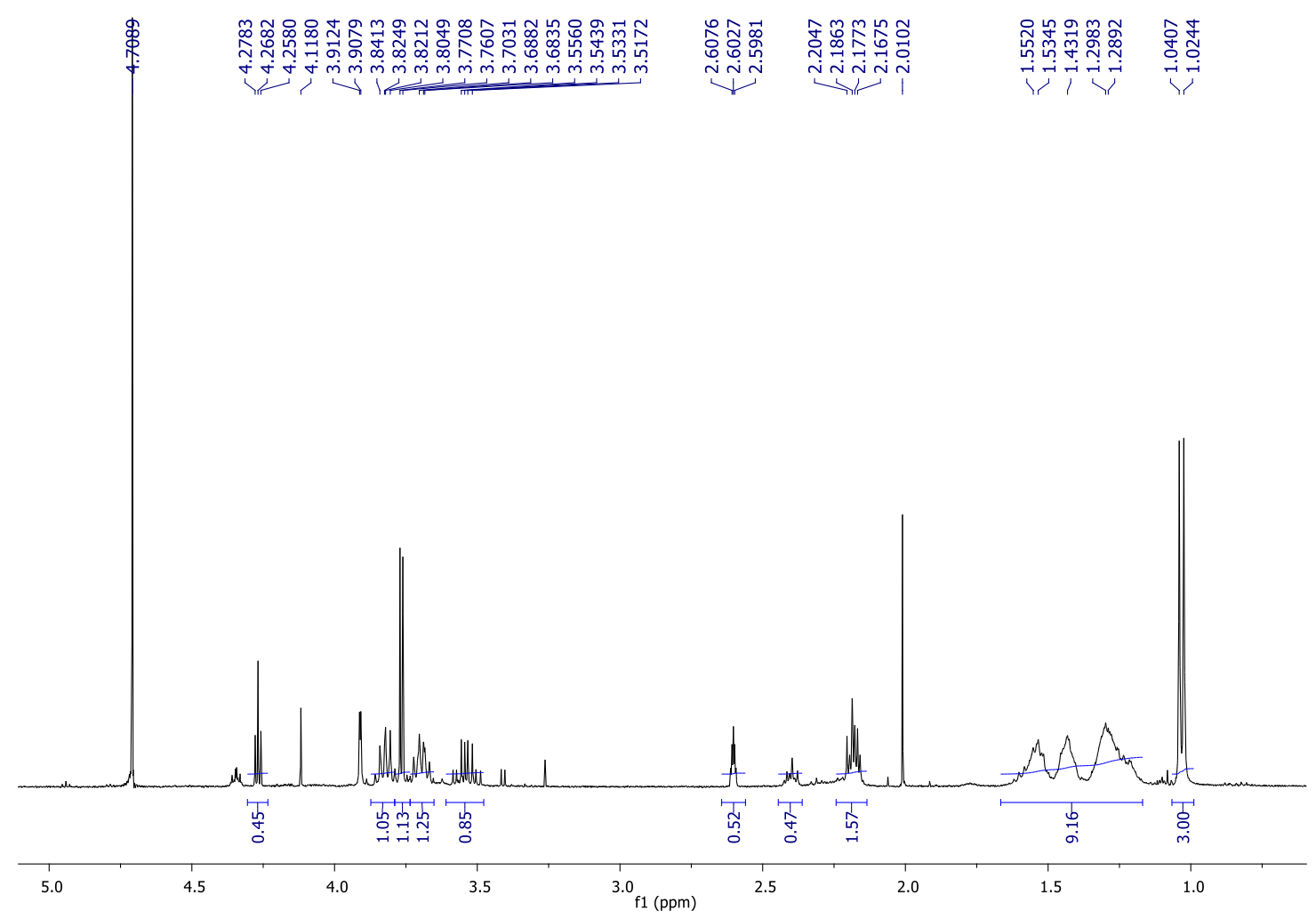

b.

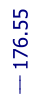

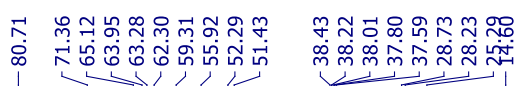

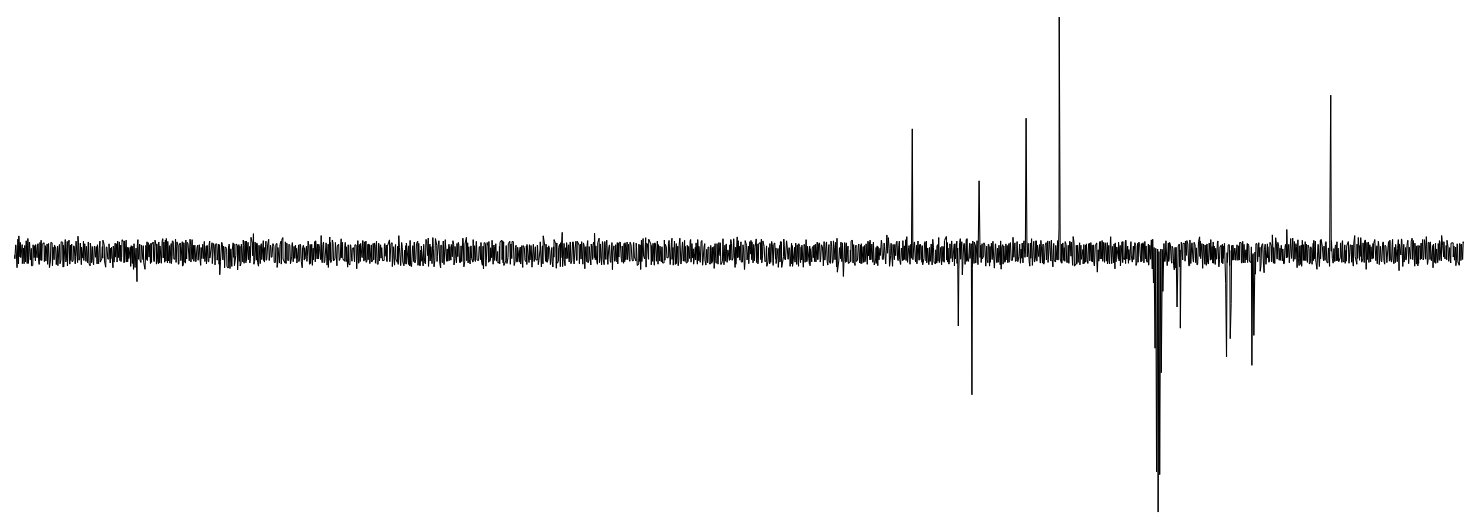

$\begin{array}{lllllllllllllllllllll}1 & 1 & 180 & 170 & 160 & 150 & 140 & 130 & 120 & 110 & 100 & 90 & 80 & 70 & 60 & 50 & 40 & 30 & 20 & 10 & 0\end{array}$

Figure S13 - ${ }^{1} \mathrm{H}$ NMR spectra of compound $\mathbf{1}(\mathrm{a}) ;{ }^{13} \mathrm{C}$ NMR spectra of compound $\mathbf{1}(\mathrm{b})$. 


\section{References}

(1) Armarego, W. L. F.; Chai, C. L. L. Purification of Laboratory Chemicals, 5th Editio.; Elsevier, Ed.; 2003.

(2) Allegretti, P. A.; Ferreira, E. M. Org. Lett. 2011, 13 (21), 5924-5927.

(3) Ascenso, O. S.; Marques, J. C.; Santos, A. R.; Xavier, K. B.; Rita Ventura, M.; Maycock, C. D. Bioorganic Med. Chem. 2011, 19 (3), 1236-1241.

(4) Rajamani, S.; Zhu, J.; Pei, D.; Sayre, R. Biochemistry 2007, 3990-3997.

(5) Torcato, I. M.; Kasal, M. R.; Brito, P. H.; Miller, S. T.; Xavier, K. B. J. Biol. Chem. 2019.

(6) Pereira, C. S.; De Regt, A. K.; Brito, P. H.; Miller, S. T.; Xavier, K. B. J. Bacteriol. 2009, 191 (22), 6975-6987. 